\author{
UNIVERSIDADE DE SÃO PAULO \\ FCF/FEA/FSP \\ Programa de Pós-Graduação Interunidades em Nutrição \\ Humana Aplicada PRONUT
}

PROJETO ESPORTE CIDADÃO: AVALIAÇÃO DE IMPACTO DE UMA POLÍTICA PÚBLICA VOLTADA AO ESPORTE EDUCACIONAL

Jemima Giron

São Paulo 


\section{UNIVERSIDADE DE SÃO PAULO \\ FCF/FEA/FSP \\ Programa de Pós-Graduação Interunidades em Nutrição \\ Humana Aplicada PRONUT}

PROJETO ESPORTE CIDADÃO: AVALIAÇÃO DE IMPACTO DE UMA POLÍTICA PÚBLICA VOLTADA AO ESPORTE EDUCACIONAL

Versão Corrigida

Jemima Giron

Tese apresentada para obtenção do Título de DOUTOR.

Orientadora: Profa. Dra. Denise

Cavallini Cyrillo

São Paulo 
Jemima Giron

\title{
PROJETO ESPORTE CIDADÃO: AVALIAÇÃO DE IMPACTO DE UMA POLÍTICA PÚBLICA VOLTADA AO ESPORTE EDUCACIONAL
}

\author{
Comissão Julgadora \\ Tese para obtenção do Título de Doutor
}

Profa. Dra. Denise Cavallini Cyrillo

Orientadora/Presidente

Profa. Dra. Maria Dolores Montoya Diaz

1ㅇ Examinador

Profa. Dra. Ana Lúcia Padrão dos Santos

2o Examinador

Dra. Maria Aparecida da Cruz Constantino

3 Examinador

São Paulo, 19 de novembro de 2020. 
Autorizo a reprodngalo e divulgaço totsl ou partial deste trabstbo, por gaviquer maio convonciousl ou oletrcuico, pars fim de ostudo e perquisa, desde que citada a fonte.

Ficha Catalografics

Elaborada pala Divisto de Biblioteca a

Documentaçiso do Conjunto das Quimicas da USP.

Bibliotectria remponsaval pola orientaçalo de catalogaçalo da publicaçalo:

Marlaue Apurecida Vieira - CRB - $8 / 5562$

Giron, Jemimz

G527p Projoto Esporte Cidadis: Avalizça de Impacto de uma politica publica voltada ao esporte educacional. / Jemima Giron - S\$o Panlo, 2020 .

$113 \mathrm{p}$ -

Tose (doutorado) - Faculdade de Ciencias Farmactuticas da USP. Faculdado de Economia, Adminiatraçăo o Contabilidado da USP. Faculdado de Saude Publica da USP. Curso Interunidades

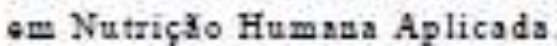

Oriestador: Cyrillo, Denise Cavallini

1. Avaliaçso do Impacto. 2. Qualidıdo do Vids. 3. Bem-estar subjotivo. 4. Estado Nutricionsl. 5 . Atividade Fisica. I. T. II. Cyrillo, Denise Cavallini, orientador. 
Ao bebê que tanto sonhei que agora cresce dentro de mim, Luísa. 


\section{AGRADECIMENTOS}

À esta universidade, corpo docente, direção e administração que oportunizaram a realização desta importante etapa em minha vida acadêmica, um sonho que nutria desde jovem há realizar, realizar.

Ao Conselho Nacional de Desenvolvimento Científico e Tecnológico (CNPq) pela bolsa concedida durante o doutorado.

À minha professora e orientadora Dra. Denise Cavallini Cyrillo que ao longo destes últimos 9 anos - entre mestrado e doutorado - foi paciente, cuidadosa na correção e direcionamento e acima de tudo por ter me conduzido neste caminho compartilhando conhecimentos e fazendo parte da minha formação.

Ao professor Dr. Francisco Baptista Assumpção Junior por ter sido a primeira pessoa a me acolher; respondeu meu e-mail, convidou-me para um café e teve início uma longa caminhada com todo carinho, muito conhecimento e experiências compartilhadas.

Ao PRONUT, seu corpo docente e equipe administrativa e à Faculdade de Economia, Administração e Contabilidade/FEA, com especial menção a Ana Ferri, que me acolheram de braços abertos mesmo sendo eu de uma área aparentemente tão distante, a psicologia.

Às professoras Dra. Maria Dolores Montoya Dias e Dra. Maria Aparecida da Cruz Constantino pelas pertinentes observações na banca de qualificação, fundamentais para que fosse possível chegar até aqui; e à professora Dra. Ana Lucia Padrão dos Santos que além da participação na banca, me acolheu no Programa de Aperfeiçoamento de Ensino/PAE; aos conhecimentos adquiridos durante o semestre que estive na EEFE/USP construíram para boa parte do material teórico aqui exposto.

Aos meus colegas do extinto Projeto Distúrbios do Desenvolvimento do Instituto de Psicologia/USP, pelo acolhimento e ensinamentos que foram fundamentais no início deste processo. 
Aos meus colegas do PRONUT que compartilharam momentos, aulas, encontros, reuniões. Mestrandos, doutorandos, estagiários, cada um contribuindo um pouquinho para tudo isso.

À minha amiga Cidinha que desde os primeiros projetos não mediu esforços, compartilhou conhecimento, experiências, acolheu-me nas angústias... foram muitos, muitos cafés juntas, sem você esta jornada teria sido muito mais difícil.

A todos os professores de todas as disciplinas cursadas, neste período que compartilharam conhecimentos teóricos e técnicos precisos e imprescindíveis.

A Secretaria de Esportes do município de Indaiatuba, nas pessoas dos coordenadores Silvia C. Queriquelli de Agostini e Heleno da Silva Luiz Junior, que desde o início desta jornada em 2013, sempre estiveram disponíveis para auxiliar em tudo o que foi preciso, dando atenção e apoio fundamental durante a realização da pesquisa de campo.

À Secretaria de Educação do município de Americana que tão gentilmente disponibilizou escolas, professores e espaço para a realização da pesquisa de campo.

Aos meus pais, Cláudio e Sandra, meu irmão Denver por sempre acreditarem nos meus sonhos e não pouparem esforços para que eu os alcançassem.

E mais recentemente, ao Rafael ... sem você eu não teria conseguido. 


\section{RESUMO}

GIRON, J. Projeto Esporte Cidadão: Avaliação de impacto de uma política pública voltada ao esporte educacional. 2020. $113 \mathrm{f}$. (Tese de Doutorado) Faculdade de Ciências Farmacêuticas, Faculdade de Economia e Administração e Contabilidade, Faculdade de Saúde Pública, Universidade de São Paulo, São Paulo, 2020.

INTRODUÇÃO: A prática de atividade física deve ser continuamente estimulada pelos efeitos positivos que ela apresenta sobre o bem-estar físico e psicológico, e também, porque a inatividade física pode agravar problemas físicos e emocionais. Devido aos seus benefícios, programas que incentivam a prática de atividade física têm recebido atenção em nosso país, demandando estudos de avaliação impacto sobre a saúde física e emocional de seus participantes. OBJETIVO: Avaliar o impacto do Projeto Esporte Cidadão da cidade de Indaiatuba/SP sobre o estado nutricional e a qualidade de vida de seus participantes. MÉTODO: Realizou-se um estudo longitudinal do tipo painel, (2018-2019), com dois grupos: Grupo Caso e Grupo Controle e duas variáveis de desfecho: estado nutricional (medidas antropométricas) e qualidade de vida (Escala Multidimensional de Satisfação com a Vida Infantil). O método adotado para a avaliação foi o de Diferenças em Diferenças. RESULTADOS: Foram avaliadas 30 crianças no Grupo Caso (média de 9,6 anos, DP $\pm 1,10$ anos, sendo $53,33 \%$ meninos) e 41 crianças do Grupo Controle (média 8,9 anos, DP $\pm 0,77$ anos, sendo $36,34 \%$ meninos). A média de idade dos responsáveis do grupo caso foi 36,96 anos ( $\mathrm{DP}=7,09)$ e do grupo controle de 35,50 anos (DP=7,36); o estado civil "casado" (caso $=90 \%$; controle $=77,5 \%$ ) e a cor de pele "branca" (caso $=43,3 \%$; controle $=60 \%$ ) foram predominantes nos dois grupos. Houve uma proporção menor de chefes com baixa escolaridade no grupo caso do que no grupo controle. Constata-se uma condição socioeconômica mais privilegiada entre as crianças do grupo caso sendo $43,3 \%$ na Classe B, enquanto no grupo controle $22 \%$. A estimação dos modelos mostrou que a participação no PEC não impactou nem o estado nutricional nem a qualidade de vida das crianças participantes, apenas o tamanho da família mostrou uma influência positiva estatisticamente significante sobre o estado nutricional e a idade da criança sobre a qualidade de vida (uma relação negativa). DISCUSSÃO: Esses resultados contrapõem os achados recentes que apontam correlação estaticamente significativa entre a prática da atividade física de lazer regular e manutenção do peso adequado, medido através do IMC. Um fator que pode explicar a ausência de impacto positivo refere-se à frequência efetiva das crianças no projeto, aspecto que não foi possível controlar. Apesar da vasta literatura que aponta para a correlação entre estas variáveis, prática de atividade física de lazer, estado nutricional e qualidade de vida sob a ótica do bem-estar, os resultados aqui apresentados não chegaram às estas mesmas conclusões. Vale ressaltar que pesquisas que estudaram a relação entre atividade física de lazer e bem-estar subjetivo ainda são incipientes, indicando a necessidade de um aprofundamento dos estudos. CONCLUSÃO: Não foram encontradas evidências que corroborem as hipóteses de que o Projeto Esporte Cidadão tem impacto sobre o estado nutricional e a qualidade de vida de seus participantes.

Palavras-Chave: Avaliação de Impacto, Qualidade de Vida, Bem-Estar Subjetivo, Políticas Públicas, Estado Nutricional, Atividade Física. 


\begin{abstract}
GIRON, J. Citizen Sport Project: Impact assessment of a public policy directed to educational sport. 2020.113 f. (PhD Thesis) Faculty of Pharmaceutical Sciences, Faculty of Economics and Administration and Accounting, Faculty of Public Health, University of São Paulo, São Paulo, 2020.
\end{abstract}

INTRODUCTION: The practice of physical activity must be continuously stimulated, essentially in behalf of the positive effects it has on physical and psychological wellbeing; supplementary to that, physical inactivity is a factor that can aggravate physical and emotional problems. As a result of their benefits, programs that encourage the practice of physical activity have been receiving a growing focus in our country, and for this reason, it is important to assess the impact that these programs can take in the physical and emotional health of its participants. OBJECTIVE: To assess the impact of the Citizen Sport Project in the city of Indaiatuba/SP on the nutritional status and quality of life of its participants. METHODS: A panel data (2018-2019) was carried out with two groups: Case Group and Control Group and two outcome variables: nutritional status (anthropometric measures) and Quality of life (Multidimensional Scale of Satisfaction with Child Life). The impact of the program was estimated using the method Differences in Differences. RESULTS: Thirty children were evaluated in the Case Group (mean 9.6 years, SD \pm 1.10 years, $53.33 \%$ being boys) and 41 children in the Control Group (mean 8.9 years, SD \pm 0.77 years, being $36.34 \%$ boys). The average age of those responsible for the case group was 36.96 years $(S D=7.09)$ and for the control group, 35.50 years $(\mathrm{SD}=7.36)$; the marital status "married (case $=90 \%$; control $=77.5 \%$ )" and white skin color (case $=43.3 \%$; control $=60 \%$ ) were predominant in both groups. There was a lower proportion of heads with low education in the case group than in the control group. There is a more privileged socioeconomic condition among children in the case group, $43.3 \%$ in Class B, while in the control group $22.0 \%$. The results of the Differences in Differences in Nutritional Status model show that only the size of the family showed a statistically significant positive influence over the nutritional status and the children's age over quality of life (a negative correlation). DISCUSSION: These results contradict the recent findings that point to a statistically significant correlation between the practice of regular physical activity and maintenance of adequate weight, measured through the BMI. One factor that may explain the absence of a positive impact is related to the effective frequency of children in the project, an aspect that was not possible to control. Despite the vast literature that points to the correlation between these variables: physical activity, nutritional status and quality of life from the perspective of well-being, the results presented here did not present the same conclusions. It is worth mentioning that research that compared subjective well-being to health-related operational variables is still embryonic, indicating the necessity of further research. CONCLUSION: Forasmuch no significant association was found, between the participation of the PEC and an improvement in the quality of life or nutritional status.

Keywords: Impact Assessment, Quality of Life, Subjective Well-Being, Public Policies, Nutritional Status, Physical Activity. 


\section{LISTA DE QUADROS}

Quadro 1 - Fatores e afirmativas da Escala Multidimensional de Satisfação de Vida

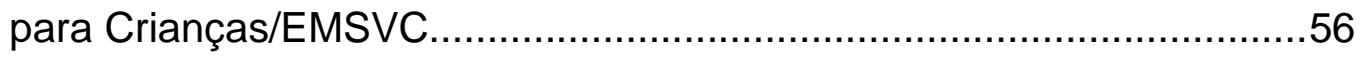

Quadro 2 - Esquema de representação do modelo Diferenças em Diferenças.........62 


\section{LISTA DE FIGURAS}

Figura 1 - Representação do procedimento de coleta de dados. 49

Figura 2 - Diagrama da execução da pesquisa.................................................50 


\section{LISTA DE TABELAS}

Tabela 1 - Distribuição dos alunos matriculados no Projeto Esporte Cidadão, segundo sexo e faixas etárias - Indaiatuba/SP - 2017

Tabela 2 - Distribuição dos alunos matriculados no Projeto Esporte Cidadão em 2017 divididos por polo e modalidade

Tabela 3 - Distribuição das crianças das amostras dos Grupos Caso e Controle, segundo idade e sexo, no Tempo 0

Tabela 4 - Distribuição das amostras dos Grupos Caso e Controle, segundo variáveis sócio demográficas, no Tempo 0 66

Tabela 5 - Distribuição das amostras dos Grupos Caso e Controle, segundo classificação socioeconômica, no Tempo 0. .66

Tabela 6 - Distribuição das crianças dos Grupos Caso e Controle, segundo estado nutricional, no Tempo 0 e no Tempo 1.

Tabela 7 - Impacto do PEC sobre o Estado Nutricional: estimativa do modelo incompleto (sem controles)

Tabela 8 - Impacto do PEC sobre o Estado Nutricional: estimativa do Modelo de Diferenças em Diferenças completo

Tabela 9 - Médias do Escore de Bem-Estar Subjetivo, segundo sexo e tempo 70

Tabela 10 - Impacto do PEC sobre o Bem-Estar Subjetivo: estimativa do Modelo de Diferenças em Diferenças completo

Tabela 11 - Coeficientes das variáveis no modelo de Diferenças em Diferenças da Qualidade de Vida, sob a ótica do Bem-Estar Subjetivo 
1. INTRODUÇÃO

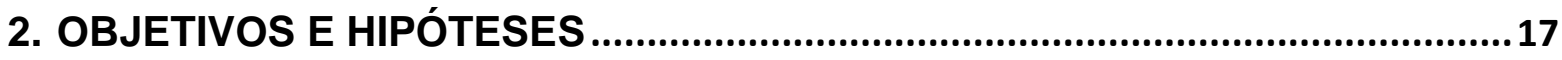

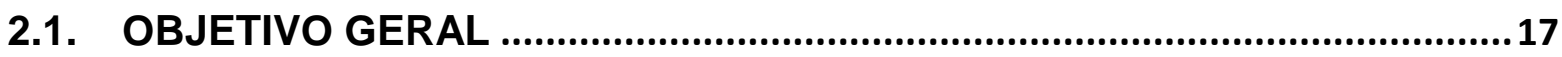

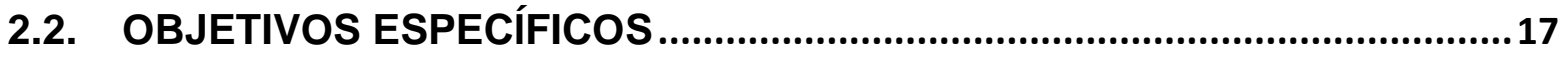

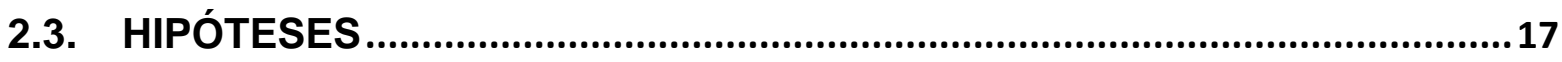

3. EMBASAMENTO TEÓRICO E EMPÍRICO: ESPORTE EDUCACIONAL E BEM-

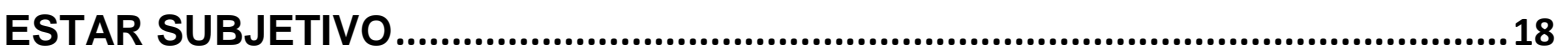

3.1. O DOMÍNIO DO CORPO ENQUANTO EQUALIZADOR SOCIAL ................20

3.2. O TERMO QUALIDADE DE VIDA E SUA RELAÇÃO COM A ATIVIDADE

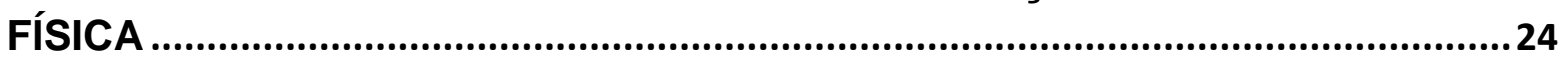

3.2.1. O PERCURSO HISTÓRICO DO CONCEITO DE QUALIDADE DE VIDA. ...24

3.2.2. A QUALIDADE DE VIDA ENQUANTO BEM-ESTAR SUBJETIVO ...............29

3.3. O ESTADO NUTRICIONAL, BEM-ESTAR SUBJETIVO E ATIVIDADE

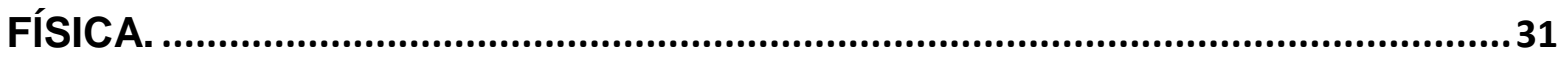

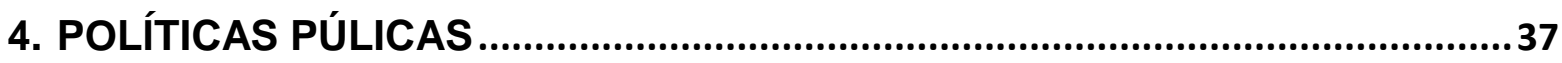

4.1. POLÍTICAS PÚBLICAS VOLTADAS À PRÁTICA DA ATIVIDADE FÍSICA.37 4.2. AVALIAÇÃO DE POLÍTICAS PÚBLICAS VOLTADAS AO ESPORTE

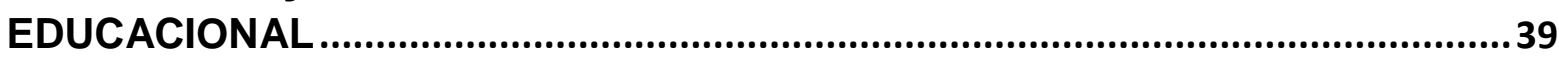

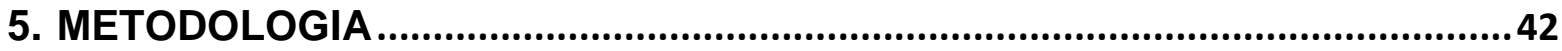

5.1. OBJETO DE ESTUDO: O PROJETO ESPORTE CIDADÃO/PEC ..................43

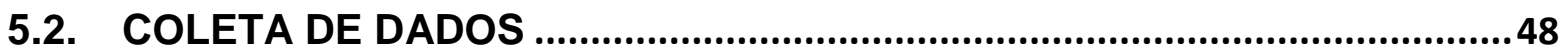

5.3. SELEÇÃO DA AMOSTRA ..............................................................................50

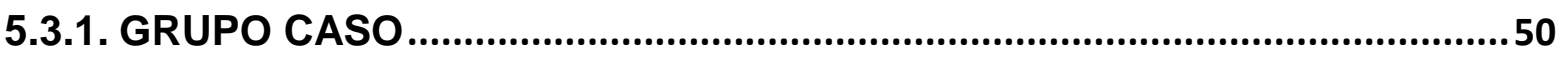

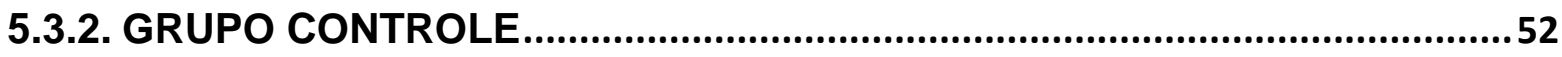

5.4. MENSURAÇÃO DAS VARIÁVEIS E INSTRUMENTOS UTILIZADOS..........54

5.4.1. AVALIAÇÃO DO ESTADO NUTRICIONAL ................................................54

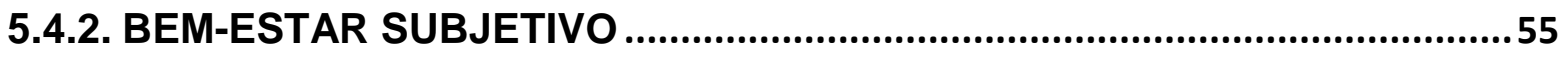

5.4.3. ASPECTOS SOCIOECONÔMICOS E DEMOGRÁFICOS...............................59

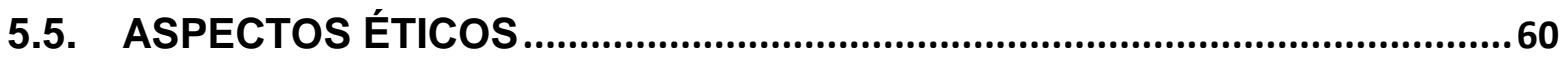




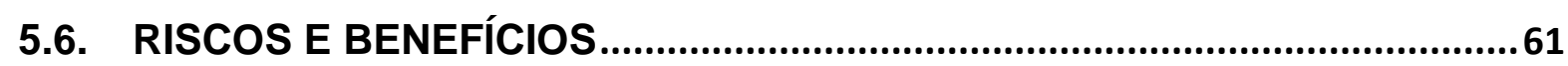

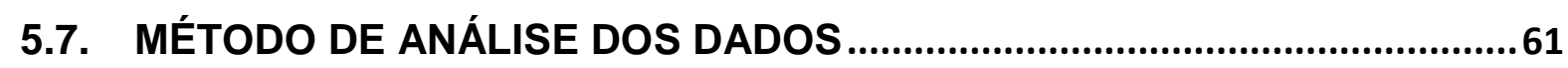

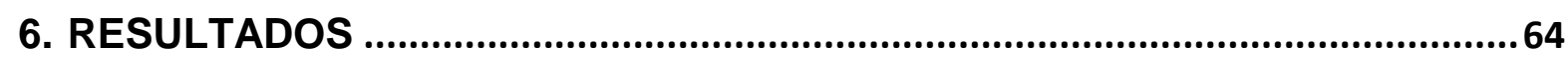

6.1. CARACTERIZAÇÃO SOCIOECONÔMICA E DEMOGRÁFICA DA AMOSTRA: GRUPOS CASO E CONTROLE ........................................................64

6.2. IMPACTO DO PEC SOBRE O ESTADO NUTRICIONAL DAS CRIANÇAS 67

6.3. IMPACTO DO PEC SOBRE O BEM-ESTAR SUBJETIVO DAS CRIANÇAS.

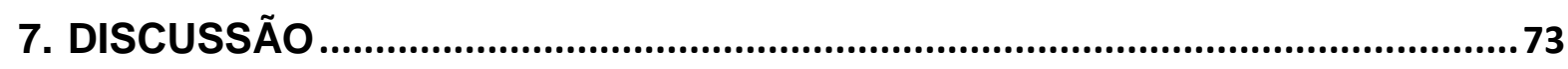

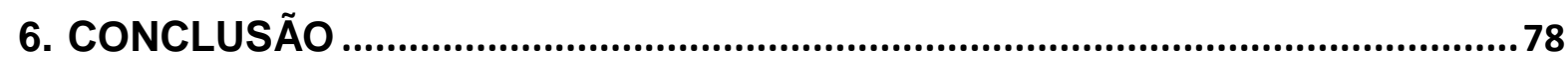

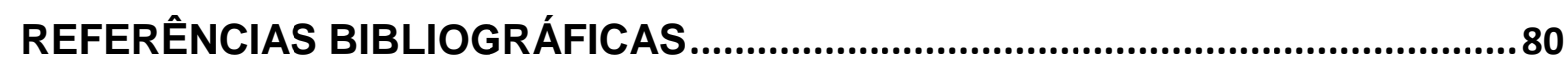

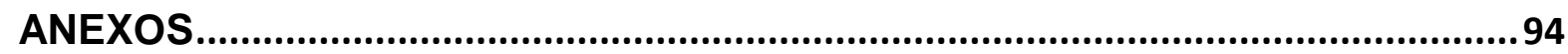

ANEXO 1 - TEMAS TRANSVERSAIS DAS AULAS DO PROJETO ESPORTE CIDADÃO - INDAIATUBA/SP - ANO 2019 …....................................................94

ANEXO 2 - ESCALA MULTIDIMENSIONAL DE SATISFAÇÃO COM A VIDA

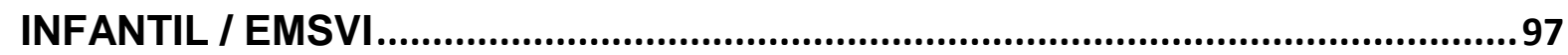

ANEXO 3 - QUESTIONÁRIO SÓCIOECONÔMICO E DEMOGRÁFICO ................101 ANEXO 4 - TERMO DE CONSENTIMENTO LIVRE E ESCLARECIDO - TCLE .104 ANEXO 5 - TERMO DE ASSENTIMENTO LIVRE E ESCLARECIDO - TALE ....106 ANEXO 6 - PARECER CONSUBSTANCIADO DO COMITÊ DE ÉTICA ...............108 


\section{INTRODUÇÃO}

A prática de atividade física regular vem sendo, ao longo das últimas décadas, apontada como uma grande aliada da saúde e da manutenção de uma vida saudável, agindo de forma preventiva, contribuindo para o controle e melhoria de várias condições de saúde, em especial no combate à obesidade infantil que é hoje um grande desafio de saúde pública (CASTRO et al., 2019).

Estimular a atividade física em crianças tem se tornado de grande interesse para a saúde pública, uma vez que a presença da obesidade nessas faixas etárias é frequentemente associada ao desenvolvimento precoce de outras doenças crônicas não transmissíveis, como hipertensão arterial, dislipidemias e Diabetes Melito. Entre os efeitos da obesidade durante a infância está uma maior probabilidade de sobrepeso/obesidade na idade adulta e consequentemente, de outras doenças crônicas; além do aumento do risco de mortalidade, especialmente por doenças do aparelho circulatório (ENES \& SLATER, 2010). E, embora grande parte das doenças relacionadas ao sedentarismo somente se manifeste na fase adulta, sabe-se que seu desenvolvimento pode se iniciar na infância (HALLAL et al., 2006).

Em adultos, um estilo de vida ativo está associado a uma redução da incidência de várias doenças crônico-degenerativas, bem como a uma redução da mortalidade em geral. Em crianças, um maior nível de atividade física contribui para melhorar o perfil lipídico e metabólico, além de aumentar a probabilidade de que ela se torne um adulto, também ativo (LAZZOLI et al., 1998).

Ademais, dos claros benefícios que a prática da atividade física regular traz à saúde, outros aspectos do desenvolvimento humano devem ser levados em consideração, principalmente aqueles que dizem respeito ao emocional. A inatividade física é apontada como um fator que pode agravar problemas emocionais, como: ansiedade, depressão e estados negativos de humor (MCGOVERN, 2008), ao passo que a atividade física vem sendo apontada como um fator que promove o bem-estar psicológico (WEINBERG \& GOULD, 2001).

Como consequência da falta da atividade física e de uma alimentação inadequada, a obesidade compromete a autoestima do jovem (ABRANTES, 
LAMOUNIER \& COLSIMO, 2002), sendo associada à baixa qualidade de vida na infância, trazendo a esses indivíduos consequências psicológicas no longo prazo (RAVENS-SIEBERER, REDEGELD \& BULLINGER, 2001; POETA, DUARTE \& GIULIANO, 2010).

Assim, do ponto de vista de saúde pública e medicina preventiva, promover a atividade física na infância significa estabelecer uma base sólida para a redução do sedentarismo na idade adulta, contribuindo, não só para a redução de doenças crônicas, mas também para uma melhor qualidade de vida, sob a ótica do bem-estar subjetivo (LAZZOLI et al.,1998).

Adicionalmente, os custos do sistema de saúde são pressionados em decorrência do sedentarismo, na medida em que este é fator de risco para doenças crônicas que elevam os gastos de saúde pública (DING et al., 2016), tanto no Brasil quanto em diversos países. De modo que, incentivar o hábito da atividade física entre crianças é uma ação que também contribui para reduzir os custos associados ao sedentarismo na vida adulta (BUENO et al., 2016).

A Constituição Federal de 1988, em seu artigo 217, preconiza o direito de todo indivíduo a oportunidade de participar de atividades esportivas e de lazer, sendo de responsabilidade dos Estados e dos Municípios proporcionar esse tipo de serviço à população (BRASIL, 1988). Neste sentido, além de ações voltadas à saúde, educação, cultura e lazer, é necessário ter ações públicas que garantam à criança o acesso à prática da atividade física regular.

Nesse contexto, foi aprovada em 2006 uma lei de âmbito nacional que permite que empresas e pessoas físicas apliquem parte do seu Imposto de Renda em projetos esportivos que tenham sido aprovados pelo Ministério da Educação, conhecida como Lei de Incentivo ao Esporte (Lei 11.438/2006, BRASIL, 2006).

Em função desta lei, a prefeitura do município de Indaiatuba/SP, criou em 2014 o Projeto Esporte Cidadão que tem por finalidade estimular atividade física de lazer e a convivência social, a promoção da qualidade de vida e o bem-estar físico de seus participantes.

De acordo com a apresentação deste projeto no site da prefeitura, "o esporte e o lazer vão além da concepção da prática de atividade física em tempo disponível, 
constituindo valiosos instrumentos de integração e inclusão social, que estimulam atitudes de cooperação, participação e ludicidade"1.

Diante dos benefícios da prática de atividade física, tanto a iniciativa pública quanto a privada, têm direcionado recursos para criar e manter programas com este objetivo para a população brasileira (REVERDITO et al., 2017). Nesse contexto, cabe avaliar a efetividade de tais programas, tendo em vista a escassa pesquisa no Brasil sobre políticas públicas que se propõem a promover a prática da atividade física de lazer visando a melhora tanto do estado nutricional quanto do bem-estar subjetivo de seus participantes, conforme defende Giacomoni e Hutz (2008).

Vale ressaltar a importância de se discutir as várias nomenclaturas usadas para designar a prática de atividade física, essa grande variedade de nomes, entendidos por vezes como sinônimos, não possuem do ponto de vista teórico o exato significado que Ihes são atribuídos comumente. Há um exemplo disso no próprio nome do projeto, que embora use a expressão "esporte", trata-se de um programa que promove a atividade física de lazer e não o esporte, além disso confunde-se aqui também, as ideias por trás do que seria esporte no sentido restrito da palavra e a expressão esporte cidadão, cabendo uma discussão teórica da evolução dos diversos termos usados nos trabalhos científicos diferenciando-os do senso comum.

Além dessa questão, outro ponto importante é o conceito de qualidade de vida. O projeto alvo deste estudo, apresenta em seus objetivos esses dois conceitos: qualidade de vida e bem-estar subjetivo. O conceito de qualidade de vida evoluiu ao longo do tempo, passando desde análises essencialmente voltadas à saúde e ausência de doença, até o uso atual da noção de bem-estar subjetivo, conceito usado neste estudo para operacionalizar a qualidade de vida (SOUZA \& KUCZYNSKI, 2018).

Portanto, ao se discutir o impacto que o Projeto Esporte Cidadão tem sobre o estado nutricional e a qualidade de vida de seus participantes, é importante realizar uma análise teórica dos termos: atividade física e qualidade de vida.

\footnotetext{
${ }^{1}$ Informações obtidas no site da Prefeitura de Indaiatuba, com acesso em 02/08/2020, https://www.indaiatuba.sp.gov.br/esportes/projeto-esporte-cidadao/
} 


\section{OBJETIVOS E HIPÓTESES}

\subsection{Objetivo Geral}

Avaliar o impacto do Projeto Esporte Cidadão da cidade de Indaiatuba/SP sobre estado nutricional e a qualidade de vida, de seus participantes.

\subsection{Objetivos específicos}

- Caracterização socioeconômica e demográfica das crianças participantes e não participantes do projeto;

- Avaliação do impacto de médio prazo sobre estado nutricional e bem-estar subjetivo dos participantes do Projeto Esporte Cidadão.

\subsection{Hipóteses}

H1) Crianças que participam do Projeto Esporte Cidadão, melhoram ou mantém em nível adequado, ao longo do tempo, seu estado nutricional.

H2) Crianças que participam do Projeto Esporte Cidadão, melhoram ou mantém em nível adequado, ao longo do tempo, seu bem-estar subjetivo. 


\section{EMBASAMENTO TEÓRICO E EMPÍRICO: ESPORTE EDUCACIONAL E BEM- ESTAR SUBJETIVO}

A concepção de que existe um mundo objetivo e independente das pessoas que nele vivem e dele falam, pavimentou a via sobre a qual a ciência construiu seus procedimentos práticos e discursivos, afirmando a objetividade, a verificação e a mensuração dos fenômenos. A partir do último quarto do século passado, essa imagem do objeto da ciência começa a se transformar em um novo paradigma. A concepção de que os fenômenos, naturais ou sociais são complexos, fez ruir a ideia de objetividade e ao mesmo tempo fez emergir as noções de subjetividade e singularidade (VAITSMANI, 1995). A busca pela subjetividade não se dá no sentido de desconsiderar o conhecimento científico, mas sim no sentido de conferir a ele multidimensionalidade e complexidade, a qual o presente trabalho se apoia. (GUATARRI, 2012; MORIN, 2011; GHIRALDHELLI \& RORTY, 2006; LYOTARD, 1986)

Depreende-se disto que, se nosso ser individual é formado na cultura e em sociedade, as influências que recebe do seu tempo histórico e lugar geográfico em que habita são muitas, e, sendo múltiplas, qualquer estudo precisa levar em conta os conhecimentos das mais diversas áreas do saber, dentro de uma perspectiva multi ou até mesmo transdisciplinar.

Portanto, propõe-se aqui 0 desafio de realizar uma investigação transdisciplinar, que, por consequência, enfrenta muitos obstáculos, sendo o principal deles reunir expressões de diferentes expertises e áreas de estudo em um único, sólido e conciso conceito.

Como exemplo mais pertinente ao tema, ao longo do levantamento bibliográfico e leitura do material que apoiariam as hipóteses aqui apresentadas, expressões como: esporte, prática esportiva, atividade esportiva e atividade física, apareciam ora como sinônimos, ora como conceitos complementares e outras vezes, como conceitos distintos. Utilizando como base a distinção entre essas nomenclaturas desenvolvida por Barbanti (2003) e o glossário apresentado pela Organização Mundial da Saúde/OMS (2010), o conceito de esporte engloba a ideia de uma "atividade 
competitiva, institucionalizada, que envolve esforço físico vigoroso ou o uso de habilidades motoras relativamente complexas". O autor também argumenta que a participação do indivíduo no esporte é motivada por uma complexa rede de fatores que incluiriam "motivos intrínsecos e extrínsecos".

Já o conceito de exercício físico inclui uma "sequência planejada de movimentos repetitivos sistematicamente com o objetivo de melhorar o rendimento", ou seja, infere-se que o exercício físico seja então uma atividade voltada para o preparo/manutenção do corpo buscando uma melhor performance e condicionamento físico (BARBANTI, 2003).

O autor ainda diferencia exercício físico do conceito de atividade física, esta por sua vez é "todo movimento corporal produzido pelos músculos esqueléticos que provoca um gasto de energia" (BARBANTI, 2003). Portanto, faz sentido que o termo atividade física, dentre estes apresentados, seja o mais adequado para representar o trabalho desenvolvido pelas crianças no Projeto Esporte Cidadão/PEC.

No entanto, o documento apresentado pela OMS destaca ainda, algumas variações dentro da atividade física. Esta prática, pode contemplar desde uma longa caminhada, como carteiros e crianças da zona rural que moram longe da escola, passando por atividades rotineiras como andar de bicicleta ou brincar no quintal, até atividades físicas mais direcionadas como no caso do PEC. O glossário apresentado pela OMS (2010), sugere outros termos ainda dentro do grande escopo atividade física, sendo a atividade física de lazer como a que melhor descreve a praticada pelo PEC pois, segundo o glossário da OMS (2010), esta seria a atividade física realizada por um indivíduo que não é exigida como uma atividade essencial da vida diária e é realizada a critério do indivíduo. As aulas incluem a participação em esportes, condicionamento físico ou treinamento e atividades recreativas, exatamente como propõe as práticas desenvolvidas no projeto objeto de estudo deste trabalho. 


\subsection{O domínio do corpo enquanto equalizador social}

Para compreender sob um olhar transdisciplinar o papel que a prática da atividade física de lazer tem para a sociedade atual, é necessário entender como a noção da educação do físico e do corpo construíram as noções modernas e pósmodernas de esporte, exercícios físicos e atividade física (FOUCAULT, 2014; BOURDIEU, 2004, 2011).

Traçar um panorama histórico é necessário para a compreensão do meio em que o indivíduo está inserido, pois é o todo que influencia o indivíduo desde as mais simples decisões até as mais complexas ao longo de toda a vida. Entender este caminhar histórico e pontuar as mudanças que estes conceitos tiveram ao longo do tempo, se interligam diretamente com a proposta de trabalho aqui apresentada de avaliar a qualidade de vida, sob a perspectiva de bem-estar subjetivo de crianças que participam de uma política pública voltada à prática da atividade física.

Nesta contextualização torna-se primordial compreender que a atividade física deve também ser compreendida a partir das ideias expostas pela sociologia do esporte pois, como afirma Padrão dos Santos (2012), a comunidade acadêmica tem produzido cada vez mais estudos sobre a temática da qualidade de vida, na tentativa de desvendar quais aspectos desse conceito são tangíveis ou intangíveis; quais as condições e modos de vida que a influenciam e as implicações do contexto histórico e cultural, nesta temática.

A preocupação com o estado de saúde da população iniciou-se no final do século XVI e começo do XVII, sob as perspectivas política e econômica - bem diferente da abordagem atual - quando a visão mercantilista via a saúde dos indivíduos como elemento fundamental para o enriquecimento da nação, na medida em que garantia um exército saudável e ativo assegurando a força real de um Estado em relação aos outros (KAMITA \& RODRIGUES, 2018; FOUCAULT, 2014).

O controle da sociedade sobre os indivíduos começou, assim pelo corpo, uma realidade biopolítica. Além do controle sob o corpo, também fazia parte dos mecanismos da época a vigilância, correção e higienização. A esse conjunto de práticas Foucault (2014) chamou biopoder, assumindo duas formas: de um lado a 
anatomo-política e de outro, uma biopolítica. A primeira diz respeito aos dispositivos disciplinares que operam para extrair do corpo humano o máximo de sua força produtiva mediante o controle do tempo e do espaço, no interior das instituições, como: escola, hospital, fábrica e prisão. A segunda, por sua vez, volta-se à regulação de taxas de natalidade e mortalidade, fluxos migratórios etc. É neste contexto que as preocupações sanitárias dos estados deram ensejo às tabelas de natalidade e mortalidade como índice de saúde da população.

Foi apenas na virada do século XIX para o XX que na Europa esta atividade física passa a ser caracterizada como ginástica, termo que segundo Soares (2004, p. 20) abarca "exercícios militares de preparação para a guerra; são jogos populares e da nobreza, acrobacias, saltos, corridas, equitação, esgrima”, sendo desenvolvida através de diversos métodos. Assim, uma prática anteriormente realizada com fins militares passa a ser difundida para toda uma sociedade, crescentemente urbana e industrial.

Em meados do século $X X$ aconteciam desordens provocadas por uma população carente de condições de sobrevivência e de educação. Naquele contexto, a prática da atividade física vinha como uma forma de higienização da população urbana. As doenças proliferavam e atrapalhavam a saúde do trabalhador. Assim, junto com inúmeras medidas sanitárias e de moralização das cidades, a atividade física, na forma da ginástica, passou a ser defendida pelos meios intelectuais como forma de aprimoramento da saúde, tanto individual quanto coletiva (SOARES, 2004).

Depreende-se disso a ideia de que as relações econômicas e mercantis extrapolam para as relações sociais no cotidiano (POLANYI \& STIGLITZ, 2016). Passando a ser, como condição obrigatória de sobrevivência, um modelo de apreensão e relação com o mundo (BARTHOLO, BITTENCOURT \& RIBEIRO, 2002) e logo, o indivíduo enquanto sujeito humano passa a reproduzir e a produzir de forma a retroalimentar a organização social. Conforme afirma Libâneo (1991) pelo simples fato de se viver em sociedade, do labor em instituições, da participação do modo de organização e funcionamento da sociedade, enquanto sujeitos depende-se das relações estabelecidas de poder e do confronto de interesses entre as classes sociais.

É a partir deste reconhecimento que, de fato, a atividade física passa a ser vista como prática capaz de potencializar a necessidade de utilidade das ações e gestos. 
Como prática capaz de permitir que o indivíduo venha a internalizar uma noção de economia de tempo, de gasto de energia e de cultivo à saúde como princípios organizadores do cotidiano (SOARES, 2004).

Caminhando neste contínuo histórico, percebe-se que a educação do corpo antecedeu e orientou toda a prática pedagógica da atividade física no Brasil, durante o século XX e desde o início dos anos 80, em vários estados do país surgem núcleos empenhados na rediscussão de temas que vão desde a redefinição do papel da atividade física, até questões ligadas às mudanças necessárias ao nível da prática efetiva nas quadras, ginásios e campos. Essa discussão é reflexo de uma abordagem maior que envolveu o país a partir do abrandamento do sistema repressivo instaurado pela Ditadura Militar, situação essa que se verificou com maior velocidade e ênfase após a anistia (GUIRALDHELLI JR., 1991).

Desta forma, a atividade física atendendo às necessidades produtivas e criando meios de atuar em prol de uma sociedade que a adotou como ferramenta, passou a ditar normas e padrões de saúde, separando os aptos daqueles que precisavam de cuidados. A atividade física por meio da exigência de desempenho e busca constante de resultados, desenvolveu um imaginário no qual o corpo deve estar sempre são, belo e preparado para as exigências de uma sociedade em constante transformação. Na escola, o corpo fará os exercícios, as repetições, a cerimônia e a avaliação, entre tantas outras práticas, fazendo com que os alunos e alunas sejam organizados, assim como os operários e operárias na fábrica, dentro de um sistema de normas de comportamento, com a imposição de uma série de tarefas que visam um objetivo maior de docilizar os corpos (BOURDIEU, 2002; FOUCAULT, 2014).

Corpos que necessitam obter aptidões e qualificações, prontos para executar o trabalho (GRANDO, 1996). A antiga (e ainda presente) exigência de rendimento, de habilidades motoras bem desenvolvidas e destreza na execução dos movimentos ginásticos, fez com que a atividade física fosse caracterizada como a prática capaz de fortalecer o corpo e a moral dos indivíduos (CONTREIRA \& CORAZZA, 2009).

À vista disto, a principal premissa da sociedade disciplinar (final do século XVIII até por volta de 1940) era a modelação do comportamento. Essa perspectiva mudou a partir de meados do século $\mathrm{XX}$, pois o indivíduo interiorizou a disciplina, independentemente da presença ou ausência de algum tipo de autoridade investida 
(HAN, 2015). É nessa linha que Deleuze (2011) nos leva a um entendimento de que a sociedade disciplinar sedimentou a sociedade de controle. Já não há muros que separam o lado de dentro das instituições do lado de fora (DELEUZE \& GUATTARI, 2011), não apenas pela disseminação dos dispositivos tecnológicos de vigilância tanto no espaço privado quanto no público. As palavras de ordem não parecem ser mais coagir, ordenar, disciplinar, reprimir, mas sim agradar e impressionar (LIPOVETSKY, 2019).

O corpo é parte do universo subjetivo, pois ele é socialmente construído (LE BRETON, 1992) e a imagem que o ser faz do próprio corpo constrói sua identidade (FREUD, 2010a; LACAN, 1998). Também, Winnicot (2011) aponta que nos estágios iniciais da infância o indivíduo ainda, não está em condições de perceber o ambiente, não existindo um self estruturado capaz de diferenciar entre o EU e o(s) OUTRO(s).

Conjectura-se assim, que os padrões culturais agem como sistemas organizados de símbolos e a cultura, vista como totalidade acumulada de tais padrões, não é apenas um ornamento da existência humana, mas uma condição essencial para ela, a principal base de sua especificidade (GEERTZ, 1981).

É com Lacan (1998), afirmando que o inconsciente é o discurso dos outros, que podemos entender como se dá a passagem da sociedade do biopoder de Foucault para a sociedade de controle deleuziana e desta, para a sociedade do cansaço de Byung-Chul Han (HAN, 2015). O próprio indivíduo manipula calculadamente os seus gestos, seus comportamentos, não porque está sendo vigiado, mas ele mesmo exerce o controle de si para se mostrar ao outro (FOUCAULT, 2014; LIPOVETSKY, 2019). É neste contexto que o corpo ganha tanta importância no imaginário coletivo e por isso a elucidação de tais pressupostos faz compreender a como e por que a educação do corpo, as atividades físicas, o lazer, a cultura, são domínios em que investem as políticas públicas e privadas (BETTINE, GUTIERREZ \& MARQUES, 2019), dentro da complexa teia do desejo - e da concretude - de viver bem. 


\subsection{O termo Qualidade de Vida e sua relação com a atividade física}

A ideia atual sobre a qualidade de vida ultrapassou sua origem na área da saúde e constitui hoje um campo cuja principal característica é a transdisplinariedade. Esta diversidade, ao mesmo tempo que disponibiliza uma riqueza de ideias, deve ser precedida como uma reflexão conceitual e grande rigor metodológico, no sentido de não perder de vista os paradigmas originais de cada área em seu processo de aproximação (BETTINE, GUTIERREZ \& MARQUES, 2019).

\subsubsection{O percurso histórico do conceito de Qualidade de Vida.}

O conceito de qualidade de vida surgiu na década de 1970 como uma medida atrelada, especificamente, à saúde como sinônimo de ausência de doença. Sob este enfoque, o instrumento do WHOQOL-Group (WHOQOL GROUP, 1995), o mais utilizado ao redor do mundo quando se fala no tema, procura avaliar o grau da qualidade de vida com base em sintomas e incapacidades do indivíduo, ou seja, mede a qualidade de vida por aspectos relacionados à condição de saúde. Ilustrando esse aspecto, um estudo da validade discriminante do instrumento, em sua versão em português de Portugal, mostrou-se eficaz em discriminar pessoas doentes da população em geral (CASTRO et al., 2013). Por outro lado, instrumentos de avaliação psiquiátrica validados para populações sadias são inadequados para avaliar quadros de populações portadoras de doenças terminais ou crônicas, dada a sobreposição de sintomas físicos e/ou mentais (SOUZA \& KUCZYNSKI, 2018).

Com o passar das últimas décadas, evidenciou-se que o conceito de qualidade de vida não deveria se restringir ao contexto da ausência da doença, mas também abranger outras áreas em um contínuo biopsicossocial (CONSTANTINO, 2016). Segundo Assumpção et al. (2000), a qualidade de vida deve ser entendida ademais, como a sensação subjetiva de bem-estar, podendo ser interpretada, segundo Araújo e Araújo (2000), como a capacidade de aproveitar a vida e de superar desafios, 
passível de observação em diferentes momentos, no trabalho, na escola, na família, em atividades culturais e esportivas, na velhice, na maturidade e durante a infância.

Shin e Johnson (1978, apud ASSUMPÇÃO et al., 2000, p.120) já acreditavam, na década de 1970, que a qualidade de vida, se relaciona com "a possessão de recursos necessários para a satisfação das necessidades e dos desejos individuais", com a "participação em atividades que permitem o desenvolvimento pessoal, com a auto realização" e com uma "comparação satisfatória entre si mesmo e os outros".

Assim, a maior dificuldade ao falar sobre qualidade de vida é considerar, de maneira clara, seu conceito. Pois este, abrange aspectos bastante distintos, que vão desde ideias difundidas pelo senso comum, passando por enfoque econômico, até sua instrumentalização para fins políticos ou mercadológicos - aparecendo em discursos e promessas de governantes que propagandeiam as benfeitorias de seus mandatos e de empresas que divulgam seus novos produtos como promotores de uma melhor qualidade de vida, se valendo exatamente da imprecisão do termo (BETTINE, GUTIERREZ \& MARQUES, 2019).

De um modo geral, a política governamental tende a refletir a teoria (econômica) mais conveniente ao ponto de vista político e o que tende a extravasar do círculo dos especialistas é a versão simplificada e vulgarizada de ciência (HOBSBAWM, 2011), ou seja, usam dessa imprecisão do termo qualidade de vida e adotam o conceito que mais se aproxima de seus interesses, ignorando o que a ciência diz sobre este termo.

A qualidade de vida pode ser entendida como algo que pode ser comprado, adquirido. De acordo com os pensamentos de Bauman (2001) sobre a pósmodernidade, a qualidade de vida também seria entendida como produto que pode ser usufruído por quem puder comprá-la, do mesmo modo, constituído como um ideal a ser perseguido pelo sujeito, individualmente. A busca ávida e sem fim por receitas de vida, é ainda uma variedade do comprar, e uma variedade da máxima importância, que atribui a nossa felicidade, seguramente, à competência pessoal.

Para ampliar os conceitos é necessário partir deste pensamento sobre a sociedade pós-moderna de consumo, e retroceder no tempo, apoiando-se nas ideias de Fromm (1965). Segundo o autor, desde o momento do pós-guerra no mundo 
ocidental, a ideia de 'homo consumericus²' já se faz presente, sendo necessário compreender que a formação do estado de bem-estar está intimamente relacionada ao consumo e com o liberalismo econômico (BOBBIO, MATTEUCCI \& PASQUINO 1998; HABERMAS, 2014).

Neste contexto, na conjunção entre economia de estado e política de estado vê-se surgir a sociedade de e para consumo. Não é sem fundamento, portanto, que o conceito de qualidade de vida passa a integrar, além das condições de saúde, a aquisição de bens materiais e os avanços educacionais. Isto paradoxalmente contribui para colocar a qualidade de vida tanto no interior da disputa entre as nações europeias ocidentais na luta, simbólica e prática, por justiça e direitos humanos (HOBSBAWM, 2012a, 2012b). Foi apenas a partir de 1990 que a ONU passou a adotar um conceito envolvendo outras dimensões além da econômica, o Índice de Desenvolvimento Humano/IDH, como medidas de educação e longevidade da população (Programa das Nações Unidas para o Desenvolvimento - PNUD, 2012).

O aspecto socioeconômico, que perpassa as três dimensões citadas acima, não inclui os aspectos subjetivos e multiculturais, que de mais a mais transita por valores e práticas como urbanidade e respeito mútuo, bases da força espiritual da democracia (GONÇALVES \& VILARTA, 2004). É indiscutível que o indivíduo em sua apreensão do mundo, em sua percepção de si próprio, na forma como ele se relaciona com outros e o significado que ele dá a todas estas associações, "são profundamente influenciadas pela quantidade de satisfação instintual que a riqueza existente torna possível" (FREUD, 2010b, pág. 05). Contudo, o enfoque meramente quantitativo, além de considerar aspectos socioeconômicos, lida com questões de saúde, incluindo no cálculo a expectativa de vida ao nascer e taxas de mortalidade da população (BETTINE, GUTIERREZ \& MARQUES, 2019). E desta forma, os padrões ocidentais modernos são tomados como referência para aferir todas as nações do planeta (GONÇALVES \& VILARTA, 2004).

Esses aspectos, que avaliam as condições de saúde, estão inseridos também no contexto histórico de criação da OMS, quando o ocidente promoveu a criação de diversas instituições universais preocupadas em promover assistência humanitária e

2 O sujeito que não está preocupado em possuir coisas, mas em consumi-las. 
defender os direitos humanos. Na esteira desse processo, desenvolveu uma consciência dando sentido a uma comunidade global, no exato momento em que o mundo europeu se via destruído pela rivalidade entre as nações (IRIYE, 2014). A fase de prosperidade, em que o velho continente entrou, com o crescimento $e$ modernização das indústrias devido, especialmente, mas não apenas, ao Plano Marshall (STEIL, 2019), fez desviar a atenção popular do consumo, das necessidades básicas para a qualidade de vida (JUDT, 2008). No pós-guerra, todas as áreas das ciências voltaram seu foco para os aspectos patológicos da vida, criando terreno para surgir a sistematização social, ou seja, quando a política se apropria das condições sociais, da educação, saúde, saneamento básico, prisões, manicômios, orientada a propiciar bem-estar e prosperidade, mitigando as possibilidades de doenças.

O termo qualidade de vida também encontra antecedentes na filosofia de Helvetius (apud SOUZA \& KUCZYNSKI, 2018), propositiva da ideia de que um homem seria um ser estritamente físico e que sua capacidade de apreensão e pensamento dependia das sensações físicas, prévias e atuais. Neste sentido, os procedimentos médico-terapêuticos deveriam não só aumentar a expectativa de vida, mas sobretudo melhorar a qualidade de vida. Assim, nas últimas décadas passou a ter mais importância o "como" o paciente se sente, em vez de como o médico acredita que ele deva se sentir, baseado em suas medidas clínicas (SOUZA \& KUCZYNSKI, 2018).

Bauman e May (2010) salientam que o contexto das mudanças surgidas na sociedade e na ciência que busca interpretar pauta e a forma de como se conduz, e como somos conduzidos pelas nossas vidas.

É no diálogo e questionamento destas premissas, que surge a proposição de um novo paradigma sobre a qualidade de vida, considerando desde a percepção e expectativas subjetivas sobre a vida, até questões mais deterministas como 0 agir clínico frente a doenças e enfermidades. A qualidade de vida não se esgota nas condições objetivas de que dispõem os indivíduos, tampouco no tempo de vida que possam ter, mas no significado que dão a essas condições e à maneira com que vivem (BETTINE, GUTIERREZ \& MARQUES, 2019).

Assim, o termo abrange muitos significados, que refletem conhecimentos, experiências e valores, histórias diferentes, sendo, portanto, uma construção social 
com a marca da relatividade cultural (MINAYO, HARTZ \& BUSS,2000). O que é boa qualidade para alguém, não é necessariamente para outra pessoa (BETTI, 1997).

Destarte, na mídia, na política, no linguajar popular, são buscados atributos que desenredam a noção do termo qualidade de vida a um só tempo operacionalizando a banalização e promovendo a inconsistência do conceito, das ideias que o nutrem. Outrossim, ensaia Trigo (2019, p.17) não se pode perder de vista que, essas discussões acontecem em um mundo desenvolvido no ocidente, onde os IDHs atingem níveis considerados mais satisfatórios, sendo que em vastas áreas do planeta a miséria impede que se chegue a um padrão elementar de condições de qualidade de vida... uma imensa massa humana aleijada das benesses do desenvolvimento material e tecnológico (BETTINE, GUTIERREZ \& MARQUES, 2019). Lançar mão de referenciais seria transpor e, é absolutamente imprescindível que se evite o transplante de conceitos de um campo para outro, de uma cultura para outra, sem levar em consideração as particularidades (KÓVACS, ANDRADE \& SGORLON, 1998).

Referenciais hegemônicos como parâmetros avaliativos generalizam grupos em questão, pois suas particularidades históricas e culturais não são levadas em consideração (GONCALVES \& VILLARTA, 2004). Referenciais médicos como parâmetros avaliativos enclausuram o foco no sintoma e não no paciente (SOUZA \& KUCZINSKY, 2018). Referenciais socioeconômicos são muito úteis para a sociologia e a economia, bem como para a organização do Estado e diretrizes de políticas públicas, mas para avaliar a qualidade de vida, de certo modo, se caracterizam como um limite metodológico, pois diferentes regiões de um mesmo país possuem condições socioeconômicas extremamente divergentes (BETTINE, GUTIERREZ \& MARQUES, 2019). Ainda que haja questões sociais objetivas que delimitem o espaço e as possibilidades de ação do indivíduo, a melhoria de vida não causa diretamente uma diminuição do mal-estar na civilização (FREUD, 2010a), pois o paradoxo é que a felicidade parece continuar inacessível, enquanto temos mais oportunidades de colher os frutos de melhores condições materiais de vida (BETTINE, GUTIERREZ \& MARQUES, 2019).

Esta perspectiva coloca o indivíduo no centro do processo e como tal, é a única perspectiva que respeita o ser qualificando-o para falar por si mesmo. Ela ultrapassa 
modelos de saúde física, incluindo percepções de bem-estar, satisfação pessoal e valorização de si mesmo, no contexto da cultura e sistema de valores nos quais se vive (BOWLING, 1997). Por colocar o indivíduo no centro do processo, falar em qualidade de vida, sob uma ótica que extrapola a ideia de não doença, é falar de algo que é subjetivo, individual; coloca-se aqui em pauta então subjetividade.

\subsubsection{A qualidade de vida enquanto bem-estar subjetivo}

Subjetividade é a capacidade da pessoa avaliar suas próprias ideias e expectativas, utilizando os processos cognitivos subjacentes para a percepção das condições da sua própria vida. Tal valoração de si mesmo só pode advir da percepção particular de cada um em torno de seu passado e seu futuro, como diz a expressão popular "de onde saí, até onde cheguei". Essa auto valoração ainda contempla marcos e conquistas sociais, com diferentes graus de influência a depender da cultura em que o indivíduo se insere. Neste pensamento entende-se que é só o indivíduo que pode responder sobre a sua qualidade de vida. A cultura, no sentido mais amplo, integra diferentes mecanismos de ação que perpassam o universo simbólico no qual o agente vive, gerando diferentes experiências percebidas pelo corpo por meio dos sentidos (LEWIN, 1997).

Além desses preceitos de bem-estar subjetivo, essa ideia de subjetividade foi discutida ainda, pela Psicologia Humanista, por autores como Maslow (2018) e Rogers (1986) que se mostraram comprometidos com os aspectos positivos do desenvolvimento humano, com esse novo olhar e perspectiva sobre o comportamento (CAMALIONTE \& BOCCALANDRO, 2017). Seligman e Csikszentmihaly (2000), também apontam que o bem-estar subjetivo se refere ao que as pessoas pensam e sentem sobre suas próprias vidas. Na prática, para esses autores, o bem-estar subjetivo é um termo mais científico para o que as pessoas chamam de felicidade. Complementando, o bem-estar subjetivo pode ser entendido como o julgamento que os indivíduos fazem em relação à qualidade da sua própria vida com base nos seus próprios critérios (DIENER et al., 1995). 
Posto que se trata de uma ferramenta científica, a investigação e a instrumentalização do bem-estar subjetivo como parâmetro para avaliar a qualidade de vida, tende a adotar diferentes aspectos e avaliar o poder preditivo de cada um deles. Seguindo uma abordagem interacionista, o bem-estar subjetivo pode ser entendido a partir da integração entre fatores intrínsecos e extrínsecos, como: a personalidade e eventos da vida (WOYCIEKOSKI, NATIVIDADE \& HUTZ, 2014); a faixa etária e o nível socioeconômico (GIACOMONI, SOUSA \& HUTZ, 2014); ainda, a etapa do ciclo vital em que a pessoa se encontra e à diversidade de contextos que ela vivência (GAZZOL et al., 2018).

Adicionalmente a isso, Kozma, Stone \& Stones (2000) definem que um alto nível de bem-estar subjetivo está relacionado com um vasto número de aspectos da vida, desde relacionamentos até satisfação conjugal, sucesso em ambientes de trabalho, melhoria na capacidade de lidar com estresse e melhorias nos aspectos de saúde.

Em um outro aspecto, o bem-estar subjetivo aparece ligado à avaliação do próprio corpo. Lemes et al. (2018) estudaram a satisfação com a imagem corporal entre adolescentes em Canoas, RS - Brasil e constataram, dentre outros indicadores, elevada frequência de insatisfação com sua imagem. Nesta fase, o adolescente está construindo sua identidade pessoal e social e muitas mudanças ocorrem concomitantemente à maturação biológica, o que aumenta as preocupações com o corpo e a aparência. Os que não possuem os biótipos desejados, se preocupam excessivamente com a aparência física, manifestam insatisfação com a imagem corporal e baixo bem-estar subjetivo. Ainda que o gênero seja um fator importante no que tange à insatisfação com a imagem corporal, é preciso considerar que tanto meninas, quanto meninos apresentam dificuldades com o tema no período da adolescência.

Outro estudo feito com 200 crianças em Maringá, PR - Brasil (GIACOMONI, SOUZA \& HUTZ, 2014) coletou informações qualitativas sobre o que crianças pensam sobre felicidade, constructo correlato ao do bem-estar subjetivo. Sobre "o que é ser feliz", as crianças trouxeram mais conteúdos sobre sentimentos positivos sobre si. As de escolas privadas mencionaram mais o lazer, as de escola pública, destacaram a satisfação de necessidades básicas e desejo de ter coisas que gostariam. Sobre 
"como é uma pessoa feliz", mais da metade da amostra apontou características subjetivas positivas, com os meninos citando mais este conteúdo.

Seguindo os achados Giacomoni, Souza e Hutz (2014) esclarecem que avaliar a felicidade, o bem-estar subjetivo e a satisfação com a vida na infância, requer conhecer a forma como a criança compreende o que significa ser uma pessoa feliz e de como uma pessoa feliz, se apresenta aos outros. Isso é relevante para que as intervenções em satisfação com a vida e bem-estar subjetivo, não desconsiderem outros domínios relevantes para o exame da felicidade infantil.

Este processo de entendimento do bem-estar como subjetivo não é outra coisa senão o reflexo e a aplicação de uma nova forma de entender o homem e, portanto, o corpo e as relações distintas que sua natureza pode estabelecer (MADRONA, 2008). Assim, distanciando-se das perspectivas médicas e socioeconômicas as quais pretensamente investigavam qualidade de vida quando na verdade, serviam a outras áreas do conhecimento que não a psicologia. Esta forma dá voz ao indivíduo no contexto de sua própria história (BETTINE, GUTIERREZ, MARQUES, 2019), sem perder de vista as dimensões macro e micro sociais dentro das quais o indivíduo se movimenta.

Seguindo a visão de Padrão dos Santos (2012), de que o conhecimento científico deve estar atento permanentemente às transformações na vida do indivíduo comum e da sociedade, este trabalho adotou a perspectiva do bem-estar subjetivo para avaliar o impacto do Projeto Esporte Cidadão sobre a qualidade de vida das crianças participantes.

\subsection{0 estado nutricional, bem-estar subjetivo e atividade física.}

Como apresentado anteriormente, embora o domínio do corpo tenha sido originalmente usado como equalizador social, ele não se limita a isso. O movimento e controle do corpo por meio da atividade física, além da sua função biopolítica, também traz inegáveis benefícios à saúde fís0ica e ao bem-estar subjetivo das pessoas. Além 
disso associado à atividade física, o estado nutricional adequado tem sido apontado como promotor de qualidade de vida e saúde.

Conforme orientação da Organização Mundial da Saúde/OMS um indivíduo, pode ser classificado sob o ponto de vista nutricional, desde a magreza até a obesidade grave, sendo o peso normal a condição desejada. Tanto a magreza quanto a obesidade têm sido apontadas como condições que trazem prejuízos ao desenvolvimento da criança, sendo preditores de problemas crônicos na vida adulta (PAIVA et al., 2002).

A obesidade, na atualidade, tem sido indicada como um dos aspectos biológicos mais impactantes na qualidade de vida de crianças e jovens. Além disso, a obesidade infantil tem sido uma das principais ameaças à saúde, não só no Brasil, mas em diversos outros países, uma vez que o índice de sobrepeso durante esta fase da vida é um dos principais fatores de risco para a obesidade adulta (SILVA et al., 2009). Pratt et al. (2013) relataram que crianças obesas tiveram 5,5 mais chances de apresentarem prejuízos na qualidade de vida do que crianças saudáveis, nível semelhante ao obtido em estudo de Schiwimmer (apud PRATT et al., 2013), sobre a qualidade de vida de crianças com câncer e crianças saudáveis.

Não se tem a ideia aqui de simplificar o conceito de obesidade, como sendo apenas o resultado de um balanço energético negativo, mas sim entender este constructo como sendo resultado de multiplicidade de fatores que afetam um indivíduo quanto a suas escolhas e hábitos alimentares, bem como os fatores que influenciam seu engajamento nas atividades físicas (GILMAN \& VOLPE, 2018).

Portanto, a obesidade infantil tem sido um problema de saúde pública que se alastra cada vez mais no Brasil, elevando os gastos públicos e sendo fator de risco para doenças crônico-degenerativas que, anteriormente, não eram detectadas em crianças (WHO, 2014), bem como acarretando diversos transtornos como a ansiedade e a depressão. Além de afetar a estética, afeta intrinsicamente o campo psicológico da criança e no seu meio social (OLIVEIRA \& COSTA, 2016).

Dados recentes mostraram que uma entre três crianças, com idades entre 5 e 9 anos, estão acima do peso ou obesas (MONTEIRO, ALMEIDA \& BUENO JR, 2020). Por isso, estimular a atividade física em crianças e adolescentes, além de toda a 
questão do controle do corpo, tem se tornado de grande interesse para a saúde pública; uma vez que a presença da obesidade, nessas faixas etárias, é frequentemente, associada ao aumento da probabilidade de sobrepeso e obesidade na idade adulta e consequentemente, de outras doenças crônicas, com aumento do risco de mortalidade, especialmente por doenças do aparelho circulatório (ENES \& SLATER, 2010).

Outros efeitos da obesidade durante a infância e a adolescência são os distúrbios metabólicos, endócrinos, hipertensão e alguns tipos de câncer (WANDERLEY \& FERREIRA, 2010) e embora, grande parte das doenças relacionadas ao sedentarismo, somente se manifeste na fase adulta, sabe-se que seu desenvolvimento pode se iniciar na infância e adolescência (HALLAL et al., 2006). Ou seja, todas estas evidências dos últimos 15 anos continuam corroborando a ideia de que crianças e adolescentes acima do peso ou obesos, permanecerão nesse quadro quando atingirem a idade adulta (LIMA et al., 2020) o que consequentemente, acarretará numa baixa satisfação com sua imagem corporal, diminuindo os índices de bem-estar subjetivo (LEMES et al., 2018).

A avaliação do estado nutricional tem suas vertentes objetivas e subjetivas. Objetivamente, é apontada como um indicador de saúde da população, e como indicador indireto de qualidade de vida, por meio de sua influência sobre aspectos emocionais e psíquicos (SIQUEIRA \& PADOVAN, 2008). E por isso, inúmeras pesquisas têm incluído a avaliação do estado nutricional como uma de suas variáveis de interesse, não só na área médica e nutricional, como indicador de saúde, mas também, na área social e da psicologia.

A obesidade, como mais provável consequência de uma alimentação inadequada e da falta da atividade física, é apontada como fator que compromete a autoestima do jovem (ABRANTES, LAMOUNIER \& COLSIMO, 2002), sendo associada à baixa qualidade de vida na infância e na adolescência, trazendo a esses indivíduos consequências psicológicas no longo prazo (RAVENS-SIEBERER, REDEGELD \& BULLINGER, 2001; POETA, DUARTE \& GIULIANO, 2010; FINNE et al., 2013)

Um estudo retrospectivo realizado por De Grandis, Armelinib e Cuestasc (2014), com 25 crianças que haviam sofrido com desnutrição grave na primeira 
infância e 28 de seus irmãos sem problemas nutricionais, constatou que mais da metade das sobreviventes da desnutrição apresentaram consequências negativas sobre o desenvolvimento emocional, a aprendizagem e as relações interpessoais. A principal conclusão deste estudo foi que a desnutrição grave precoce foi significativamente associada com redução considerável da qualidade de vida durante a idade escolar nas dimensões físicas, emocionais e sociais. Evidenciou-se a capacidade reduzida do indivíduo de interagir com o ambiente e com os seus pares, limitando seu potencial para ter uma vida saudável e produtiva (DE GRANDIS, ARMELINIB \& CUESTASC, 2008).

O sobrepeso e a obesidade, no outro extremo, que é a acumulação excessiva de gordura corporal comumente resultante de uma ingestão de calorias incompatível com o gasto energético (MENEZES \& MARUCCI, 2020), estão associados a uma ampla gama de complicações, semelhantes às associadas à desnutrição, incluindo consequências psicológicas e sociais negativas, como: ansiedade, depressão, angústia, baixa autoestima, sentimento de culpa, problemas de ajustamento social e distúrbios de comportamento/conduta (TURCO et al., 2013; POETA, DUARTE \& GIULIANO, 2010, 2013).

Como posto, existem estudos que associam o sobrepeso a diversos quadros negativos, tanto do ponto de vista da saúde física como mental; como complemento, é possível citar ainda que a obesidade infantil desencadeia cansaço físico mais acentuado, baixo nível de aptidão física e atraso no desempenho das habilidades motoras (SIQUEIRA, ALVES \& FIGUEIRO, 2009). Em outro estudo, o estado nutricional foi associado a dor de cabeça crônica, crianças obesas apresentaram mais dor de cabeça do que crianças não obesas, sendo que este incômodo foi associado à redução na qualidade de vida (CASTRO et al., 2013). Neste sentido, é notório o papel que a avaliação do estado nutricional tem para a qualidade de vida, sob a ótica da saúde (MELLO, 2002) cabendo então, investigar ainda mais seu o papel sobre a sensação subjetiva de bem-estar.

No lado oposto, entre os fatores associados a quadros positivos de saúde e bem-estar, está a prática da atividade física regular. Uma vida ativa é apontada como uma grande aliada na manutenção de um estado nutricional adequado e saudável, 
agindo de forma preventiva, contribuindo para o controle e melhora de condições como a obesidade (COELHO et al., 2012).

Em adultos, um estilo de vida ativo está associado a uma redução da incidência de várias doenças crônico-degenerativas bem como a uma redução da mortalidade em geral. Em crianças e adolescentes, um maior nível de atividade física contribui para melhorar o perfil lipídico e metabólico, além do fato de que é mais provável que uma criança ou um adolescente fisicamente ativo torne-se um adulto ativo (LAZZOLI et al., 1998) embora isso, não seja garantido (PADRÃO, 2012). Entretanto, quanto mais avançada a idade do indivíduo, mais difícil implementar mudanças de hábitos alimentares e de estilo de vida, e assim alterar condições metabólicas consolidadas ao longo da vida (SILVA, TEIXEIRA \& FERREIRA, 2014).

Entre os benefícios da atividade física se destaca a sua contribuição para a redução do risco de morbidade e mortalidade (ZHAO, FORD \& MOKDAD, 2008) o qual pode ainda, ser intensificado se aliado à intervenção dietética (SHAW et al., 2006). A importância da atividade física para indivíduos com excesso de peso/obesidade foi demonstrada pela meta-análise realizada por Fogelholm (2010) na qual, o tratamento dos dados recolhidos indica que o risco para todas as causas de mortalidade cardiovascular foi menor em indivíduos com IMC elevado, mas com uma boa aptidão física, quando comparados com indivíduos com IMC normal e baixa aptidão física. Ou seja, a prática da atividade física se mostra muito importante mesmo que, do ponto de vista nutricional, a condição do indivíduo não esteja equacionada/equilibrada.

Além de a atividade física ser um hábito importante para a manutenção da saúde, prevenção de doenças e desenvolvimento psicomotor, apresentando maior equilíbrio no balanço energético e no controle da massa corporal (HUMPHREYS, MCLEOD \& RUSESKI,2014), é apontada como um fator que promove o bem-estar subjetivo. A prática da atividade física promove menor reatividade ao estresse, diminuindo a ansiedade, depressão e hostilidade, tanto em pessoas saudáveis quanto em pacientes clínicos, melhorando de modo geral o estado de humor do indivíduo (WERNECK \& NAVARRO, 2011).

Um estudo transversal comparou variáveis psicológicas de indivíduos ativos e sedentários, concluindo que os participantes com melhores níveis de aptidão física 
apresentavam melhores estados de humor. Segundo os autores, duas hipóteses podem ser destacadas para essa relação entre exercício e humor: a atividade física melhora a saúde mental e uma melhor saúde mental leva as pessoas a serem ativas (WERNECK \& NAVARRO, 2011).

Ante o exposto, fica evidenciada a relação direta entre estado nutricional e saúde, o que levou, neste trabalho, a se adotar o estado nutricional como indicador de saúde. Ficou também, indicada a influência da atividade física sobre a saúde e sobre o estado nutricional, favorecendo assim, o uso do estado nutricional para avaliar o impacto do Projeto Esporte Cidadão sobre a saúde das crianças participantes.

Todavia, é importante observar que várias circunstâncias podem influenciar a efetiva realização da atividade física. A esse conjunto de diferentes influências potenciais que podem promover ou desestimular a atividade física e em igual medida atuar sobre os hábitos de vida, é o que Seabra et al. (2008) chamou de ambiente. 


\section{POLÍTICAS PÚLICAS}

\subsection{Políticas públicas voltadas à prática da atividade física.}

A promulgação da Constituição Federal de 1988 consolidou diversos direitos do cidadão, muitos dos quais se associaram a políticas públicas. Entre esses direitos, a Constituição Federal tornou em seu artigo 217, dever do Estado "fomentar práticas desportivas formais e não-formais, como direito de cada um" observada "a destinação de recursos públicos para a promoção prioritária do desporto educacional e, em casos específicos, para o desporto de alto rendimento", viabilizando a alocação de recursos públicos para o cumprimento desse dever (BRASIL, 1988).

A partir desta época, as discussões avançaram tanto no campo da educação física escolar, quanto no campo esportivo, ampliando a visão de atividade física e desportiva para além do aspecto profissional, compreendendo o contexto educacional e de lazer para a formação plena do ser humano (MACHADO et al., 2007), e portanto, o esporte educacional passou a ser usado muitas vezes como sinônimo de atividade física guiada e voltada ao desenvolvimento de outras competências, não apenas àquelas ligadas diretamente ao esporte ou ao exercício físico competitivo, como conceituado e entendido por Barbanti (2003) (GUIRALDHELLI, 1991).

Do contexto Constitucional, foi criada em 1996 a Lei de Diretrizes e Bases da Educação Nacional (LDB no 93994/96, BRASIL, 1996) que tornou obrigatória a aula de educação física, antes fazendo parte do currículo complementar com oferecimento opcional. Essa Lei transformou a Educação Física em uma disciplina integrante do currículo escolar, componente da grade regular a ser obrigatoriamente oferecida no ensino fundamental e trazendo a atividade física para o cotidiano da criança.

No entanto, naquela época, a prática atividade física dentro da escola era uma forma de identificar e fornecer talentos para o esporte de alto rendimento; o esporte como apelo popular e que faria com que o Brasil alcançasse altos postos em campeonatos mundiais (FARJALLA, 2015). Mais complicada foi a relação dessa concepção competitiva e a prática cotidiana Educação Física escolar, pois nem sempre as descobertas acadêmicas sobre educação física chegavam no nível da 
prática escolar, existindo diferenças regionais e entre países. As ideias do esporte competitivo permaneciam vivas dentro da mente e da prática dos professores de educação física escolar (GHIRALDHELLI, 1991).

Na contramão das ideias competitivas, surgiu em meados da década de 1990, em nível federal, o Programa Esporte Solidário e Esporte na Escola, tendo como principais finalidades levar a prática do esporte às populações carentes e diminuir as situações de exclusão social (VERONEZ, 2005). Paralelamente surgiram duas leis: a Lei Zico (Lei 8.672 de 1993 - BRASIL, 1993) revogada em 1998 e a Lei Pelé (Lei 9.615 de 1998 - BRASIL, 1998) que substituiu a primeira, criadas para melhorar e profissionalizar o esporte brasileiro. Entre seus artigos, contudo, a Lei Zico enfatizava o desporto como direito social e atribuía ao desporto educacional a finalidade de desenvolver integralmente a criança, bem como contribuir para a formação da cidadania e promover o lazer. A Lei Pelé, manteve esses aspectos, destacando o pleno desenvolvimento dos praticantes, sem o foco na competitividade; mas privilegiando a identificação de novos talentos e o esporte de participação, destinado às práticas no momento de lazer; afirmando o esporte como promotor da formação humana e do desenvolvimento da autonomia. Essa lei impôs regras para o disciplinamento do esporte profissional e a definição da origem dos recursos, entre outros aspectos (BRASIL, 1993; 1998; MACHADO et al., 2007).

Desde então, diversos projetos e programas sociais têm surgido a fim de fomentar a prática da atividade física em uma perspectiva educacional cidadã, atendendo, principalmente, a população em situação de risco pessoal e social. Em meados da primeira década deste século, uma nova Lei foi instituída visando o esporte educacional, a Lei 11.438 de 2006 (BRASIL, 2006) conhecida como a Lei de Incentivo ao Esporte/LIE, de âmbito federal. A LIE permite que empresas ou pessoas físicas, por meio da dedução de impostos fiscais, possam patrocinar ou apoiar projetos esportivos de todas as estâncias, previamente aprovados pelo Ministério do Esporte nas três dimensões: educacional, de participação ou de alto rendimento, tendo como prioridade atender crianças e adolescentes no contra turno escolar, por meio de práticas esportivas e educacionais.

Logo em seguida, foi criado o Programa Esportivo Segundo Tempo/PST (BRASIL, 2007) que prioriza áreas de vulnerabilidade social e tem como foco a 
democratização do acesso, da prática e à cultura de esporte. O programa, no âmbito federal, tem como prioridade 0 atendimento a crianças, adolescentes e jovens expostos a situações de risco social e a universalização do esporte, como ferramenta para potencializar elementos educativos. Este resultado fortaleceu as ações de ONGs e do Terceiro setor no país, ancorados basicamente na LIE (REVERDITO et al., 2016).

\subsection{Avaliação de Políticas Públicas voltadas ao esporte educacional}

Avaliação de impacto refere-se a investigar o resultado derivado de uma ação, sendo um julgamento objetivo de um projeto (ação planejada), programa ou política pública, em andamento ou concluído, com base em critérios claros. A decisão de se implantar, de manter uma política pública ou programa deve se embasar em uma avaliação do seu impacto em relação aos objetivos planejados, bem como comparando seus resultados com os de programas alternativos, até mesmo com o que ocorreria na ausência de qualquer programa. A avaliação de impacto, portanto investiga as mudanças ao longo do tempo, procurando identificar o efeito exclusivo do programa, ao controlar outras influências (GERTLER et al., 2015), servindo para dar racionalidade aos processos decisórios a partir de dados objetivamente mensurados (FARIA, 2005; SECCHI, 2013).

Kravchychyn e Oliveira (2015) realizaram uma revisão da literatura sobre a quantidade e qualidade de estudos de avaliação de políticas públicas voltadas ao esporte educacional no Brasil, encontrando indícios de que o interesse em avaliar políticas públicas voltadas a esta prática, embora tenha de fato crescido a partir da década de 1990, ainda é escasso quando comparado ao grande potencial destes programas. Verificaram também a variedade e a evolução dos tipos de estudo e métodos empregados nessas investigações.

Esses autores encontraram 28 artigos publicados entre 2004 e 2013, sobre avaliação de projetos e programas sociais esportivos (esporte educacional), no Brasil (18 estudos qualitativos e 9 estudos quali-quantitativos) (KRAVCHYCHYN \& OLIVEIRA, 2015). Para efeitos de comparação, os estudos foram divididos em duas categorias de acordo com seu objetivo principal: avaliação de processo ou avaliação de impacto. Para esta classificação, os autores da revisão se valeram dos conceitos 
expostos por Cohen e Franco (2008) que consideram avaliação de processo como a aferição da implantação e execução do programa, conforme as diretrizes concebidas inicialmente; já a avaliação de impacto diz respeito aos efeitos que tal programa ou projeto apresentariam sobre a população sujeito da ação.

Do total de artigos selecionados, os autores constataram predomínio de avaliações de processo sobre as de impacto. Ou seja, 23 deles tinham como objetivo principal a avaliação da implantação e da execução, e visavam, portanto, sugerir melhorias na eficiência operacional do projeto avaliado. Dentre as variáveis analisadas por estes estudos de avaliação de processos, estavam: formação e capacitação pedagógica dos profissionais de educação física, rotatividade dos recursos humanos, parcerias com instituições públicas e privadas na execução dos projetos, relação professor/aluno, participação da comunidade nos processos decisórios, frequência e evasão dos alunos, conteúdos e métodos de ensino (KRAVCHYCHYN \& OLIVEIRA, 2015).

Dos cinco estudos apontados pelos autores como sendo avaliação de impacto, três deles não apresentaram resultados significativos. Esses estudos tinham como objetivo compreender a contribuição das práticas esportivas nas representações dos alunos sobre o esporte (MOLINA, SILVA \& SILVEIRA, 2004); refletir sobre o papel do esporte no desenvolvimento da região (MATTOS et al., 2010); e, investigar a percepção de professores sobre o desenvolvimento de seus alunos e sobre a intervenção institucional (AZEVEDO \& VIANA, 2016). Estes três estudos valeram-se de análises descritivas, quali-quantitativas e usaram amostras inferiores a 25 sujeitos (KRAVCHYCHYN \& OLIVEIRA, 2015).

Já os outros dois estudos de avaliação de impacto, obtiveram alguns resultados. Um deles verificou a interferência das atividades no desempenho escolar, níveis de estresse infantil e qualidade de vida dos alunos (MACHADO et al., 2007) e o outro, apontou resultados de crescimento físico e melhora do comportamento de alunos com déficit intelectual (FERREIRA, 2014).

Machado et al. (2007) realizaram um estudo experimental (antes e depois) com o objetivo de verificar o impacto de um programa esportivo. O estudo envolveu 39 alunos, que responderam três instrumentos psicométricos: Teste de Desempenho Escolar (TDE), Escala de Stress Infantil (ESI) e Escala de Avaliação de Qualidade de 
Vida (AUQEI - Autoquestionnaire Qualité de Vie Enfant Imagé). Na avaliação do desempenho escolar, os resultados deste estudo mostraram que as crianças que participaram do projeto alcançaram escores mais altos no seu desempenho escolar, todavia essas diferenças não foram significativas. Na mesma direção, a avaliação do estresse infantil mostrou resultados que sugerem que o projeto tem efeito positivo nas crianças participantes, entretanto não apresentou resultados significativos sob o ponto de vista estatístico (MACHADO et al., 2007).

O outro estudo, conduzido por Kalinoski et al. (2013) não especifica o tamanho da amostra e declara ter avaliado o impacto do Programa Segundo Tempo a partir de conversas (entrevistas semidirigidas) com os pais, nas quais foi declarada a percepção de melhora: na aptidão física, desempenho motor, controle de estresse, ansiedades/frustrações, autoestima, autoimagem, autonomia, socialização, motivação e diminuição do preconceito, em seus filhos participantes do projeto. No entanto, embora o estudo fosse de avaliação de impacto, seus resultados precisam ser vistos com cautela, uma vez que foram baseados apenas na percepção dos pais, excluindo-se medições diretas e objetivas com os participantes do programa.

Um estudo relativamente recente desenvolvido em relação ao programa anterior ao Projeto Esporte Cidadão, realizou uma análise custo-efetividade do Programa de Iniciação, Recreação e Aperfeiçoamento/PRIA, na cidade de Indaiatuba/SP (ARANHA, 2014). No que tange ao impacto do PRIA, os resultados apontaram para a existência de melhora do estado nutricional, da qualidade de vida sob a ótica do bem-estar (AUQEI - ASSUMPÇÃO et al., 2000) das crianças e do desempenho escolar, sendo a melhora desta última, a única estatisticamente significante. Uma possível razão para o impacto não estatisticamente significativo em relação ao estado nutricional e à qualidade de vida, apontada neste estudo, foi o período relativamente curto da avaliação, apenas três meses entre a coleta 1 e coleta 2 , tempo relativamente insuficiente para que fosse possível verificar o impacto sobre perfil corporal e alterações na qualidade de vida, associado a atividade física.

Essa breve revisão reitera a escassez de pesquisas de avaliação de impacto de políticas públicas voltadas para o esporte educacional/atividade física de lazer, evidenciando a relevância do presente estudo. 


\section{METODOLOGIA}

O presente estudo foi desenvolvido em parceria com a Secretaria de Esportes de Indaiatuba, por meio do Termo de Cooperação Técnica entre a Prefeitura de Indaiatuba e a Fundação Instituto de Pesquisas Econômicas (FIPE), desde o ano de 2011 e renovado em 2016.

A pesquisa foi de caráter longitudinal quantitativo, não-experimental, prospectivo e procurou observar os fenômenos, tais como se apresentam em seu contexto natural. O estudo longitudinal e prospectivo se mostrou adequado à proposta deste trabalho, pois é este um método destinado à realização de avaliações de impacto que visam a coleta de dados ao longo do tempo, em períodos determinados. Desta forma, é possível investigar o efeito de mudanças que venham ocorrer derivadas de uma ação planejada (SAMPIERI, COLLADO \& LUCIO, 2006) como o programa voltado à prática de atividade física de lazer, foco do presente estudo.

Dentre os três modelos comumente usados em estudos longitudinais (modelos de tendência, de coorte e do tipo painel), o modelo aqui proposto é do tipo painel, tendo como característica principal realizar o acompanhamento de um mesmo grupo de pessoas, prospectivamente a partir de um determinado momento (GRIMES \& SCHULZ, 2002). Em síntese, o princípio fundamental deste tipo de estudo prevê a comparação de grupos exposto e não exposto a uma determinada ação, ou seja, o Grupo Caso (exposto ao programa) e Grupo Controle (não exposto ao programa), sendo sua característica principal o seguimento dos sujeitos de pesquisa no decorrer do tempo para avaliar a ocorrência de determinado desfecho, ante a exposição ou não a determinada ação (HADDAD, 2004).

Os estudos longitudinais podem ser conduzidos com diversas finalidades, incluindo a avaliação de fatores de risco para doenças ou desfechos, estudo do impacto de fatores prognósticos, ou seja, que traça o provável desenvolvimento futuro ou o resultado de um processo, além do estudo de intervenções diagnósticas e terapêuticas (SAMPIERI, COLLADO \& LUCIO, 2006). 
O presente estudo utilizou ferramentas econométricas para conduzir uma avaliação de impacto de uma política pública voltada à prática de atividade física, sobre o estado nutricional e o bem-estar subjetivo de seus participantes.

\subsection{Objeto de estudo: o Projeto Esporte Cidadão/PEC}

Em decorrência da Lei de Incentivo ao Esporte/LIE (a Lei 11.438 de 2006), em 2014 a Secretaria de Esportes do município de Indaiatuba, no estado de São Paulo, implantou o Projeto Esporte Cidadão ${ }^{3}$. Esse Projeto foi criado pautado na ideia de que a atividade física no contexto do esporte educacional constitui um valioso instrumento de integração e inclusão social, estimulando atitudes de cooperação, participação e ludicidade.

O Projeto Esporte Cidadão visa estimular e democratizar o esporte por meio da atividade física de lazer e a convivência na comunidade, ressaltando a qualidade de vida, o bem-estar físico e social. Conforme informações da prefeitura de Indaiatuba, além da LIE o projeto também, conta com a parceria da Organização Nacional das Entidades do Desporto/ONED 4 fundada em junho de 2001, órgão este que representa a prática esportiva dentro do segmento de atividades físicas, no contexto do esporte educacional. Cabe à ONED promover, colaborar, coordenar, administrar ou executar ações e projetos que visem atividades desportivas e paradesportivas não enquadradas como olímpicas e paraolímpicas, e dentre os projetos apoiados está o Projeto Esporte Cidadão, do município de Indaiatuba ${ }^{5}$.

Assim, juntos, a Prefeitura Municipal de Indaiatuba/SP e a ONED, promovem o Projeto Esporte Cidadão, disponibilizando à população 7 mil vagas anuais, para a prática de atividade física de lazer oferecendo 19 modalidades esportivas, dentro de 19 núcleos esportivos, distribuídos por todas as regiões do município de Indaiatuba. Intensificando as possibilidades da educação para e pelo lazer, bem como indo além da superação do simples divertimento, por meio do qual a prática da atividade física

\footnotetext{
${ }^{3}$ https://www.indaiatuba.sp.gov.br/esportes/projeto-esporte-cidadao/; acesso em 24 de fevereiro de 2018.

${ }^{4}$ http://www.oned.com.br/; acesso em 24 de fevereiro de 2018.

${ }^{5}$ http://www.oned.com.br/livro-ii-das-atribuicoes-e-finalidades/; acesso em 10 de julho de 2020.
} 
torna-se um meio para a busca do desenvolvimento social. Segundo o site oficial da prefeitura ${ }^{6}$, a missão do projeto não é o ensino do esporte para a descoberta de atletas de alto rendimento, mas sim "contribuir para a cidadania, sociabilização, qualidade de vida, ética, moral e o pleno desenvolvimento de cada indivíduo participante", por meio da prática esportiva como uma "ferramenta de apoio educacional". Nesse contexto, poder-se-ia atribuir ao Projeto o oferecimento de atividades físicas de lazer e não exatamente, atividades esportivas.

Portanto, a missão do projeto, conforme exposto pela prefeitura é, por meio da prática da atividade física de lazer, promover o desenvolvimento de outras competências e não apenas àquelas ligadas diretamente aos vieses higienista, militarista e competitivista, atribuídos originalmente ao esporte.

Segundo informações obtidas junto aos professores de educação física e coordenadores do projeto, Sra. Silvia C. Queriquelli de Agostini e Heleno da Silva Luiz Junior, em 2017 estavam matriculados no Programa 6054 crianças e adolescentes, sendo a maioria meninos (62,21\%) e quase a metade de crianças entre 8 e 11 anos $(47,39 \%)$, que podiam participar de mais de uma modalidade, conforme apresentado na Tabela 1.

A matrícula no projeto é feita em dois momentos do ano, em fevereiro e em agosto. O projeto é amplamente divulgado entre todas as escolas do município, tanto públicas quanto particulares, não havendo nenhuma restrição quanto à origem do aluno, nem tão pouco à sua classe social ou participação de qualquer tipo de programa assistencial, sendo a única exigência da Secretaria de Esportes a necessidade de comprovar residência no município.

\footnotetext{
${ }^{6}$ É importante mencionar que a documentação do programa é exígua ou inacessível, de modo que muitas das informações aqui apresentadas foram obtidas a partir de entrevistas junto aos coordenadores e professores, bem como derivadas da observação in loco, pela pesquisadora.
} 
Tabela 1 - Distribuição dos alunos matriculados no Projeto Esporte Cidadão, segundo sexo e faixas etárias - Indaiatuba/SP - 2017.

\begin{tabular}{lrrrrrr} 
& \multicolumn{2}{c}{ Feminino } & \multicolumn{2}{c}{ Masculino } & \multicolumn{2}{c}{ Total Geral } \\
\cline { 2 - 8 } & \multicolumn{1}{c}{$\mathbf{n}$} & \multicolumn{1}{c}{$\%$} & $\mathbf{N}$ & \multicolumn{1}{c}{$\%$} & $\mathbf{n}$ & \multicolumn{1}{c}{$\%$} \\
\hline \hline $\mathbf{5}$ anos & 82 & 3,58 & 168 & 4,46 & 250 & 4,13 \\
$\mathbf{6}$ anos & 276 & 12,06 & 397 & 10,54 & 673 & 11,12 \\
$\mathbf{7}$ anos & 328 & 14,34 & 432 & 11,47 & 760 & 12,55 \\
$\mathbf{8}$ anos & 315 & 13,77 & 449 & 11,92 & 764 & 12,62 \\
$\mathbf{9}$ anos & 301 & 13,16 & 468 & 12,43 & 769 & 12,70 \\
$\mathbf{1 0}$ anos & 263 & 11,49 & 426 & 11,31 & 689 & 11,38 \\
$\mathbf{1 1}$ anos & 237 & 10,36 & 410 & 10,89 & 647 & 10,69 \\
$\mathbf{1 2}$ anos & 183 & 8,00 & 372 & 9,88 & 555 & 9,17 \\
$\mathbf{1 3}$ anos & 170 & 7,43 & 345 & 9,16 & 515 & 8,51 \\
$\mathbf{1 4}$ anos & 104 & 4,55 & 204 & 5,42 & 308 & 5,09 \\
$\mathbf{1 5}$ anos & 28 & 1,22 & 88 & 2,34 & 116 & 1,92 \\
$\mathbf{1 6}$ anos & 1 & 0,04 & 7 & 0,19 & 8 & 0,13 \\
\hline Total Geral & 2288 & 100,00 & 3766 & 100,00 & 6054 & 100,00
\end{tabular}

Fonte: Dados primários fornecidos pela prefeitura de Indaiatuba/SP.

A Tabela 2 apresenta a distribuição dos alunos matriculados em 2017, segundo os 18 polos (núcleos) e as 19 modalidades oferecidas no projeto. Como é possível perceber, o maior polo, em número de matriculados, é o Centro Esportivo do Trabalhador, com 1174 alunos representando $19,38 \%$ do total. Neste polo são oferecidas 9 das 19 modalidades. Do ponto de vista da estrutura física dos polos, há uma grande variedade entre eles, sendo o polo do SESI o que apresenta maior e melhor estrutura física, no entanto ele não é inteiramente destinado ao Projeto esporte Cidadão, sendo também utilizado pela comunidade de seu entorno. 


\section{Tabela 2 - Distribuição dos alunos matriculados no Projeto Esporte Cidadão em 2017, divididos por Polo e Modalidade.}

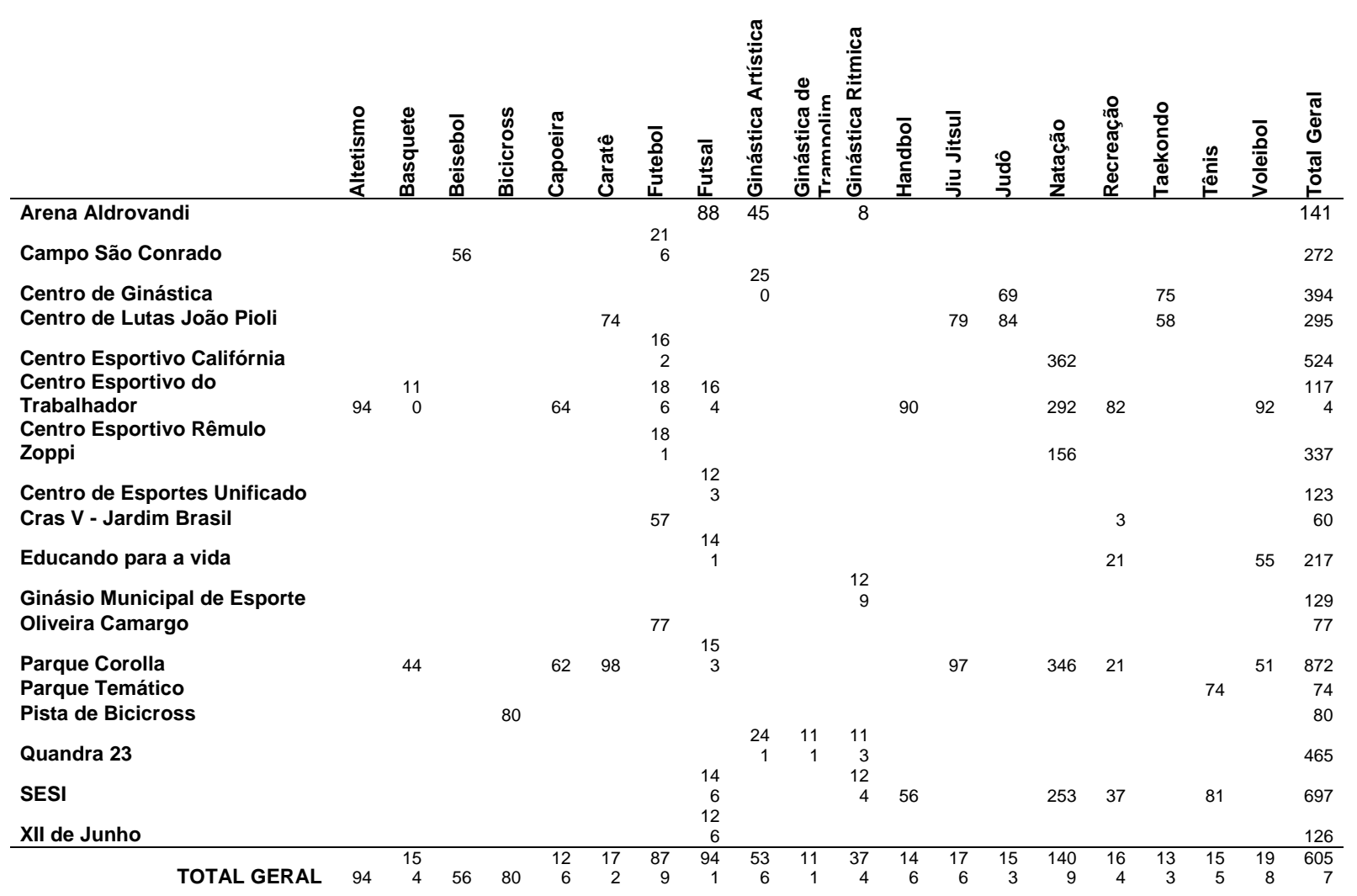

Fonte: Dados primários fornecidos pela prefeitura de Indaiatuba/SP.

No que se refere às modalidades, o projeto é bastante eclético e oferece aulas em modalidades bastantes populares como natação, futebol e vôlei, mas também oferece aulas pouco convencionais como por exemplo, Beisebol e Bicicross. Como mostra a Tabela 2, a modalidade com maior número de alunos é a Natação, com 1409 alunos representando $23,26 \%$, dos matriculados.

Como visto no embasamento teórico, apesar da palavra esporte estar no nome do projeto, o melhor conceito que se aplica ao que de fato é oferecido é prática de atividade física de lazer. Em 2018, segundo os coordenadores do projeto, vários temas transversais foram tratados, entre eles destacam-se: meio ambiente, alimentação saudável, higiene, civismo (a lista completa consta do Anexo 1). Para embasar essa prática e promover discussões sobre os temas escolhidos, acontecem reuniões pedagógicas periódicas com os professores, conforme se pode constatar 
durante as visitas ao projeto. Essas reuniões aconteciam todas às segundas-feiras das $14 \mathrm{~h}$ às 18h, na sede da Secretaria de Esportes da Prefeitura de Indaiatuba.

Nessas reuniões os professores, além de receberem informações de cunho administrativo, eles também trabalhavam de forma colaborativa em formato de brainstorm reunidos por área de interesse - em geral ficam no mesmo grupo professores, aqueles que ministram as mesmas modalidades - para que possam decidir juntos que atividades devem ser feitas e assim, cumprir com o objetivo proposto pelos temas transversais. Durante uma dessas dinâmicas, foi possível observar que os professores sugeriram gincanas infantis que tinham fundo moral, uso de cantigas infantis comuns em nossa cultura, adaptação de jogos e brincadeiras comumente usadas em nosso folclore como Cabra Cega e o Rei Manda, sempre com o objetivo de encaixar o trabalho proposto pelo tema transversal.

Algumas dessas propostas foram observadas durante as visitas aos polos e a sua execução constatada conforme o planejamento, na maioria das vezes. Em certas ocasiões os professores realizaram adaptações em função de suas habilidades e preferências.

Além das aulas semanais, que acontecem duas vezes por semana, com duração de 50 minutos cada, os alunos participantes do projeto têm eventos de confraternização, em julho e dezembro. Segundo os coordenadores, um destes eventos tem como objetivo a integração e confraternização entre os alunos e o outro, fazer pequenas competições internas, sendo os times divididos por modalidade e idade. No entanto, como ressaltaram os coordenadores, não é incentivado durante esses eventos a rivalidade entre os times, uma vez que todos os alunos recebem prêmios, medalhas e troféus, pela participação independente do resultado de cada jogo.

No ano de 2019, havia a ideia de visitar um desses eventos, no entanto a secretaria de esportes passou por grandes transformações. Cerca de $70 \%$ dos professores contratados foram trocados, por profissionais concursados, nomeados em 2019, após concurso público realizado pela prefeitura. Estas mudanças ocorreram no ano de conclusão da pesquisa, de modo que não foi possível verificar na prática, se houve alguma alteração na postura dos professores durante as aulas. Segundo informações colhidas, via e-mail com os coordenadores, os novos professores 
estavam recebendo treinamentos e sendo acompanhados de perto pela equipe da prefeitura, visando observar o mesmo protocolo, até então seguido pelos professores contratados para o Projeto.

\subsection{Coleta de dados}

A coleta dos dados foi realizada em dois tempos: Tempo 0 - março de 2018, com as crianças que estavam se matriculando naquele ano (antes da participação) e Tempo 1 - novembro de 2019 (após dois anos de participação no Projeto) (Figura 1), tanto com o Grupo Caso, quanto com o Grupo Controle, como será descrito no tópico 5.3 Seleção da Amostra.

Em cada uma das coletas (em cada Tempo), primeiramente foram entregues aos pais/responsáveis, via participante, o Termo de Consentimento Livre e Esclarecido/TCLE (descrito no tópico 5.5), juntamente com o Questionário Socioeconômico e Demográfico (descrito no tópico 5.4.3).

Após a anuência e assinatura do TCLE, a coleta dos demais dados foi feita de forma presencial pelo pesquisador. O Termo de Assentimento Livre e EsclarecidofTALE (descrito no tópico 5.5) e a Escala Multidimensional de Satisfação com a Vida para Crianças (descrita no tópico 5.4.2) foram preenchidos em folha de papel A4, utilizando lápis e prancheta pela própria criança, já os dados antropométricos (descritos no tópico 5.4.1) foram aferidos e registrados pelo próprio pesquisador, também em uma folha de papel A4, com os dados de identificação de cada participante. Ao final, todos os questionários e folhas preenchidas, tanto pelos pais/responsáveis, quanto pela criança, quanto pelo pesquisador, foram grampeadas formando blocos; cada bloco individual recebeu um código para identificação e foram arquivados.

A fim de que os resultados pudessem ser melhor manuseados, todas as informações em papel foram transferidas para plataforma eletrônica REDCap® (Research Electronic Data Capture) que é uma plataforma online utilizada em diversas universidades ao redor do mundo para coletar, armazenar e tratar dados oriundos de 
pesquisas de campo. No Brasil a plataforma REDCap® está sob concessão da Universidade de São Paulo, mas pode ser usada por qualquer equipe de pesquisa no território nacional, desde que obtenham devido treinamento e autorização para tal.

A coleta dos dados junto ao Grupo Participante (grupo caso) foi realizada durante as aulas das diversas modalidades do Projeto, nos respectivos polos; e a coleta referente ao Grupo Não Participante (grupo controle) foi realizada durante o período de aulas, dentro das escolas participantes. Para preservar a intimidade de cada criança durante a aferição dos dados antropométricos, em todos os locais foram montados espaços reservados com dias e horários diferentes para meninos e meninas, onde o pesquisador realizou a pesagem e mensuração da altura das crianças. Todas as coletas foram acompanhadas tanto pelos respectivos professores de cada modalidade, quanto por funcionários das escolas participantes.

\section{Figura 1- Representação do procedimento de Coleta de Dados.}

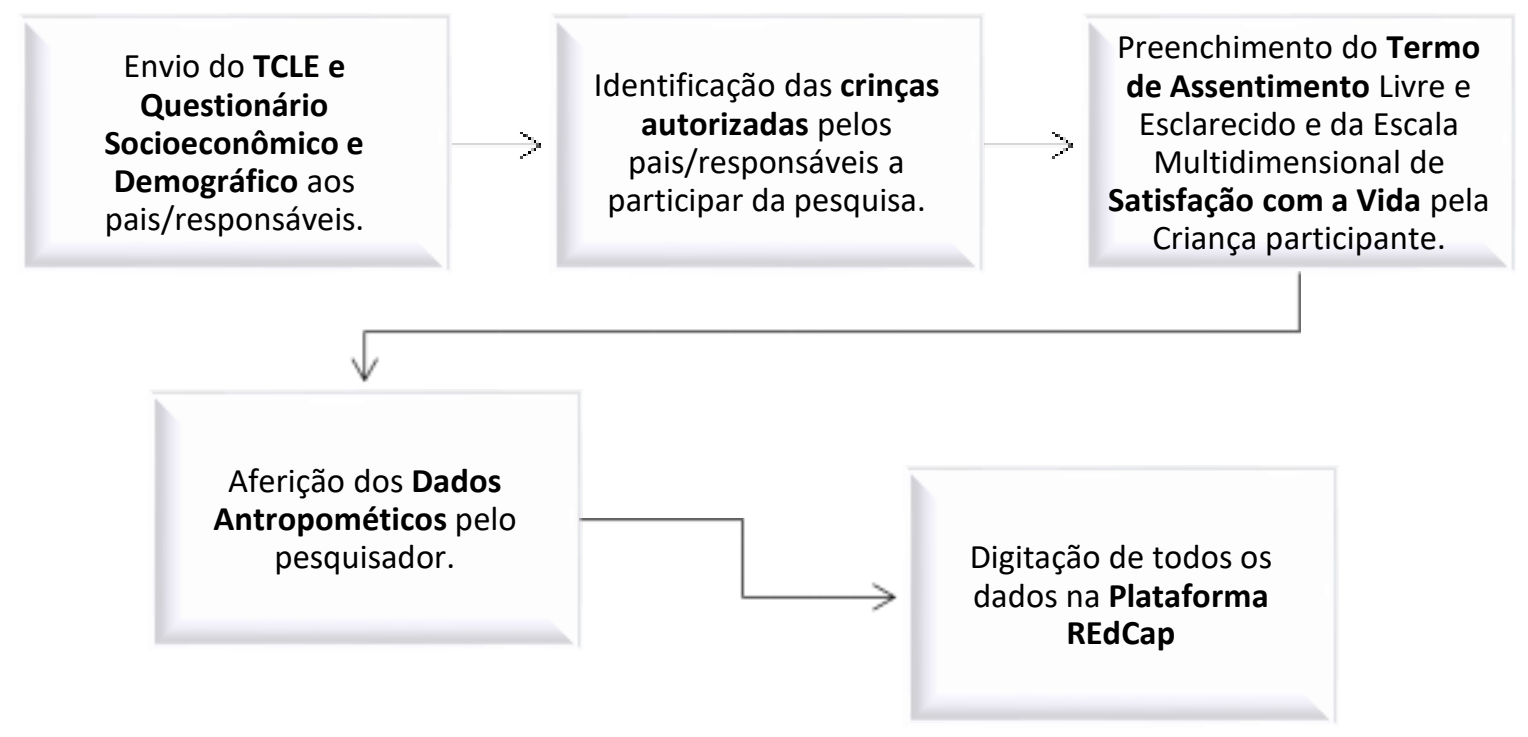

Para melhor visualização do processo, a Figura 2 abaixo representa, de forma gráfica, o procedimento realizado para a coleta de dados. Este procedimento aconteceu da mesma forma em ambos os Tempos da pesquisa (Tempo 0 e Tempo 1) e para ambos os Grupos (Caso e Controle). 
Figura 2 - Diagrama da execução da pesquisa.
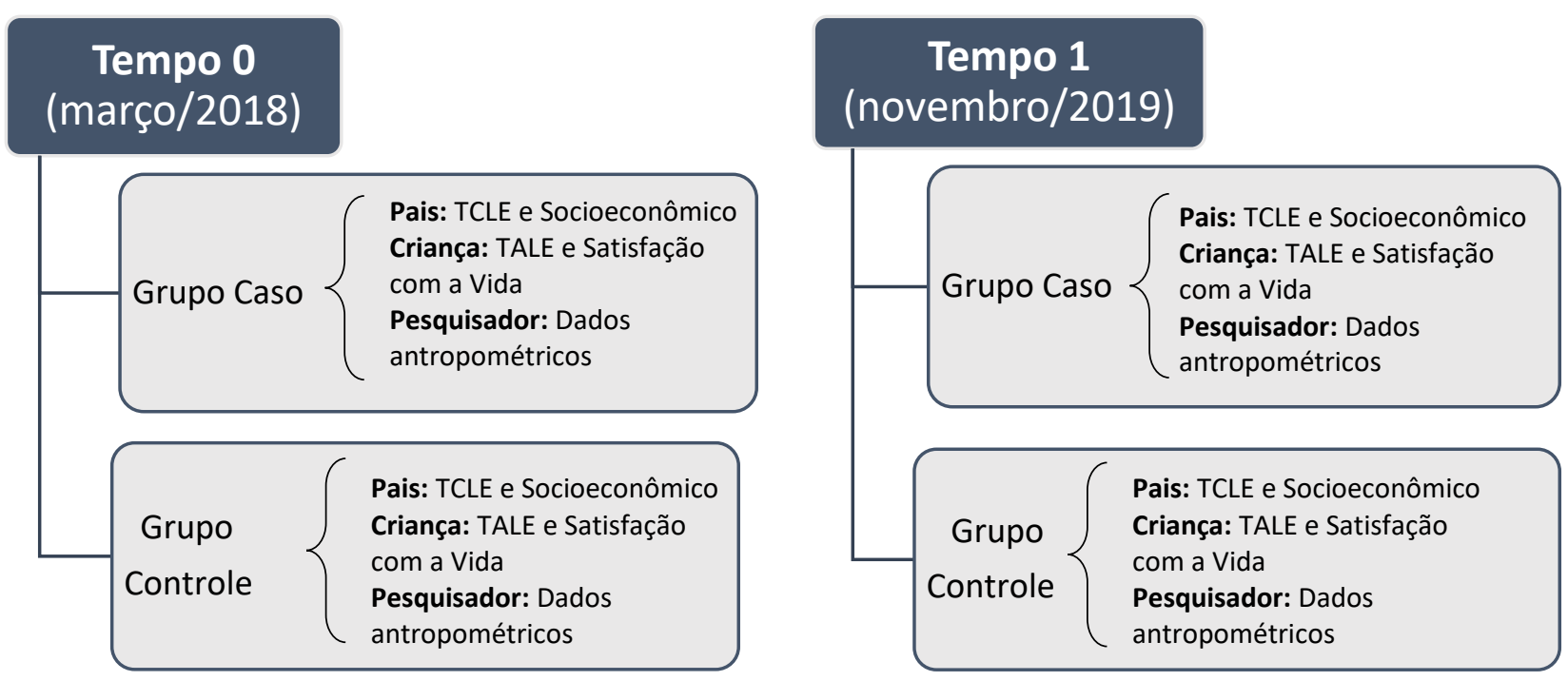

\subsection{Seleção da Amostra}

Para a concretização dos objetivos aqui propostos, a população do estudo foi composta por dois conjuntos de crianças: Grupo Participante (Grupo Caso) e Grupo Não Participante (Grupo Controle), compondo duas amostras de conveniência.

\subsubsection{Grupo Caso}

Para compor a amostra do Grupo Participante foram adotados os seguintes critérios de exclusão: ter participado em anos anteriores do Programa Esporte Cidadão; e ter qualquer patologia, deficiência física e/ou cognitiva declarada pelo responsável. Os alunos excluídos do estudo passaram pelos mesmos procedimentos que os demais colegas, para não sofrerem qualquer constrangimento.

O Grupo Participante deste estudo foi composto por uma amostra de crianças de 08 até 11 anos completos, que estiveram devidamente matriculados no Projeto Esporte Cidadão do município de Indaiatuba/SP, durante os anos de 2018 a 2019. Em 2018, primeiro ano do estudo (Tempo 0), os alunos cujos pais assinaram o TCLE, foram incorporados ao estudo, exceto aqueles que já haviam participado do projeto em anos anteriores. No tempo 1 (2019) foram coletados os dados dos mesmos alunos que se mantiveram matriculados e participantes do Projeto. 
Estima-se $^{7}$ que cerca de 300 crianças entre 8 e 11 anos de idade tenham se inscrito pela primeira vez no Projeto Esporte Cidadão, no ano de 2018. Todas essas crianças foram convidadas a participar da pesquisa, este convite foi feito diretamente ao responsável da criança ou adolescente, no ato da matrícula, por meio da entrega da Carta Convite e do Termo de Consentimento Livre e Esclarecido com todas as informações referentes à pesquisa.

Ao longo das primeiras semanas de aula, aqueles alunos que trouxeram o Termo de Consentimento Livre e Esclarecido, preenchido e assinado pelos pais, foram incluídos na amostra do Grupo Caso (Grupo Participante), sendo inicialmente composta por 126 crianças de 8 a 11 anos.

Devido a diversos fatores, o número de crianças pesquisados no Tempo 1 diminuiu em relação à amostra inicial da pesquisa; das 126 crianças que fizeram parte da amostra do Grupo Caso no início de 2018, 52 delas não renovaram sua matrícula no Projeto Esporte Cidadão no ano de 2019 e, portanto, deixaram de fazer parte da amostra da coleta Tempo 1. Das 74 crianças que permaneceram no Projeto Esporte Cidadão em 2019 e fizeram parte da nossa amostra no Tempo 0, 34 delas não foram incluídas na amostra do Tempo 1 (2019) por motivos como: pais e/ou responsáveis não concordaram com sua participação na segunda etapa da pesquisa ou ainda, e maior parte, os participantes faltaram à aula nos dias destinados às coletas, mesmo depois dos pesquisadores terem entrado em contato com a família, via telefone cerca de 2 a 3 vezes, solicitando a presença da criança na aula. Alguns pais alegaram que o filho (a) estava doente ou havia compromissos na escola regular que o impediam de frequentar as aulas do Projeto na época da coleta, ou ainda que devido à proximidade do final do ano já não estavam mais frequentando as aulas.

Sendo assim, a amostra do Grupo Caso ficou reduzida a 30 crianças, cujos dados foram considerados para os dois tempos.

\footnotetext{
${ }^{7}$ Esta estimativa foi obtida com a equipe administrativa da Secretaria de Esportes do município, no entanto não é possível ter o número exato de novos ingressantes, pois os dados de matrículas são feitos em papel por cada professor sem o auxílio, até este ano de aparato eletrônico/digital, e podendo, portanto, ocorrer erros na estimativa de alunos novos.
} 


\subsubsection{Grupo Controle}

Para conduzir um estudo de avaliação de impacto, é necessário definir uma forma de avaliar como o grupo de pessoas que recebeu determinada intervenção ou tratamento teria evoluído caso não tivesse participado da política pública, para isso pesquisadores utilizam um grupo controle. No entanto, uma série de aspectos precisam ser levados em consideração para se encontrar um bom grupo de controle.

O desafio do pesquisador em um estudo de impacto, é encontrar um grupo de indivíduos que represente adequadamente a situação de não tratamento, um grupo que funcione como um bom contra factual do grupo tratado, ou seja, um grupo semelhante ao grupo caso, diferenciando-se apenas por não participar da intervenção. Um cuidado importante na escolha do grupo controle é escolher indivíduos que não tenham uma característica específica que justifique a não participação no Projeto. Por exemplo, no presente estudo, um grupo de crianças que não goste de esporte, ou seja, pessoas que deliberadamente não optariam em participar do projeto, não se constituiriam um bom grupo controle, pois com esse viés não seriam uma base adequada de comparação para os efeitos do programa. $O$ ideal é que os dois grupos (caso e controle) tenham, no Tempo 0 , características socioeconômicas, demográficas físicas e emocionais semelhantes, prevenindo o que é chamado viés de auto seleção ${ }^{8}$ (MENEZES FILHO, 2015).

Para controlar o viés de auto seleção, o grupo controle foi composto por indivíduos de 8 a 11 anos do município de Americana, que não oferece um programa público de esportes. O município de Americana pode ser considerado equivalente à cidade de Indaiatuba em termos regionais e demográficos. Ambas as cidades estão situadas na região metropolitana da cidade de Campinas, distantes de São Paulo capital pouco mais de $100 \mathrm{~km}$ (Americana $126 \mathrm{~km}$, Indaiatuba $106 \mathrm{~km}$ ); com população estimada de 234 mil e 241 mil habitantes, ${ }^{9}$ respectivamente; Produto Interno Bruto per capta de $\mathrm{R} \$ 44.050,42$ mil (Americana) e $\mathrm{R} \$ 52.628,52 \mathrm{mil}^{10}$ (Indaiatuba); bem como,

\footnotetext{
8 Viés de auto seleção ocorre quando a participação no programa depende da decisão do indivíduo, e esta por sua vez está relacionada a outras características individuais que afetarão os resultados do programa, mas que não podem ser observadas, como por exemplo a motivação à prática de esportes, no presente estudo. Em resumo, características individuais que podem estar relacionadas com o impacto do programa (MENEZES FILHO, 2015).

${ }^{9}$ Ano referência 2017, Disponível em: https://cidades.ibge.gov.br/brasil/sp, acesso em 02.03.2018.

${ }^{10}$ Ano referência 2015, Disponível em: https://cidades.ibge.gov.br/brasil/sp, acesso em 02.03.2018.
} 
Índices de Desenvolvimento Humano-IDH próximos (0,811 - Americana e 0,788 ${ }^{11}$ Indaiatuba).

As crianças de Americana que compuseram o grupo controle foram selecionadas por conveniência de forma a abranger, em termos geográficos, toda a cidade, incorporando assim, na amostra crianças, diferentes condições socioeconômicas. A partir do contato direto com a Secretaria Municipal de Educação, três escolas, em três bairros diferentes da cidade, foram escolhidas pela Secretaria para fazerem parte da amostra. Ao entrar em contato com estas escolas, foi feito o convite a todos os alunos que estavam dentro da faixa etária escolhida para pesquisa (8 a 11 anos) e foram avaliados aqueles cujos pais concordaram com sua participação. Portanto, o Grupo Controle foi composto de crianças matriculadas em escolas do município de Americana/SP, pareadas às participantes do Projeto Esporte Cidadão de Indaiatuba em termos de: idade e sexo. No Tempo 0 foi possível coletar os dados de 170 crianças, mas no Tempo 1, a quantidade de crianças cujos pais autorizaram a segunda etapa e a presença no dia da coleta, resultou em uma amostra de apenas 41 alunos, cujos dados foram considerados nos dois Tempos.

As escolas do município de Americana, de onde foram coletados os dados do grupo controle, foram escolhidas, portanto por conveniência. Após a assinatura do Termo de Anuência, consentindo para realização da pesquisa, a Secretaria Municipal de Educação de Americana apresentou o presente projeto aos diretores e coordenadores de todas as escolas do município e deu a oportunidade dos gestores se candidatarem voluntariamente a cederem seu espaço para as coletas, a única solicitação feita pelos pesquisadores foi a candidatura de escolas situadas geograficamente distantes umas das outras e que o perfil socioeconômico da população atendida por cada escola fosse variado, para que assim a amostra pudesse ser pareada com a do Grupo Caso.

Os critérios de exclusão adotados na seleção do grupo controle foram os mesmos aplicados na seleção dos participantes do grupo caso, a saber: ter qualquer patologia, deficiência física e/ou cognitiva, declarada pelo responsável. Adicionalmente, também não foram selecionados aqueles alunos que declararam participar de atividade física fora da escola, por no mínimo duas vezes por semana.

${ }^{11}$ Ano referência 2010, Disponível em: https://cidades.ibge.gov.br/brasil/sp, acesso em 02.03.2018. 
E a semelhança do procedimento aplicado ao grupo caso, os alunos excluídos do estudo foram avaliados como os selecionados para não sofrerem qualquer constrangimento.

\subsection{Mensuração das Variáveis e instrumentos utilizados}

Como descrito anteriormente, entre os objetivos do PEC destacaram-se a melhoria do estado de saúde, o qual foi obtido pelo indicador estado nutricional e a qualidade de vida estudada, sob a sob a ótica do bem-estar subjetivo. Estas são as variáveis dependentes dos modelos estimados. As variáveis explicativas envolveram dados Socioeconômicos, Demográficos e a participação ou não do PEC. A coleta dos dados relativos a essas variáveis foi realizada por meio dos instrumentos descritos a seguir:

\subsubsection{Avaliação do Estado Nutricional}

A avaliação do Estado Nutricional foi realizada por meio dos parâmetros antropométricos de peso e altura, permitindo o cálculo do Índice de Massa Corpórea $\left(\mathrm{IMC}=\right.$ Peso $(\mathrm{kg}) /$ Altura $\left.(\mathrm{m})^{2}\right)$. As medidas antropométricas foram aferidas com os participantes da pesquisa sem sapatos e com o mínimo de roupa possível (traje de Educação Física) para a maior fidedignidade dos dados coletados. As medições foram realizadas sempre no período matutino das $7 \mathrm{~h}$ às $12 \mathrm{~h}$ e no período vespertino, das 13 às $18 \mathrm{~h}$, em ginásios poliesportivos dos polos do projeto e das escolas participantes.

Foi utilizada uma balança plataforma, marca FILIZOLA (São Paulo, Brasil), com precisão de $0,1 \mathrm{~kg}$, sendo o dado anotado em quilogramas. $O$ avaliador ficou em pé, de frente para a escala de medida. $O$ avaliado ficou em pé na posição ereta, pés afastados à largura do quadril, com peso dividido em ambos os pés, mantendo a cabeça no plano de Frankfurt, ombros descontraídos e braços soltos lateralmente (posição ortostática), de frente para o avaliador (BRASIL, 2011). 
Para medir a altura foi utilizado um estadiômetro vertical de madeira com 210 $\mathrm{cm}$ de comprimento e escala de $0,1 \mathrm{~cm}$. As crianças permaneceram descalças, com os pés unidos e a planta dos pés totalmente apoiados no chão, os calcanhares, glúteos, ombros e cabeça totalmente encostados na parede. No momento da medida, o participante fez uma inspiração máxima e manteve o olhar direcionado para o horizonte orientado no plano de Frankfurt (BRASIL, 2011).

O valor do IMC, calculado a partir das aferições das medidas antropométricas, foi transformado em percentil, segundo tabelas de IMC para idade e sexo elaboradas pelo Ministério da Saúde para a população Brasileira. Após a obtenção do percentil, cada participante teve seu estado nutricional classificado em: Magreza, Peso Normal, Sobrepeso, Obesidade e Obesidade Grave, conforme classificação Proposta pela Organização Mundial da Saúde (BRASIL, 2011).

\subsubsection{Bem-Estar Subjetivo}

Para avaliar o bem-estar subjetivo das crianças, foi utilizada a Escala Multidimensional de Satisfação de Vida para Crianças/EMSVC, por sua ampla utilização em estudos recentes sobre bem-estar subjetivo de crianças brasileiras em diversos contextos. Essa escala está embasada no conceito de satisfação com a vida como componente cognitivo do bem-estar subjetivo, que avalia o nível de contentamento que alguém sente a respeito de sua vida, de um modo geral (HUTZ, 2014; POLETTO, 2011).

A EMSVC é composta com 50 afirmativas que avaliam as percepções subjetivas de satisfação com a vida/bem-estar de crianças, por meio dos seis fatores conforme determinado pelos estudos de validade e fidedignidade de Giacomoni e Hutz (2008), sendo:

- Self: este fator é composto por itens que descrevem o self (eu) com características positivas, como: autoestima, bom-humor, capacidade de relacionar-se, capacidade de demonstrar afeto, etc. 
- Self Comparado: itens que compararam seu eu com seus pares, ou seja, com outras crianças. Os itens possuem conteúdos relacionados ao lazer, à amizade e à satisfação de desejos e afetos.

- Não-violência: itens com conteúdo associados a comportamentos agressivos, sendo esperado que a criança identifique estes comportamentos como não presentes em sua vida.

- Família: envolve itens descritores de um ambiente familiar saudável, harmônico, afetivo, de relacionamentos satisfatórios, além de indicações de satisfação quanto à diversão;

- Amizade: fator que se caracteriza pelos relacionamentos com pares (seus colegas, outras crianças, nível de satisfação desses relacionamentos e algumas indicações ao lazer, situações de diversão e apoio;

- Escola: os itens descrevem a importância da escola, do ambiente escolar, dos relacionamentos interpessoais nesse espaço e o nível de satisfação em relação a esse ambiente.

Para melhor visualização dos itens que compõe 0 instrumento, no quadro abaixo estão os seis fatores e as afirmativas referentes a cada fator. A ordem correta das perguntas como proposto pelo estudo de validade e o modo exato de como o instrumento foi apresentado para as crianças na pesquisa, consta no Anexo 2.

\section{Quadro 1 - Fatores e Afirmativas da Escala Multidimensional de Satisfação de Vida para Crianças/EMSVC.}

\begin{tabular}{|l|l|}
\hline FATOR & \multicolumn{1}{|c|}{ ITENS QUE COMPÓE O FATOR } \\
\hline & Eu sou uma pessoa bem-humorada. \\
& Eu sorrio bastante. \\
& Eu sou divertido. \\
Eu sou alegre. & \\
Self & Mantenho a calma. \\
& Eu me sinto calmo, tranquilo. \\
& Eu sou uma pessoa carinhosa. \\
& Tenho facilidade para fazer amigos. \\
& Eu sou esperto. \\
\hline
\end{tabular}




\begin{tabular}{|c|c|}
\hline & Eu me divirto com muitas coisas. \\
\hline Self-Comparado & $\begin{array}{l}\text { Meus amigos podem fazer mais coisas do que eu. } \\
\text { Meus amigos se divertem mais do que eu. } \\
\text { Meus amigos são mais alegres do que eu. } \\
\text { Meus amigos brincam mais do que eu. } \\
\text { Meus amigos ganham mais presentes do que eu. } \\
\text { As outras crianças são mais alegres do que eu. } \\
\text { As outras crianças têm mais amigos do que eu. } \\
\text { Preciso receber mais atenção. }\end{array}$ \\
\hline Não violência & $\begin{array}{l}\text { Gosto de brigas. } \\
\text { Brigo muito com meus amigos. } \\
\text { Sou irritado. } \\
\text { Brigar resolve os problemas. }\end{array}$ \\
\hline Família & $\begin{array}{l}\text { Meus pais são carinhosos comigo. } \\
\text { Minha família gosta de mim. } \\
\text { Eu me divirto com a minha família. } \\
\text { Minha família me faz feliz. } \\
\text { Gostaria que minha família fosse diferente. } \\
\text { Os membros da minha família se dão bem. } \\
\text { Minha família me ajuda quando preciso. } \\
\text { Eu fico feliz quando a minha família se reúne. } \\
\text { Eu me divirto com as coisas que eu tenho. } \\
\text { Tenho pessoas que me ajudam. } \\
\text { Procuro fazer coisas que me deixam feliz. }\end{array}$ \\
\hline Amizade & $\begin{array}{l}\text { Estou satisfeito com os amigos que tenho. } \\
\text { Meus amigos me ajudam quando eu preciso. } \\
\text { Meus amigos gostam de mim. } \\
\text { Eu gostaria que meus amigos fossem diferentes. } \\
\text { Eu me divirto com meus amigos. } \\
\text { Gosto de conversar com meus amigos. } \\
\text { Meus amigos brigam muito comigo. } \\
\text { Eu me relaciono bem com meus colegas. } \\
\text { É bom brincar com meus amigos. } \\
\text { Sempre encontro ajuda quando preciso. }\end{array}$ \\
\hline Escola & $\begin{array}{l}\text { Eu gosto de ir à escola. } \\
\text { Eu gosto das atividades da escola. }\end{array}$ \\
\hline
\end{tabular}




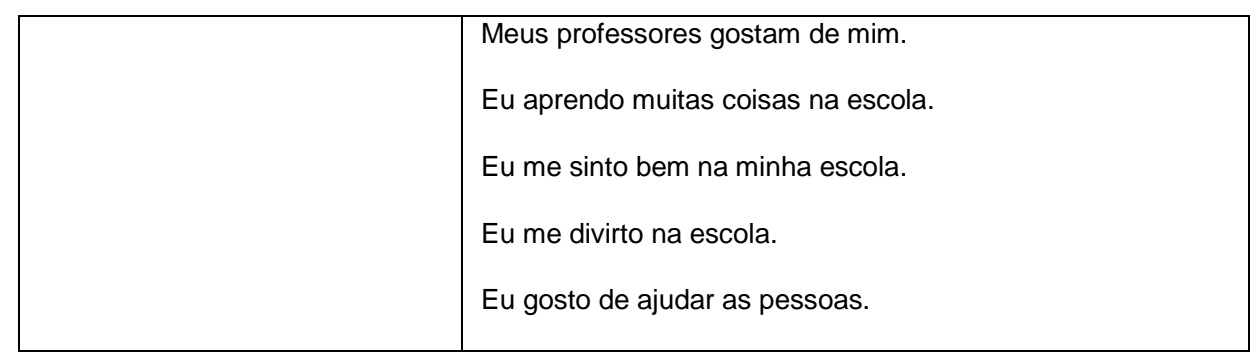

Fonte: GIACOMONI e HUTZ, 2008.

Durante a pesquisa, cada participante teve em mãos o questionário impresso apoiado em uma prancheta e deveria assinalar à lápis qual o nível de concordância que apresentava com cada uma das afirmativas expostas. Conforme é possível visualizar no Anexo 2, para cada item (afirmativa) a criança, baseada na sua opinião sobre sua própria vida, assinalava em uma escala do tipo likert de cinco pontos, dizendo quanto aquela frase era verdadeira ou não para sua vida no momento atual, respondendo entre: Nem um pouco, Um pouco, Mais ou menos, Bastante, Muitíssimo. Cada resposta representava uma pontuação, dependendo da direção da afirmativa.

Se a afirmativa tem direção positiva, o esperado é que a criança diga concordar muito com a afirmativa, neste caso a pontuação é de 1 a 5 sendo: Nem um Pouco 1 ponto até Muitíssimo 5 pontos. Um exemplo de afirmativas com direção positiva é o item 1 - Eu sou uma pessoa bem humorada (Fator Self), ou seja, uma criança com uma sensação subjetiva de bem-estar adequada irá responder positivamente à esta afirmativa, assinalando a opção Bastante (4 pontos) ou Muitíssimo (5 pontos).

Por outro lado, algumas afirmativas têm direção negativa, é esperado que a criança responda que este comportamento não faz parte da sua vida. Um exemplo de item com direção negativa é o item 33 - Gosto de brigas (Fator Não-Violência), ou seja, é esperado que uma criança com uma sensação subjetiva de bem-estar adequada responda Nem um Pouco (5 pontos) ou Um pouco (4 pontos) para esta afirmativa; neste caso a pontuação é invertida, sendo o $\mathrm{Nem}$ um pouco a resposta esperada e portanto, a que vale mais.

Com o intuito de não induzir a criança a nenhum tipo de resposta, a pontuação não é apresentada para a criança, apenas as opções de Nem um Pouco até 
Muitíssimo para que ela assinale sua resposta com um $\mathrm{X}$, sendo a pontuação dada apenas no momento da digitação das respostas no programa RedCap®. Fazem parte deste grupo de questões com direção negativa os itens: $3,5,9,11,15,19,21,25,32$, $34,43,44,47$ e 49.

O somatório final das respostas dadas gerou o Escore Total, indo desde 50 até 250, sendo 50 baixa Sensação subjetiva de bem-estar e 250 máximos de bem-estar; este Escore Total foi o valor utilizado como indicador do bem-estar subjetivo, para os dois Tempos e para ambos os grupos.

\subsubsection{Aspectos Socioeconômicos e Demográficos}

Outro fator que pode interferir nas avaliações de impacto são as mudanças no ambiente socioeconômico, elas podem mascarar os resultados no grupo de pessoas atendidas à medida que, se não controlado, pode parecer que o grupo não participante, por motivos socioeconômicos, também alcançou bons resultados nos itens avaliados pelo estudo (MENEZES FILHO, 2015).

Portanto, as características socioeconômicas podem agir como fatores de confusão, sendo necessário coletar informações para incluir, nos modelos, variáveis para controlar tais fatores. Para tal, foi utilizado um questionário adaptado do questionário do IBGE e da Associação Brasileira de Empresas e Pesquisas/ABEP 12 pelo Grupo de Pesquisa PRINUTHA, ${ }^{13}$ ligado ao PRONUT/USP (Anexo 3).

Esse questionário permitiu traçar o perfil socioeconômico das famílias adotando-se a classificação da ABEP. Esta classificação é usada para estimar o poder aquisitivo dos indivíduos e das famílias, categorizando a população brasileira em cinco níveis socioeconômicos que vão do $A$ ao $E$, sendo $A$ - classe econômica mais alta $e$ $E$ - classe econômica mais baixa. Além da classe social, este questionário também foi capaz de fornecer dados sobre trabalho, moradia e nível de escolaridade do chefe da

\footnotetext{
12 Órgão responsável pela definição do Critério de Classificação Econômica Brasil / CCEB. ${ }^{13}$ PRINUTHA - PROJETO INTEGRADO EM NUTRIÇÃO HUMANA APLICADA - grupo de pesquisa com foco em nutrição e alimentação, sob a abordagem interdisciplinar na Nutrição Humana Aplicada; também envolve a prestação serviço em economia e administração pública.
} 
família, indicadores usados também para avaliar os aspectos socioeconômicos (Anexo 3).

E ainda, foram coletadas ainda informações a respeito da participação da criança no Projeto Esporte Cidadão, por meio de um questionário que foi preenchido pelos pais e /ou responsáveis sobre aspectos como: qual a modalidade a criança participava, qual o Polo e em qual período do dia frequentava as aulas do Programa.

\subsection{Aspectos Éticos}

Foi encaminhado aos pais/responsáveis um Convite para participar da pesquisa e o Termo de Consentimento Livre e Esclarecido/TCLE (Anexo 4), no qual se informava os objetivos do estudo e que a pesquisa apresentava risco mínimo para a população pesquisada. Os pais/responsáveis que concordassem com a participação de seus filhos assinavam o TCLE e apenas após a pesquisa era iniciada.

Após o consentimento dos pais/responsáveis a pesquisa era explicada a cada criança participante, mostrando as etapas as quais passaria, o que seria necessário preencher e as medidas que seriam colhidas (dados antropométricos). A fim de cumprir com o que é proposto pela RESOLUÇÃO № 466 de 2012 do Conselho Nacional de Saúde, que versa sobre pesquisas científicas envolvendo seres humanos, após a explicação da pesquisa as crianças participantes foram convidadas a assentirem com sua participação, por meio de anuência e assinatura do Termo de Assentimento Livre e Esclarecido/TALE (Anexo 5). Mesmo que os pais/responsáveis tenham consentido com a participação da criança, se a própria criança não concordava com sua participação a pesquisa não foi realizada, assim dessa forma todos os requisitos éticos foram rigorosamente cumpridos.

O presente projeto foi submetido ao Comitê de Ética da Faculdade de Ciências Farmacêuticas (FCF), tendo sido autorizado, conforme Parecer Número 2.468.512 de dezembro de 2017 (Anexo 6). Ressalta-se que os pesquisadores responsáveis por este estudo não estão ligados direta ou indiretamente ao programa esportivo em foco, não havendo, portanto, qualquer conflito de interesse nem viés de interpretação da avaliação realizada. 


\subsection{Riscos e Benefícios}

A pesquisa apresentou risco mínimo para os participantes, consistindo de coleta de dados por meio de questionários e mensuração de medidas antropométricas. Os participantes receberam informações, na forma de palestras e encontros de sensibilização, sobre alimentação saudável e sobre a importância de manter a prática regular de atividade física.

\subsection{Método de Análise dos Dados}

O Impacto do Projeto Esporte Cidadão foi estimado por meio do método econométrico de Diferenças em Diferenças, que permite a comparação das variáveis de desfecho dos Grupos Caso e Controle em dois momentos, controlada por variáveis de confusão. No presente estudo, foram estimados dois modelos, o primeiro referente à variável de desfecho estado nutricional, representante do estado de saúde da criança; o segundo para a variável de desfecho sensação subjetiva de bem-estar medido através do escore da Escala Multidimensional de Satisfação com a Vida. Ambas variáveis de desfecho foram computadas em dois momentos a saber: Tempo 0 (antes do tratamento, ou seja, antes da participação nas atividades esportivas); Tempo 1 (dois anos decorridos de tratamento).

O método Diferenças em Diferenças é baseado no cálculo de uma dupla subtração: a primeira se refere a diferença das variáveis de desfecho (Estado Nutricional e Bem-Estar Subjetivo) entre os Tempo 0 e Tempo 1 para o grupo caso e para o grupo controle, sendo possível perceber mudanças dentro do próprio grupo, ou seja, o quanto cada grupo se modificou ao longo do tempo. A segunda subtração refere-se à diferença entre os dois grupos, ou seja, para se conhecer se as diferenças dentro de cada grupo foram decorrentes apenas da passagem do tempo, ou se a diferença apresentada pelo Grupo Caso pode ser explicada pela exposição ao tratamento (WOOLDRIDGE, 2011). 
O Quadro 2 permite visualizar o esquema de comparação dos dois grupos aplicado para cada variável de desfecho.

\section{Quadro 2 - Esquema de representação do Modelo diferenças em Diferenças.}

\begin{tabular}{|l|c|c|c|}
\hline & Tempo 0 & Tempo 1 & Diferenças \\
\hline Diferenças dentro do Grupo Caso & A0 & A1 & A1 - A0 \\
\hline Diferenças dentro do Grupo Controle & B0 & B1 & B1 - B0 \\
\hline Diferenças em Diferenças & & & (A1 - A0) - (B1 - B0) \\
\hline
\end{tabular}

Diante disto, foi possível calcular o efeito do tratamento para os dois grupos de indivíduos semelhantes em determinada combinação de características, comparando a diferença que cada grupo apresentou em relação às duas variáveis de desfecho, após 2 anos do início da pesquisa (Tempo 0). Assim, o método Diferenças em Diferenças foi aplicado para a comparação destes dois Grupos, pareados pelas características aqui definidas.

O impacto líquido do programa foi estimado por meio das seguintes funções que visam testar a influência da participação no PEC sobre a saúde e a qualidade de vida, medidos através do estado nutricional e do bem-estar subjetivo.

Função para medir o impacto do PEC sobre o estado nutricional:

$$
Y=\beta_{0}+\delta_{0 .} T_{0(1)}+\beta_{1} \cdot P E C+\delta_{1} \cdot T_{0(1)} \cdot P E C+\beta_{j} X j+\mu
$$

Onde:

Y - Estado Nutricional - variável dummy sendo 1 - Peso Normal e 0 demais classificações.

$\mathrm{T}_{\text {o(1) }}$ (variável dummy) - é igual a 1 quando os dados se referirem ao Tempo 1 após o início do tratamento e 0 quando se referirem ao tempo antes do tratamento;

PEC (variável dummy) - indica a participação do indivíduo no projeto esporte cidadão; é igual a 1 para indivíduos do grupo caso e igual a 0 para indivíduos do grupo controle;

$T_{0(1)}$ PEC - é a variável que mostra o impacto líquido do programa, interagindo o tempo com a participação no PEC;

$\mathbf{X} \mathbf{j}$ - é um vetor de variáveis de confusão que engloba classe social (variável dummy Classe $B=1$ e 0 para as demais), idade (variável contínua), sexo (variável dummy, $1=$ Masculino e $0=$ 
Feminimo), cor da pele (variável dummy $0=$ Branco, $1=$ demais), educação (variável ordinal), Idade (variável contínua) e estado civil do responsável (variável dummy $0=$ casado, $1=0$ outros), tamanho da família variável contínua e tipo de trabalho (variável dummy $0=e m p r e g a d o$ assalariado/Regime CLT, 1=outros)

$\boldsymbol{\mu}$ - é o erro que capta efeitos não observáveis.

Função para medir o impacto do PEC sobre o bem estar subjetivo:

$$
Y=\beta_{0}+\delta_{0} \cdot T_{0(1)}+\beta_{1} \cdot P E C+\delta_{1} \cdot T_{0(1)} \cdot P E C+\beta_{2} \cdot E N+\beta_{j} X j+\mu
$$

Onde:

Y -Grau de Satisfação com a Vida = pontuação obtida por cada indivíduo na ESVI em cada um dos Tempos 0 e 1;

$\mathbf{T}_{0(1)}$ (variável dummy) - é igual a 1 quando os dados se referirem ao Tempo 1 após o início do tratamento e 0 quando se referirem ao tempo antes do tratamento;

PEC (variável dummy) - indica a participação do indivíduo no projeto esporte cidadão; é igual a 1 para indivíduos do grupo caso e igual a 0 para indivíduos do grupo controle;

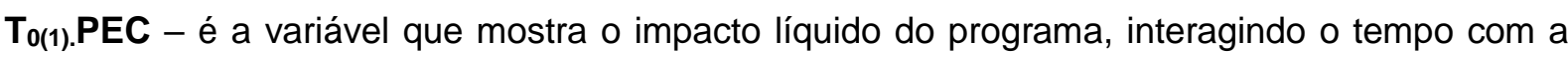
participação no PEC;

EN - Estado Nutricional - variável dummy sendo 1 - Peso Normal e 0 demais classificações.

$\mathbf{X j}$ - é um vetor de variáveis de confusão que engloba classe social (variável dummy Classe $B=1$ e 0 para as demais), idade (variável contínua), sexo (variável dummy, $1=$ Masculino e $0=$ Feminimo), cor da pele (variável dummy 0 = Branco, 1 = demais), educação (variável ordinal), Idade (variável contínua) e estado civil do responsável (variável dummy $0=$ casado, $1=$ outros), tamanho da família variável contínua e tipo de trabalho (variável dummy $0=e m p r e g a d o$ assalariado/Regime CLT, 1=outros)

$\boldsymbol{\mu}$ - é o erro que capta efeitos não observáveis.

Todas as análises estatísticas descritivas foram realizadas com o auxílio do programa Excel $\AA$ do pacote Office $2013 \AA$ e para a estimação dos modelos de regressão de Diferenças em Diferenças foi utilizado o programa SPSS $\AA$ for Windows $\AA$ versão 16.0 . 


\section{RESULTADOS}

Os resultados obtidos no presente estudo está dividido em duas seções. $\mathrm{Na}$ primeira é descrita a caracterização das amostras de crianças que participaram da pesquisa, separadas nos grupos caso e controle, no Tempo 0 (2018), representando o diagnóstico inicial do grupo controle e do grupo caso, este antes da participação das crianças no PEC. Na segunda, realiza-se a análise do impacto do PEC sobre as variáveis de desfecho selecionadas, a saber: Estado Nutricional e Bem-Estar Subjetivo, conforme exposto no capítulo de Metodologia.

\subsection{Caracterização Socioeconômica e Demográfica da amostra: grupos caso e controle}

A Tabela 3 apresenta a distribuição das amostras dos dois grupos, segundo idades e sexo no Tempo 0 , antes portanto, das crianças do grupo caso iniciarem sua participação no PEC. Como já mencionado, 126 crianças foram autorizadas a participar da pesquisa pelos pais, naquele momento (Tempo 0 - 2018), todavia apenas 30 crianças, em 2019, permaneciam matriculadas no Projeto. Em relação ao grupo controle, 170 foram autorizadas pelos pais a participarem da pesquisa em 2018, entretanto apenas 41 crianças foram localizadas em 2019, como já descrito na seção 5.3 do capítulo de metodologia.

No geral, predominaram as crianças menores com 8 e 9 anos $(69,01 \%)$. No grupo caso, a proporção das crianças dessas idades ficou abaixo da geral $(53,33 \%)$, de modo que a idade média das crianças desse grupo - Grupo Caso (9,6 anos, DP \pm 1,10 anos) ficou acima da do outro grupo - Grupo Controle (8,9 anos, DP $\pm 0,77$ anos), mas essa diferença não foi estatisticamente significante. 
Tabela 3 - Distribuição das crianças das amostras dos Grupos Caso e Controle, segundo Idade e Sexo, no Tempo 0.

\begin{tabular}{rrrrrrrrrr}
\multirow{2}{*}{$\begin{array}{c}\text { Idade } \\
\text { em anos }\end{array}$} & \multicolumn{2}{c}{ Grupo Caso } & \multicolumn{3}{c}{ Grupo Controle } & \multicolumn{2}{c}{ Total } \\
\cline { 2 - 8 } & Feminino & Masculino & Total & Feminino & Masculino & Total & Geral & $(\%)$ \\
\hline 8 & 8 & 2 & 10 & 7 & 7 & 14 & 24 & 33,80 \\
9 & 2 & 4 & 6 & 10 & 9 & 19 & 25 & 35,21 \\
10 & 2 & 7 & 9 & 4 & 3 & 7 & 16 & 22,54 \\
11 & 2 & 3 & 5 & 1 & & 1 & 6 & 8,45 \\
\hline Total Geral & $\mathbf{1 4}$ & $\mathbf{1 6}$ & $\mathbf{3 0}$ & $\mathbf{2 2}$ & $\mathbf{1 9}$ & $\mathbf{4 1}$ & $\mathbf{7 1}$ & $\mathbf{1 0 0 , 0 0}$
\end{tabular}

Fonte: Dados primários da pesquisa, 2018.

A Tabela 4 apresenta a distribuição das crianças segundo algumas variáveis sócio demográficas. Como se pode verificar a partir dos dados dessa tabela, o grupo caso foi constituído por uma maioria de meninos $(53,33 \%)$, ao passo que o grupo controle de meninas $(53,66 \%)$. No que tange à idade média dos responsáveis, não se constatou diferença estatisticamente significante, constituindo-se adultos jovens (Grupo Caso: 36,96 (DP=7,09) anos e Grupo Controle: 35,50 (DP=7,36)). O estado civil casado foi predominante nos dois grupos, embora a proporção de responsáveis casados no grupo caso tenha sido bastante elevada, ainda assim, a diferença entre os grupos não foi estatisticamente significante. A distribuição das crianças segundo a quantidade de pessoas no domicílio, mostrou proporção estatisticamente diferente entre os dois grupos (famílias mais numerosas no grupo caso), assim como a proporção de responsáveis que se autodeclararam brancos (proporção maior no grupo controle). No que se refere à escolaridade do chefe da família, verificou-se uma proporção menor de chefes com baixa escolaridade (ensino médio ou menos), no grupo caso do que a no grupo controle, diferença essa estatisticamente significante a $5 \%$. 
Tabela 4 - Distribuição das amostras dos Grupos Caso e Controle, segundo Variáveis Sócio Demográficas, no Tempo 0.

\begin{tabular}{|c|c|c|c|c|c|c|}
\hline & $\begin{array}{c}\text { Grupo } \\
\text { Caso }\end{array}$ & $(\%)$ & $\begin{array}{l}\text { Grupo } \\
\text { Controle }\end{array}$ & (\%) & Total Geral & $(\%)$ \\
\hline Meninas & 14 & 46,7 & 22 & 53,7 & 36 & 50,7 \\
\hline Responsável Casado & 27 & 90,0 & 31 & 77,5 & 58 & 82,9 \\
\hline Fam. pequenas (até 3 membros) $\left(^{*}\right.$ ) & 8 & 30,8 & 14 & 38,9 & 22 & 35,5 \\
\hline Responsável Branco $\left(^{*}\right)$ & 13 & 43,3 & 24 & 60,0 & 37 & 52,9 \\
\hline Respons. Bx Escolaridade ( $\left.{ }^{*}\right)$ & 9 & 30,0 & 14 & 34,1 & 23 & 32,4 \\
\hline
\end{tabular}

Fonte: Dados primários da pesquisa, 2018

A classificação socioeconômica das famílias dos dois grupos está demonstrada na Tabela 5, onde se observa que não participaram da pesquisa crianças de famílias pertencentes às classificações mais alta $(A)$ ou mais baixa $(E)$ em nenhum dos dois grupos, todavia comparando-os constata-se uma condição socioeconômica mais privilegiada entre as crianças do grupo caso, em que $43,3 \%$ delas apresentaram um escore que as classificou na Classe B, proporção essa estatisticamente diferente da calculada para o grupo controle $(22,0 \%)$.

Tabela 5 - Distribuição das amostras dos Grupos Caso e Controle, segundo Classificação Socioeconômica, no Tempo 0.

\begin{tabular}{|c|c|c|c|c|c|c|}
\hline & Grupo Caso & (\%) & Grupo Controle & $(\%)$ & Total Geral & (\%) \\
\hline \multicolumn{7}{|l|}{ Classe A } \\
\hline Classe B $\left(^{*}\right)$ & 13 & 43,3 & 9 & 22,0 & 22 & 31,0 \\
\hline Classe C & 17 & 56,7 & 30 & 73,2 & 47 & 66,2 \\
\hline Classe D & & & 2 & 4,9 & 2 & 2,8 \\
\hline \multicolumn{7}{|l|}{ Classe E } \\
\hline Total Geral & 30 & 100,0 & 41 & 100,0 & $\begin{array}{r}71 \\
* p-v a\end{array}$ & $\begin{array}{r}100,0 \\
\text { lor }<0,05\end{array}$ \\
\hline
\end{tabular}

Fonte: Dados primários da pesquisa, 2018.

Conclui-se que as duas amostras eram semelhantes, segundo as variáveis demográficas sexo das crianças, idade e estado civil dos responsáveis, mas distinguiam-se segundo o tamanho da família, a cor da pele declarada, a escolaridade 
do responsável e a condição socioeconômica. Estas diferenças poderiam ter influenciado o papel que o PEC proporcionou sobre a saúde e a qualidade de vida das crianças, aspecto que será analisado na próxima seção.

\subsection{Impacto do PEC sobre o Estado Nutricional das Crianças}

Como descrito na metodologia, a variável operacional para medir o impacto sobre a saúde das crianças, participantes do PEC, foi o estado nutricional. Esta variável, calculada aqui a partir do IMC e interpretada pelas curvas do crescimento conforme determina o Ministério da Saúde, resultou na classificação das crianças em Magreza, Peso Normal/Adequado, Sobrepeso e Obesidade. Para fins da análise, agregou-se essas 4 classificações em duas: Peso Adequado e Outros (Magreza, Sobrepeso e Obesidade), pois considerou-se o objetivo proposto pelo PEC que é manter uma saúde adequada, o que pode ser interpretado como a manutenção de um peso normal, dada a influência da atividade física sobre o peso corporal, ao lado de outras variáveis, como discutido na seção sobre determinantes do Estado Nutricional, como a alimentação adequada.

A Tabela 6 apresenta a quantidade de crianças com Peso Adequado e Outros, dos dois grupos e as respetivas proporções, no Tempo 0 e no Tempo 1. Como se pode perceber, a proporção de crianças com Peso Adequado do grupo caso aumentou e essa diferença foi estatisticamente significante, o mesmo não se observou entre as crianças do grupo controle. A questão que se coloca é se essa melhoria do estado nutricional, das crianças participantes do PEC deve-se exclusivamente ao impacto das atividades físicas, proporcionadas pelo Projeto. Essa questão pode ser elucidada pela estimação dos modelos de diferenças em diferenças, cujos resultados são apresentados a seguir. 
Tabela 6 - Distribuição das crianças dos Grupos Caso e Controle, segundo estado nutricional, no Tempo 0 e no Tempo 1.

\begin{tabular}{lrrrrrr} 
Tempor/E.Nutricional & $\begin{array}{c}\text { Grupo } \\
\text { Caso }\end{array}$ & \multicolumn{1}{c}{$\begin{array}{c}\text { Grupo } \\
\text { Controle }\end{array}$} & (\%) & Total Geral & $(\%)$ \\
\hline T0 -Peso Adequado & 9 & $30,0^{*}$ & 23 & 56,1 & 32 & 45,1 \\
T1 - Peso Adequado & 11 & $36,7^{*}$ & 23 & 56,1 & 34 & 47,9 \\
T0 - Outros & 21 & $70,0^{*}$ & 18 & 43,9 & 39 & 54,9 \\
T1 - Outros & 19 & $63,3^{*}$ & 18 & 43,9 & 37 & 52,1 \\
\hline & & & & & & * p-valor $<0,05$
\end{tabular}

Fonte: Dados primários da pesquisa, 2018/2019.

Os dados apresentados na Tabela 7 abaixo, modelo sem controles, confirma que a proporção de crianças com peso normal cresce do tempo 0 ao 1 no grupo caso, de 0,30 (Tempo 0) para 0,37 (Tempo 1) e não se alterou no grupo controle, sugerindo que o programa teve efeito positivo, ainda que não significante estatisticamente. Todavia, é importante incluir outras variáveis que podem ter influenciado o estado nutricional das crianças. Na Tabela 8, apresentam-se os resultados da estimação do Modelo Dif em Dif, completo, ou seja, incluindo variáveis de confusão tais como: sexo das crianças, idade do responsável, escolaridade do chefe de família, tamanho da família e cor da pele, variáveis essas que diferenciaram os dois grupos.

\section{Tabela 7 - Impacto do PEC sobre o Estado Nutricional: Estimativa do modelo} incompleto (sem controles).

\begin{tabular}{|c|c|c|c|c|c|c|c|}
\hline $\begin{array}{l}\text { Variável } \\
\text { Dependente }\end{array}$ & $\begin{array}{c}\text { Grupo } \\
\text { Caso }\end{array}$ & $\begin{array}{c}\text { Grupo } \\
\text { Controle }\end{array}$ & $\begin{array}{l}\text { Diff } \\
\text { (pré) }\end{array}$ & $\begin{array}{c}\text { Grupo } \\
\text { Caso }\end{array}$ & $\begin{array}{c}\text { Grupo } \\
\text { Controle }\end{array}$ & $\begin{array}{c}\text { Diff } \\
\text { (pós) }\end{array}$ & $\begin{array}{c}\text { Diff- } \\
\text { in-Diff }\end{array}$ \\
\hline Estado Nutricional & 0,30 & 0,56 & $0,26^{\star *}$ & 0,37 & 0,56 & 0,19 & 0,07 \\
\hline erro padrão & 0,09 & 0,08 & 0,12 & 0,09 & 0,08 & 0,12 & 0,17 \\
\hline razão-t & 3,33 & 7,15 & 2,22 & 4,11 & 7,15 & 1,63 & 0,40 \\
\hline & & & & & & \multicolumn{2}{|c|}{$\begin{array}{l}\text { ** p-valor }<0,05 \\
F(3,138)=2,29\end{array}$} \\
\hline & & & & & & \multicolumn{2}{|c|}{$\begin{array}{l}\text {-saquared }=0,0527 \\
\text { Root } \mathrm{MSE}=0,49242\end{array}$} \\
\hline
\end{tabular}

Fonte: Dados primários da pesquisa, 2018/2019.

$\mathrm{Na}$ Tabela 8, estão apresentados os coeficientes das variáveis consideradas no modelo completo, o erro padrão e a estatística t de student. Em primeiro lugar, verifica-se que dentre as variáveis de confusão incluídas no modelo, apenas o 
tamanho da família mostrou uma influência estatisticamente significante positiva, a 10\%. Das demais, cabe ainda registrar, que embora não significantes observou-se uma relação positiva no que tange à idade da criança, mas negativa em relação à idade do responsável; o tipo de trabalho formal com efeito favorável, assim como o nível de escolaridade do responsável. Por outro lado, os coeficientes das variáveis classe social e cor da pele apresentaram sinais contrários ao esperado. Em segundo lugar, no que diz respeito às variáveis relacionadas ao PEC, observou-se que a participação no projeto, considerada isoladamente, teve um impacto favorável sobre o estado nutricional das crianças participantes, efeito esse estatisticamente significante a 10\%, todavia a influência do tempo e a interação deste com a participação, não foram estatisticamente significantes, além do que a relação entre o peso normal e o tempo, foi negativa.

Em síntese, os resultados mostram que nenhuma das variáveis consideradas exerceram efeito relevante do ponto de vista estatístico, sob o estado nutricional das crianças, nem a participação no PEC.

\section{Tabela 8 - Impacto do PEC sobre o Estado Nutricional: Estimativa do Modelo de Diferenças em Diferenças Completo.}

\begin{tabular}{lrrrrrr} 
Variáveis independentes & Coeficientes & $\begin{array}{c}\text { Erro } \\
\text { Padrão }\end{array}$ & $\mathbf{t}$ & $\mathbf{p}>|\mathbf{t}|$ & \multicolumn{2}{c}{$\begin{array}{c}\text { Intervalo de } \\
\text { Confiança (95\%) }\end{array}$} \\
\hline Tempo (T) & 0,043 & 0,130 & 0,310 & 0,758 & $-0,232$ & 0,318 \\
Tratamento (PEC) & $-0,242$ & 0,130 & $-1,850$ & $\mathbf{0 , 0 6 8}$ & $-0,501$ & 0,018 \\
Tratamento*tempo (T*PEC) & 0,041 & 0,174 & 0,240 & 0,813 & $-0,304$ & 0,386 \\
Classe Social B & $-0,065$ & 0,120 & $-0,540$ & 0,592 & $-0,304$ & 0,174 \\
Masculino & $-0,049$ & 0,094 & $-0,520$ & 0,601 & $-0,235$ & 0,137 \\
Idade & 0,021 & 0,052 & 0,400 & 0,687 & $-0,082$ & 0,124 \\
Não-Brancos & 0,076 & 0,091 & 0,830 & 0,407 & $-0,105$ & 0,257 \\
Educação do responsável & 0,046 & 0,077 & 0,600 & 0,551 & $-0,106$ & 0,199 \\
Idade do responsável & $-0,007$ & 0,007 & $-1,110$ & 0,268 & $-0,020$ & 0,006 \\
Não-Casados & 0,205 & 0,124 & 1,650 & 0,102 & $-0,042$ & 0,451 \\
Tamanho da família & 0,086 & 0,046 & 1,880 & $\mathbf{0 , 0 6 2}$ & $-0,005$ & 0,180 \\
Não-Trabalho CLT & $-0,128$ & 0,096 & $-1,340$ & 0,182 & $-0,318$ & 0,061 \\
Constante & $-0,207$ & 0,547 & $-0,380$ & 0,705 & $-1,291$ & 0,876 \\
\hline
\end{tabular}

$F(12,109)=2,29$

Prob $>F=0,0123$

R-squared $=0,1446$ Root MSE $=0,48686$

Fonte: Dados primários da pesquisa, 2018/2019. 


\subsection{Impacto do PEC sobre o Bem-Estar Subjetivo das Crianças.}

A variável operacional para medir o impacto sobre a qualidade de vida das crianças participantes do PEC foi o bem-estar subjetivo. As médias do indicador do bem-estar subjetivo, calculado a partir do escore da Escala Multidimensional de Satisfação de Vida para Crianças/EMSVC, conforme descrito na Metodologia, estão demonstradas na Tabela 9. Nessa tabela, constata-se que não há diferença estatística entre o bem-estar subjetivo, entre meninas e meninos, nos dois grupos caso e controle, contudo o bem-estar subjetivo mostra-se mais alto no Grupo Caso (213,0 T0; e 215,0 - T1), do que no grupo controle (191,6 - T0 e 199,8 - T1), em ambos os tempos e essas diferenças são estatisticamente significantes ( $p$-valor 0,000). Entretanto, a evolução do bem-estar subjetivo ao longo do tempo do Grupo Caso foi bem menor do que a evolução do Grupo Controle, sugerindo ausência de impacto favorável do PEC sobre as crianças participantes. Para reiterar esse resultado, as Tabelas 10 e 11 demonstram os resultados da estimação do modelo incompleto (sem a inclusão de variáveis de confusão) e do modelo completo, respectivamente, de acordo com o método de Diferenças em Diferenças.

Tabela 9 - Médias do Escore de Bem-Estar Subjetivo segundo sexo e tempo.

\begin{tabular}{lcccccccccc} 
& \multicolumn{3}{c}{ Grupo Caso } & \multicolumn{4}{c}{ Grupo Controle } & \multicolumn{3}{c}{ Total Geral } \\
\cline { 2 - 11 } T0 - Sexo & Média & DP & N & Média & DP & N & Média & DP & N \\
\hline Meninas & 217,9 & 14,873 & 14 & 193,7 & 21,561 & 22 & 203,1 & 22,437 & 36 \\
Meninos & 208,7 & 16,656 & 16 & 189,1 & 26,102 & 19 & 198,1 & 24,105 & 35 \\
Total Geral & 213,0 & 16,258 & 30 & 191,6 & 23,582 & 41 & 200,6 & 23,247 & 71 \\
T1-Sexo & Média & DP & N & Média & DP & N & Média & DP & N \\
\hline Meninas & 218,7 & 17,394 & 14 & 199,2 & 11,900 & 22 & 206,8 & 18,094 & 36 \\
Meninos & 211,7 & 15,105 & 16 & 200,5 & 13,470 & 19 & 205,6 & 15,263 & 35 \\
Total Geral & $215,0\left(^{*}\right)$ & 16,184 & 30 & $199,8\left(^{*}\right)$ & 13,040 & 41 & 206,2 & 16,649 & 71 \\
\hline
\end{tabular}

Fonte: Dados primários da pesquisa, 2018/2019.

A análise de regressão do modelo sem controles, sugere que o grupo caso possuía, antes da intervenção, um nível de bem-estar subjetivo superior ao do grupo controle (T0) e essa diferença era estatisticamente significante. Tal significância, 
contudo, não se mantém no Tempo 1, nem em relação ao efeito líquido do PEC, ou seja, a diferença entre os dois grupos diminuiu ao longo do tempo, sugerindo que o grupo controle teve uma melhoria mais expressiva do que o grupo caso (Tabela 10). Esse resultado pode estar viesado pela influência de outras variáveis sobre o bemestar das crianças, como aspectos familiares, seu cotidiano, outras atividades que realizam durante o dia, etc., obscurecendo o efeito líquido do PEC.

\section{Tabela 10 - Impacto do PEC sobre o Bem Estar Subjetivo}

\begin{tabular}{|c|c|c|c|c|c|c|c|}
\hline $\begin{array}{c}\text { Variável } \\
\text { Dependente }\end{array}$ & $\begin{array}{c}\text { Grupo } \\
\text { Controle }\end{array}$ & $\begin{array}{l}\text { Grupo } \\
\text { Caso }\end{array}$ & Diff (pré) & $\begin{array}{c}\text { Grupo } \\
\text { Controle }\end{array}$ & $\begin{array}{c}\text { Grupo } \\
\text { Caso }\end{array}$ & $\begin{array}{l}\text { Diff } \\
\text { (pós) }\end{array}$ & $\begin{array}{c}\text { Diff-in- } \\
\text { Diff }\end{array}$ \\
\hline Bem-estar Subjetivo & 191,59 & 212,97 & $-21,38^{* *}$ & 199,78 & 214,97 & $-15,19$ & $-6,20$ \\
\hline erro padrão & 3,68 & 2,97 & 5,00 & 2,53 & 2,38 & 3,59 & 5,87 \\
\hline razão-t & 52,02 & 71,75 & $-4,27$ & 79,06 & 108,80 & $-4,22$ & $-1,06$ \\
\hline & & & & & & \multicolumn{2}{|c|}{$\begin{array}{l}{ }^{*} p \text {-valor }<0,1 \\
* * \text { p-valor }<0,05\end{array}$} \\
\hline & & & & & & \multicolumn{2}{|c|}{$F(3,138)=13,62$} \\
\hline & & & & & & \multicolumn{2}{|c|}{ Prob $>F=0,0000$} \\
\hline & & & & & & \multicolumn{2}{|c|}{ R-saquared $=0,2232$} \\
\hline & & & & & & \multicolumn{2}{|c|}{ Root $\mathrm{MSE}=18,121$} \\
\hline
\end{tabular}

Fonte: Dados primários da pesquisa, 2018/2019.

A Tabela 11 apresenta os resultados da estimação do modelo considerando, também um conjunto de variáveis de confusão. $O$ modelo é estatisticamente significante $(F<0,000)$ e com $R^{2}$ de $30 \%$. Entretanto, a única variável com efeito estatisticamente significante sobre o bem-estar subjetivo foi a idade da criança, mostrando que as mais velhas têm menor bem-estar. Entre as demais variáveis foi testada a influência do estado nutricional ${ }^{14}$, esperando-se que crianças com peso normal tivessem um nível de bem-estar subjetivo mais elevado, contudo o coeficiente estimado foi negativo e não significante estatisticamente. Entre as outras variáveis testadas, vale mencionar a semelhança dos sinais das variáveis classe social, sexo, tamanho da família, educação do responsável e tipo de vínculo de trabalho, ao passo que sinal oposto foi obtido em relação ao estado civil do responsável.

No que tange ao impacto do PEC, a estimação do modelo completo reitera os resultados obtidos com o modelo sem as variáveis de confusão. Ou seja, a análise

\footnotetext{
${ }^{14}$ Foram realizados testes anteriores, sem a inclusão da variável operacional Estado Nutricional e os resultados obtidos não se diferiram destes apresentados.
} 
dos resultados sugere que o PEC não teve, ao longo de 2 anos, um efeito líquido positivo sobre o bem-estar das crianças, embora a participação no PEC (ou melhor dizendo, as crianças de Indaiatuba), com a passagem do tempo, tenham apresentados um efeito favorável e estatisticamente significativo, sobre o indicador do bem-estar. Contudo, o efeito líquido (interação tempo e participação) apresentou-se com sinal negativo e não significante, em nível estatístico. Em outras palavras, o nível mais elevado de bem-estar das crianças de Indaiatuba não se deve ao PEC.

Tabela 11 - Coeficientes das variáveis avaliadas no modelo de Diferenças in Diferenças da Qualidade de Vida, sob a ótica do bem-estar (com controles).

\begin{tabular}{lrrrrrr} 
Variáveis independentes & Coeficientes & $\begin{array}{c}\text { Erro } \\
\text { Padrão }\end{array}$ & $\mathbf{t}$ & $\mathbf{p}>|\mathbf{t}|$ & Intervalo de Confiança (95\%) \\
\hline Estado Nutricional & $-0,463$ & 3,507 & $-0,13$ & 0,895 & $-7,414$ & 6,489 \\
Tempo (T) & 12,649 & 5,248 & 2,41 & 0,018 & 2,245 & 23,052 \\
Tratamento (PEC) & 24,058 & 5,123 & 4,7 & 0,000 & 13,903 & 34,213 \\
Tratamento*tempo (T*PEC) & $-5,904$ & 6,409 & $-0,92$ & 0,359 & $-18,608$ & 6,799 \\
Classe Social B & $-1,635$ & 4,794 & $-0,34$ & 0,734 & $-11,139$ & 7,869 \\
Masculino & $-4,301$ & 3,215 & $-1,34$ & 0,184 & $-10,673$ & 2,071 \\
Idade & $-3,703$ & 1,617 & $-2,29$ & 0,024 & $-6,909$ & $-0,497$ \\
Não-Brancos & 1,127 & 3,209 & 0,35 & 0,726 & $-5,234$ & 7,488 \\
Educação do responsável & 0,066 & 2,742 & 0,02 & 0,981 & $-5,37$ & 5,502 \\
Idade do responsável & 0,018 & 0,219 & 0,08 & 0,935 & $-0,416$ & 0,452 \\
Não-Casados & $-4,639$ & 4,98 & $-0,93$ & 0,354 & $-14,509$ & 5,232 \\
Tamanho da família & 0,193 & 2,091 & 0,09 & 0,927 & $-3,953$ & 4,339 \\
Não-Trabalho CLT & 0,923 & 3,232 & 0,29 & 0,776 & $-5,484$ & 7,33 \\
Constante & 233,819 & 16,95 & 13,79 & 0,000 & 200,221 & 267,418 \\
\hline
\end{tabular}




\section{DISCUSSÃO}

A análise econômica é um elemento importante para definir a melhor forma de utilizar os recursos da sociedade para melhorar as condições de vida da população. A questão da saúde e em particular a nutricional, ante o cenário da crescente epidemia de obesidade infantil que está instalada não só no Brasil, mas no mundo, é um tema que demanda estudos econômicos ante a escassez relativa de recursos na Economia.

Os estudos econômicos são desenvolvidos em duas etapas, na primeira investiga-se se o programa tem impacto, sobre as variáveis de desfecho visadas pelo programa, e uma vez constatado o impacto, investiga-se o custo do programa comparando a sua relação custo/impacto, a de um programa alternativo. O presente trabalho dedicou-se a investigar impacto de uma política pública, cujo objetivo expresso é a melhoria da saúde e da qualidade de vida das crianças: o Projeto Esporte Cidadão - PEC.

Com base na revisão da literatura exposta nos capítulos iniciais, esperava-se encontrar resultados que evidenciassem efeitos positivos sobre o estado nutricional e qualidade de vida, das crianças participantes do PEC, uma vez que a atividade física regular ajuda prevenir e tratar diversas doenças não transmissíveis, além de ajudar a prevenir hipertensão, sobrepeso e obesidade e pode melhorar a saúde mental, qualidade de vida e bem-estar (OMS, 2018). No entanto, os resultados aqui obtidos não corroboraram com os achados que discutem o tema.

Em relação à saúde, estudada aqui por meio de acompanhamento do estado nutricional de crianças participantes e não participantes do PEC, observou-se que houve um aumento da proporção de crianças com peso adequado do grupo caso, em comparação com a proporção de crianças nessa classificação do grupo controle, todavia a análise por meio da estimação do modelo econométrico, de diferenças em diferenças, demonstrou que essa variação não pode ser atribuída ao PEC. Esse resultado se contrapõe aos encontrados por Coelho et al. (2012), Claros, Álvarez \& Sánchez (2019) e Scherr et al. (2019) que apontam correlação estaticamente significativa, entre a prática da atividade física regular e manutenção do peso adequado, medido através do IMC. 
Além disso, a OMS (2010) aponta que diversos estudos encontraram níveis mais elevados de atividade física, estão estando associados a parâmetros de saúde mais favoráveis, como: melhora da aptidão cardiorrespiratória e força muscular, gordura corporal e risco de doenças metabólicas, reduzida além da melhora óssea.

Uma razão para a falta de impacto sobre o estado nutricional, constatada no presente estudo, pode se relacionar ao fato de que o impacto da atividade física de lazer seja melhor vista a partir de outros indicadores, como as citadas pela OMS (2010) capacidade cardiorrespiratória (GONÇALVES et al., 2017) ou coordenação motora (HERDMAN et al., 2017), consideradas medidas mais sensíveis aos efeitos da atividade física de lazer, como a proporcionada pelo PEC.

Outra questão que se levanta é a quantidade de tempo destinada à atividade física de lazer para que seja possível observar uma mudança significativa no estado nutricional. Como aponta o estudo de Oliveira et al. (2017) para evitar excesso de peso e obesidade seria necessário $66 \mathrm{~min} /$ dia (meninos) e $46 \mathrm{~min} /$ dia (meninas) de atividade física moderada, o que estaria para além do que oferece o PEC, e por isso talvez, o resultado esperado não tenha sido alcançado neste estudo. Além disso, a frequência das crianças às aulas do PEC, não foi uma variável controlada, outro fator que pode ter minimizado os efeitos da prática de atividade física do PEC, sobre o estado nutricional.

As orientações da OMS (2010) para atividade física de lazer, inclui brincadeiras, jogos, esportes, transporte, recreação, educação física ou exercício planejado, no contexto das atividades familiares, escolares e comunitárias. Aqui neste estudo estas variáveis externas não foram controlas. Ainda de acordo com a OMS (2010) seriam necessários 60 minutos diários de atividade física, de intensidade moderada a vigorosa, para que os benefícios para a saúde, incluindo o estado nutricional, pudessem ser notados em crianças, submetidas às atividades oferecidas pelo PEC.

Outro ponto importante a se destacar, são os resultados encontrados no estudo de Aranha (2014) que teve como objetivo a avaliação de impacto de um programa público de prática esportiva (Programa de Recreação, Iniciação e Aperfeiçoamento /PRIA) presente no mesmo município, Indaiatuba/SP. Apesar destes programas terem propostas, meta e missão diferentes, os dois programas foram executados pela mesma equipe de profissionais e seguiam nos mesmos moldes, 
sendo o PEC uma continuação do PRIA. O estudo acima referido, também utilizou o método de diferenças in diferenças, não encontrando efeito significativo sobre o estado nutricional, nem na qualidade de vida das crianças participantes, mas sim, no desempenho acadêmico. Esse estudo diferencia-se do aqui apresentado, tanto pela duração considerada (3 meses) da participação das crianças no Programa, como pelo instrumento para avaliar a qualidade de vida.

Apesar da presente pesquisa e do estudo anterior de Aranha (2014), não terem encontrado correlação estatisticamente significativa entre a participação em projetos esportivos e a melhora do estado nutricional, não se pode ignorar os benefícios da prática da atividade física para a saúde das crianças, a longo prazo (FOGELHOLM, 2010); talvez estes efeitos só possam ser notados em estudos de coorte de duração maior, com no mínimo 5 anos de acompanhamento.

Em relação à avaliação da qualidade de vida, a análise aqui desenvolvida não concluiu sobre a existência de um impacto favorável da atividade física desenvolvida no âmbito do PEC, sobre a qualidade de vida, que foi representada por um indicador de sensação de bem-estar subjetivo. É importante enfatizar que não existem muitos estudos que adotam esse indicador para representar a qualidade de vida, a maioria deles, citados aqui, adota indicadores de qualidade de vida construídos especificamente, para condições relacionadas a problemas de saúde e que demonstram impactos positivos da atividade física regular sobre a qualidade de vida, sob a perspectiva da saúde.

Este processo de entendimento do bem-estar como subjetivo, não é outra coisa senão o reflexo e a aplicação de uma nova forma de entender o homem. Esta forma de embasamento distancia-se das perspectivas médicas e socioeconômicas que associam a qualidade de vida ao bem-estar físico ou à satisfação de necessidades materiais e não a percepção psicológica da qualidade de vida. O conceito aqui adotado, dá voz ao indivíduo, no contexto de sua própria história (BETTINE, GUTIERREZ, MARQUES, 2019), sem perder de vista as dimensões macro e micro sociais, dentro das quais o indivíduo se movimenta. No entanto, ainda é muito incipiente os estudos voltados a esta área, principalmente aqueles que desejam comparar o bem-estar subjetivo a variáveis operacionais relacionadas à saúde. 
Também, é importante considerar que esta fase do desenvolvimento, a infância, é uma etapa de intensas mudanças, na qual ainda não se tem formado, de modo pleno, o pensamento abstrato e formal, impactando assim, tanto nas avaliações subjetivas quanto nas noções do bem-estar. Além do mais, as crianças recebem durante este período, inúmeras mensagens ambíguas da sociedade ao mesmo tempo, sobre o que é felicidade, o que ela precisa ter, o que precisa fazer, o que tende a se tornar confuso para o pensamento e julgamento de um ser humano, ainda em formação.

Assim, a complexidade desta fase, do conceito de bem-estar subjetivo e da escassez de pesquisas nesta vertente da qualidade de vida, sugerem a necessidade de mais estudos que investiguem empiricamente, para além dos fatores socioeconômicos e demográficos, aspectos psicológicos como qualidade do relacionamento familiar (GIRON, 2016), aspectos de personalidade (WOYCIEKOSKI, NATIVIDADE \& HUTZ, 2014) e outros fatores individuais, como a satisfação com os amigos, escola (GIACOMONI \& HUTZ, 2008) que podem influenciar a sensação de bem-estar subjetivo, ideia proposta pelos autores Assumpção et al. (2000) e Giacomoni \& Hutz, (2008). Contudo, vale ainda ressaltar que o bem-estar subjetivo seja uma variável tão individual que não possa ser explicada por variáveis de fácil observação.

Apesar da vasta literatura que mostra correlação entre saúde e prática de atividade física, entre qualidade de vida e atividade física, assim como estudos que associam o sobrepeso a diversos quadros psicológicos negativos (SIGULEM, DEVINCENZI \& LESSA, 2000; DE GRANDIS, ARMELINIB \& CUESTASC, 2008; TURCO et al., 2003; PRATT et al., 2003; OLIVEIRA \& COSTA, 2016; LEMES et al., 2018; ABRANTES, LAMOUNIER \& COLSIMO, 2002; RAVENS-SIEBERER, REDEGELD \& BULLINGER, 2001; POETA, DUARTE \& GIULIANO, 2010, 2013; FINNE et al., 2013; COELHO et al., 2012; WERNECK \& NAVARRO, 2011) - os resultados aqui encontrados não corroboraram tais achados. Neste estudo não foi encontrada relação significativa, nem entre a participação do PEC e a qualidade de vida, nem com a saúde e nem ainda, entre estado nutricional e qualidade de vida.

Em última instância, as poucas conclusões sobre o impacto de políticas públicas voltadas ao esporte educacional podem estar no fato de que a decisão final 
de continuar se exercitando regularmente se dá sempre na esfera particular, dentro das mais diversificadas motivações e justificativas (AMORIM, 2013). É preciso, portanto que novas possibilidades de análise desses programas sejam estruturadas, como por exemplo: analisar o quanto a prática da atividade física regular afeta no comportamento da criança em casa e na escola, e ainda outros índices de saúde como, capacidade cardiorrespiratória e força muscular, entendendo que seus benefícios podem estar mais relacionados a estes aspectos do que as medidas globais como IMC e a questões subjetivas, o bem-estar.

Identifica-se como limitação do estudo, a queda do número de participantes no PEC, assim como do número de crianças de Americana, localizadas na segunda etapa da coleta de dados (Tempo 1), bem como as mudanças administrativas que tumultuaram, em alguma medida, também a segunda coleta. Estudos longitudinais precisam de amostras amplas para garantir que a perda de observações ao longo do tempo não comprometa os resultados. Infelizmente, no presente estudo não foi possível garantir o tamanho da amostra inicial. 


\section{CONCLUSÃO}

Este trabalho teve como objetivo avaliar o impacto do Projeto Esporte Cidadão/PEC da cidade de Indaiatuba/SP, sobre a saúde e a qualidade de vida de seus participantes, sendo que para esse teste utilizaram-se o estado nutricional e a sensação de bem-estar subjetivo, representando essas variáveis, respectivamente. As hipóteses do trabalho eram de que as crianças que participam do Projeto Esporte Cidadão, melhoram ou mantêm em nível adequado, ao longo do tempo, seu estado nutricional e seu bem-estar subjetivo.

A fim de cumprir com estes objetivos foi realizada uma análise teórica da evolução histórica do conceito de esporte educacional e atividade física; uma análise da evolução conceitual de qualidade de vida, até a noção de bem-estar subjetivo.

Utilizados na literatura como sinônimos, complementares ou distintos, os termos esporte, exercício físico e atividade física foram discutidos e aqui entendidos, a partir da ideia posta por Barbanti (2003). Segundo ele, esporte é um termo mais adequado para um esforço vigoroso, feito num contexto competitivo e ambiente institucionalizado; já exercício físico designaria uma prática planejada para melhoria de rendimento e a atividade física seria como todo movimento corporal produzido pelos músculos esqueléticos que provoca um gasto de energia. A partir do conhecimento da rotina observada do Projeto Esporte Cidadão, entendese que o termo atividade física, mais especificamente a atividade física de lazer, se faz mais adequado à atividade promovida para as crianças participantes do projeto.

Ademais, observou-se como o eixo principal das pesquisas sobre qualidade de vida sofreu uma mudança profunda: do (importante) instrumento do WHOQOLGroup de 1970, que media a qualidade vida, por aspectos relacionados a saúde e as condições socioeconômicas, como meio de ter acesso aos bens da crescente sociedade de consumo, passou-se a adotar outra perspectiva nos últimos anos, o conceito de sensação subjetiva de bem-estar, dando voz ao sujeito e não a métricas socioculturais e/ou higienizadoras.

Após a análise do desenvolvimento dos conceitos de atividade física de lazer e qualidade de vida, foi realizada uma avaliação do impacto do Projeto Esporte Cidadão, 
rejeitando-se as hipóteses iniciais de que o PEC teria um papel de manter ou melhorar o estado nutricional e a qualidade de vida de seus participantes, ou seja, não foi encontrado evidências de que o PEC teve efeito positivo sob estas duas variáveis.

E por fim, a qualidade de vida, sob a ótica subjetiva de bem-estar, por ainda ser um constructo pouco estudado, não tem seus determinantes estabelecidos, podendo captar efeitos de variáveis não observadas. Mais pesquisas utilizando essa variável são necessárias. 


\section{REFERÊNCIAS BIBLIOGRÁFICAS}

ABRANTES, M. M., LAMOUNIER, J. A., COLSIMO, E. Prevalência de sobrepeso e obesidade nas regiões sudeste e nordeste. Jornal de Pediatria, Rio de Janeiro, 78:335-40, 2002.

ARANHA, J. G. Impacto de um programa público de iniciação esportiva para crianças: gastos, antropometria, rendimento escolar e qualidade de vida. Dissertação: Mestrado. Universidade de São Paulo. São Paulo/SP, 2014.

ARAÚJO, D. S. M. S.; ARAÚJO, C. G. S. Aptidão física, saúde e qualidade de vida relacionada à saúde em adultos. Revista Brasileira de Medicina do Esporte, v. 6, n.5, p.194-203, 2000.

ASSUMPÇÃO, F. B. JR.; KUCZYNSKI, E.; SPROVIERI, M. H.; ARANHA, E. M. G. Escala de avaliação de qualidade de vida (AUQEI - Autoquestionnaire Qualité de Vie Enfant Imagé): validade e confiabilidade de uma escala para qualidade de vida em crianças de 4 a 12 anos. Arq Neuro-Psiquiatr. Vol. 58, n.1, p.119-127, São Paulo, 2000.

AZEVEDO, I. L. C. \& VIANA, H. B. Percepção dos professores em relação à atuação do psicopedagogo. Educare: Revista Cientifica de Educação, Vol. 2, №. 1, p. 5373. Paraíba, 2016.

BARBANTI, V. J. Dicionário de Educação Física e do Esporte. Ed. Manole Ltda., São Paulo, 2003.

BARBOSA, K. S. S., CASTRO, S. S., LEITE, C. F., NACCI, F. R. \& ACCIOLY, M. F. Validação da versão brasileira do World Health Organization Disability Assessment Schedule 2.0 em indivíduos HIV/AIDS. Ciênc. Saúde coletiva, Vol. 25, №. 3, p. 837844. Rio de Janeiro, mar. 2020.

BARTHOLO, R., BITTENCOURT, J. \& RIBEIRO, H. Ética e Sustentabilidade. Epapers servicos editoriais. Rio de Janeiro, 2002.

BAUMAN, Z. Modernidade Líquida. Zahar. Rio de Janeiro, 2001. 
BAUMAN, Z., MAY, T. Aprendendo a pensar com a Sociologia. 1 Edição, Zahar. São Paulo, 2010.

BETTI, M. Esporte e sociologia. IN: TAMBUCCI, L. P., OLIVEIRA, J. G. M., SOBRINHO, J. C. Esporte e jornalismo. CEPEUSP. São Paulo, 1997.

BETTINE, M., GUTIERREZ, G. \& MARQUES, R. Qualidade de Vida: definição, conceitos e interfaces com outras áreas de pesquisa. Edições EACH/USP, São Paulo, 2019.

BOBBIO, N., MATTEUCCI, N. \& PASQUINO, G. Dicionário de Política. 13 Edição, UNB. Brasília, 2008.

BOWLING, A. Measuring Health: A Review of Quality of Life Measurements Scales. Open University Press. Buckinham, 1997.

BRASIL. Constituição da República Federativa do Brasil. Brasília, DF: Senado Federal. 1988.

BRASIL, Lei 8.672 de 6 de julho de 1993. Institui o Código Civil. Diário Oficial da União: seção 1, Brasília, DF, ano 130, p. 9.379, 7 jul. 1993.

BRASIL, 9.615 de 24 de março de 1998. Institui o Código Civil. Diário Oficial da União: seção 1, Brasília, DF, ano 135, p. 1, 24 mar. 1998.

BRASIL. LEI № 8.672, de 6 de JULHO DE 1993 - Institui normas gerais sobre desportos e dá outras providências. Brasília - DF, 1993.

BRASIL. LEI № 9.615, de 24 de MARÇO DE 1998 - Institui normas gerais sobre desporto e dá outras providências. Brasília - DF, 1998.

BRASIL. Ministério do Esporte. Lei de Incentivo ao Esporte. Lei no 9.394, de 29 de dez de 2006.

BRASIL. Ministério do Esporte. Manual de orientações para implantação de núcleos do Programa Segundo Tempo. Brasília - DF, 2007. 
BRASIL. Ministério da Saúde. Orientações para a Coleta e Análise de dados antropométricos em serviços de saúde. Norma Técnica do sistema de vigilância Alimentar e nutricional - SISVAN. Brasília - DF, 2011.

BOURDIEU, P. A Produção da Crença: Contribuição para uma economia dos bens simbólicos. 3ํㅡㄹição, Editora Zouk. Porto Alegre, 2004.

BOURDIEU, P. A Economia das trocas simbólicas. $7^{\circ}$ Edição. Editora Perspectiva. São Paulo, 2011.

BOURDIEU, P. A dominação masculina. Bertrand Brasil. Rio de Janeiro, 2002.

BUENO, D. R., MARUCI, M. F. N., CODOGNO, J. S., ROEDIGER, M. A. The costs of physical inactivity in the world: a general review. Ciênc. saúde coletiva, vol.21, no.4, Rio de Janeiro, abril, 2016.

CAMALIONTE, L. G. \& BOCCALANDRO, M. P. R. Felicidade e bem-estar na visão da psicologia positiva. Bol. - Acad. Paul. Psicol. Vol.37, №.93, pp. 206-227, 2017.

CAStRo, A. O., GALVÃO, T. F., FERREIRA, C. M., REIS, N. D. \& GUSMÃO, R. Prevalência da obesidade infantil no Brasil: revisão sistemática e meta-análise. Revista dos Trabalhos de Iniciação Científica da UNICAMP, n.27. Campinas, out. 2019.

CASTRO, K.; ROCKETT, F. C.; BILLO, M.; OLIVEIRA, G. T.; KLEIN, L. S. Lifestyle, quality of life, nutritional status and headache in school-aged children. Nutricion Hospitalia, v.28, n.5, p.1546-1551, 2013.

ClAROS, J. A. V., ÁLVAREZ, C. V. \& SÁNCHEZ, J. H. P. Physical activity and body mass index in Colombian school children. Hacia la Promoción de la Salud, Vol. 24, No. 1, p. 44 - 55, Enero - Junio, 2019.

COELHO, L. G., CÂNDIDO, A. P. C., MACHADO-COELHO, G. L. L., FREITAS, S. N. Associação entre estado nutricional, hábitos alimentares e nível de atividade física em escolares. Jornal de Pediatria, Vol. 88, № 5, 2012.

COHEN, E. \& FRANCO, R. Avaliação de projetos sociais. Ed.Vozes, Petrópolis, 2008. 
CONSTANTINO, M. A. C. Qualidade de Vida de Adolescentes: desenvolvimento e validação de instrumento, com alunos do Projeto Esporte Cidadão - Secretaria de Esportes de Indaiatuba. Tese de Doutorado. Universidade de São Paulo/SP, 2016.

CONTREIRA, A. R \& CORAZZA, S. T. A prática de exercícios físicos e a melhoria nos elementos perceptivo-motores: estudo de revisão. Lecturas: Educación Física y Deportes, Vol. 14 - № 132. Buenos Aires, 2009.

DE GRANDIS, E.S.; ARMELINIB, P.A.; CUESTASC, E. Evaluación de la calidad de vida en escolares con antecedentes de desnutrición temprana severa. Anales de Pediatría, v.81, n.6, p.368-73, 2014.

DELEUZE, G. \& GUATTARI, F. O Anti-Édipo. 2º Edição, Editora 34. São Paulo, 2011. DELEUZE, G. Crítica e Clínica. Editora 34. São Paulo, 2011.

DIENER, E., SUH, E. M., LUCAS, R. E. \& SIMITH, H.L. Subjetive well-being: Three decades of progress. Psychological Bulletin, 125, 276-302, 1995.

DING, D., LAWSON, K., KOLBE-ALEXANDER, T. L., FINKELSTEIN, E. A., KATZMARZYK, P. T., MECHELEN, W. V., PRATT, M. The economic burden of physical inactivity: a global analysis of major non-communicable diseases. The Lancet, V. 388, oㅜ 10051, p.1311-1324, setembro, 2016.

ENES, C. C., SLATER, B. Obesidade na adolescência e seus principais fatores determinantes. Rev. Bras. Epidemiol, V.13, ํo1, p.163-171. São Paulo, 2010.

FROMM, E. Socialist Humanism: An International Symposium. Garden City, NY: Doubleday, 1965.

FERREIRA, E. F. Habilidade sociais e deficiência intelectual: Influência de um programa de educação física baseado na cultura corporal. Dissertação (Mestrado). Universidade Federal de São Carlos, 2014.

IRIYE, Akira. Global Interdependence: the world after 1945. 1 Edição. Massachussets: Bleknap Press, 2014. 
HABERMAS, J. Para a reconstrução do materialismo histórico. 1 Edição. Unesp. São Paulo, 2014.

FARIA, C. A. P. A política da avaliação de políticas públicas. Revista Brasileira de Ciências Sociais, Vol. 20, №. 59, 2005.

FARJALLA, R. Análise do impacto das políticas públicas de esportes e Lazer em Petrópolis. Licere, Vol 18, №.2. Belo Horizonte, mar, 2015.

FINNE, E.; REINEHR, T; SCHAFER, A.; WINKEL, K.; KOLIP, P. Health-related quality of life in overweight German children and adolescents: do treatment-seeking youth have lower quality of life levels? Comparison of a clinical sample with the general population using a multilevel model approach. BMC Public Health, Vol.13, № 561, p.1-17, 2013.

FOGELHOLM, M. Physical activity, fitness and fatness: relations to mortality, morbidity and disease risk factors. A systematic review. Obesity reviews. Vol.11, № 3, p. 202$221,2010$.

FOUCAULT, M. Microfísica do Poder. Paz e Terra. Rio de Janeiro, 2014.

FREUD, S. Introdução ao Narcisismo: Ensaios de Metapsicologia e outros textos. Companhia das Letras. São Paulo, 2010A.

FREUD, Sigmund. O Mal-Estar na Civilização e Outros Textos. 1 Edição. São Paulo: Companhia das Letras, 26 de outubro de 2010B.

GAZZOL, K., PEZZINI, K., FAVARETTO, T. C., ANTUNES, C. L., GARCEZ, L. \& TEIXEIRA, C. R. O Desenvolvimento Humano ao Longo do Ciclo Vital. Psicologado, 2018.

GEERTZ, C. A Interpretação das Culturas. LTC. São Paulo, 1981.

GERTLER, P. J. MARTINEZ, S. PREMAND, P. RAWLINGS, L. B. VERMEERSCH, C. M. J. Avaliação de Impacto na prática. Grupo Banco Mundial. Washington D.C., 2015. 
GIACOMONI, C. H. \& HUTZ, C. S. Escala multidimensional de satisfação de vida para crianças: estudos de construção. Estudos psicológicos, Vol 25 no. 1, Campinas, Jan/Mar, 2008.

GIACOMONI, C. H., SOUZA, L. K. \& HUTZ, C. S. O conceito de felicidade em crianças. Psico-USF, v. 19, n. 1, p. 143-153. Bragança Paulista, 2014.

GILMAN, A. D. \& VOLPE, S. L. Physical Activity in the Prevention of Childhood Obesity. Pensar en Movimiento. Vol.16 no.2. San José, 2018.

GHIRALDHELLI JR., P. Educação Física Progressista: A pedagogia crítico-social dos conteúdos e a educação física brasileira. 10ำ Edição, Edições Loyola. São Paulo, 1991.

GHIRALDHELLI, P. \& RORTY, R. Ensaios Pragmatistas: sobre subjetividade e verdade. Editora DP\&A. São Paulo, 2006.

GIRON, J. Qualidade de Vida: o papel do estado nutricional e da percepção do relacionamento familiar de crianças do município de Indaiatuba/SP. Dissertação (Mestrado). Universidade de São Paulo, 2016.

GONÇALVES, R. B., FERREIRA, L. G., ASSUMPÇÃO, M. S. \& SCHIVINSKI, C. I. S. Impact of sports activities on respiratory function and mechanics in children. Fisioter. mov., Vol. 30, №. 3, p. 485-492. Curitiba, Sept, 2017.

GONÇALVES, A.; VILARTA, R. (org.). Qualidade de vida e atividade física: explorando teoria e prática. Manole. Barueri, 2004.

GRANDO, J. C. Sacralização do corpo: a educação física na formação da força de trabalho brasileira. Ed. da FURB. Blumenau, 1996.

GUATTARI, F. Caosmose: um novo paradigma estético. $2^{\circ}$ Edição. Editora 34 . São Paulo, 2012.

GRIMES, D. A., SCHULZ, K. F. Cohort studies: marching towards outcomes. Lancet, 359, 341-345, 2002. 
HADDAD, N. Metodologia de Estudos em Ciências da Saúde: como Planejar, Analisar e Apresentar um Trabalho Científico. Editora Roca, São Paulo, 2004.

HALLAL, P. C., BERTOLDI, A. D., GONÇALVES, H., VICTORA, C. G. Prevalence of sedentary lifestyle and associated factors in adolescents 10 to 12 years of age. Cadernos de Saúde Pública, 22:1277-87, 2006.

HAN, B-C. Sociedade do Cansaço. 2ํㅡㄹ Edição, Editora Vozes. Petrópolis, 2015.

HARDMAN, C. M., WANDERLEY JR, R. S., OLIVEIRA, E. S. A. \& BARROS, M. V. G. Relationship between physical activity and BMI with level of motor coordination performance in schoolchildren. Rev Bras Cineantropom Desempenho Hum, Vol.19, № 1, p. 50-61, 2017.

HOBSBAWM, Eric. A Era do Capital: 1848-1875. Edição Revista. Rio de Janeiro: Editora Paz e Terra, 31 de dezembro de 2012A.

HOBSBAWM, Eric. A Era dos Impérios: 1875-1914. Edição Revista. Rio de Janeiro: Editora Paz e Terra, 31 de dezembro de 2012B.

HOBSBAWM, E. Da Revolução Industrial Inglesa ao Imperialismo. 6ำ Edição. Forense Universitária. São Paulo, 2011.

HUMPHREYS, B. R., MCLEOD, L. \& RUSESKI, J. E. Physical activity and health outcomes: evidence from Canada. Health Econ. Vol. 23, №1, p. 33-54, 2014.

HUTZ, C. S. (Org.). Avaliação em psicologia positiva. Artmed. Porto Alegre, 2014. JUDT, T. Pós-Guerra: Uma História da Europa desde 1945. 1 Edição, Objetiva. São Paulo, 2008.

KAMITA, J. \& RODRIGUES, A. História Moderna: Os momentos fundadores da cultura ocidental. Editora Vozes. Rio de Janeiro, 2018.

KALINOSKI, A. X. et al. Núcleo Especial do Programa Segundo Tempo na Esef-Ufpel. Revista Brasileira de Atividade Física e Saúde, v.18, n.2, p.236-241, mar. Pelotas, 2013. 
KRAVCHYCHYN, C. \& OLIVEIRA, A. A. B. Projetos e programas sociais esportivos no brasil: uma revisão sistemática. Movimento, Vol. 21, № 4, p. 1051-1065. Porto Alegre, out./dez, 2015.

KÓVACS M.J., ANDRADE FILHO A.C.C. \& SGORLON A.C.L. Avaliação da qualidade de vida em pacientes oncológicos em estado avançado de doença. IN.: CARVALHO M.M.M.J. (org) Psico-Oncologia no Brasil: Resgatando o Viver. Summus. São Paulo, 1998.

KOZMA, A., STONE, S., STONES, M. J. Stability in components and predictors of subjective well-being (SWB): Implications for SWB structure. IN: DIENER, E., RAHTZ, D. R. Advances in quality of life theory and research. Kluwer Academic, 2000.

MINAYO, M. C. S.; HARTZ, Z. M. A., BUSS, P. M. Qualidade de Vida e Saúde: um debate necessário. Ciênc. Saúde Coletiva, vol.5, n.1, pp.7-18, 2000.

LACAN, J. Escritos. Editora Zahar. São Paulo, 1998.

LAZZOLI, J. K., NÓBREGA, A. C. L., CARVALHO, T., OLIVEIRA, M. A. B., TEIXEIRA, J. A. C., LEITÃO, M. B., LEITE, N., MEYER, F., DRUMMOND, F. A., PESSOAS, M. S. V., REZENDE, L., ROSE, E. H. BARBOSA, S. T., MAGNI, J. R. T., NAHAS, R. M., GLAYCON, M. \& MATSUDO, V. Atividade física e saúde na infância e adolescência. Rev Bras Med Esporte, Vol.4 № 4. Niterói, 1998.

LAZZOLI, J. K., NÓBREGA, A. C. L., CARVALHO, T., OLIVEIRA, M. A. B., TEIXEIRA, J. A. C., LEITÃO, M. B., LEITE, N., MEYER, F., DRUMMOND, F. A., PESSOAS, M. S. V., REZENDE, L., ROSE, E. H. BARBOSA, S. T., MAGNI, J. R. T., NAHAS, R. M., GLAYCON, M. \& MATSUDO, V. Treatment of pedriatric obesity. A systematic review and meta-analysis of randomized trials. The Journal of Clinical Endocrinology \& Metabolism, dez. 2008.

LE BRETON, D. Sociologia do Corpo. 6ํㅡㄹㅗão. Editora Vozes. Rio de Janeiro, 2012.

LEMES, D. C. M., CÂMARA, S. G., ALVES, G. G. \& AERTS, D. Satisfação com a imagem corporal e bem-estar subjetivo entre adolescentes escolares do ensino 
fundamental da rede pública estadual de Canoas/RS, Brasil. Ciênc. Saúde Coletiva. Vol.23 no.12. Rio de Janeiro, 2018.

LEWIN, K. Resolving Social Conflicts: And, Field Theory in Social Science. Amer Psychological Assn. Massachussets, 1997.

LIBANEO J. C. Educação Física Progressista. In: GHIRALDHELLI JR., P. Educação Física Progressista: A pedagogia crítico-social dos conteúdos e a educação física brasileira. 10 Edição. Edições Loyola. São Paulo, 1991.

LIMA, R. D., PEREIRA, R. M., MUÑOZ, V. R. CANCIGLIERI, R. S. \& CANCIGLIERI, P. H. Occurrence of overweight in schoolchildren and analysis of agreement between anthropometric methods. Rev. bras. cineantropom. desempenho hum., Vol. 22, № 67037. Florianópolis, 2020.

LIPOVETSKY, G. A Sociedade da Sedução: Democracia e Narcisismo na Hipermodernidade Global. Manole. São Paulo, 2019.

LYOTARD, J-F. A Condição pós-moderna. 17º Edição. Editora José Olympio. São Paulo, 1986.

MADRONA, P. G., VILLORA, S. G., JORDAN, O. R. C. \& BARRETO, I. C. Justificação de la educación física en la educación infantil. Educ Educ. Vol. 11, №. 2, p. 159-177. Chia, Dec. 2008.

MASLOW, A. H. Toward a psychology of Being. Wilder Publications. Radford, 2018.

MATTOS, D.C., SILVA, C. A. F., LOPES, J. P. S. R. \& CAPINUSSÚ, J. M. O esporte náutico e a dinâmica da hélice tríplice no projeto Grael: um estudo de caso. Movimento, Vol.16, №.3, p.221-239, jul./set. Porto Alegre, 2010.

MACHADO, G. V., ALMEIDA, R. S., CHANON, E. M. Q. O., PAES, R. R. A Análise da Evolução das Políticas Públicas em Esporte Educacional no Brasil. Revista Ciências Humanas - Educação e Desenvolvimento Humano - UNITAU. Vol. 10, № Extra, p. 103 - 115, Taubaté/SP, 2017. 
MCGOVERN, L., JOHNSON J. N., PAULO, R., HETTINGER, A., SINGHAL, V., KAMATH, C., ERWIN, P.J., MONTORI, V.M. Clinical review: treatment of pediatric obesity: a systematic review and meta-analysis of randomized trials. $\mathbf{J}$ Clin Endocrinol Metab. Vol. 93, № 12. setembro, 2008.

MELLO, E. D. O que significa a avaliação do Estado Nutricional. Jornal de Pediatria, v.78, n.5, p.357-358, 2002.

MENEZES FILHO, N. A. (org.) Avaliação Econômica de Projetos Sociais. Fundação Itaú Social. São Paulo - SP, 2015.

MENEZES; T. N. \& MARUCC, M. F. N. Valor energético total e contribuição percentual de calorias por macronutrientes da alimentação de idosos domiciliados em Fortaleza - CE. Rev. Assoc. Med. Bras., Vol.58, No.1. São Paulo, Jan./Feb. 2012.

MOLINA, R. M. K., SILVA, L. O. \& SILVEIRA, F. V. Celebração e transgressão: a representação do esporte na adolescência. Revista Brasileira de Educação Física e Esporte, Vol.18, №.2, p.125-36, abr./jun. São Paulo, 2004.

MONTEIRO, C. P., ALMEIDA, M. L. \& BUENO JR, C. R. Dance in the treatment of childhood obesity: a proposed protocol. Rev Bras Med Esporte, Vol.26 No.1 São Paulo, Jan./Feb. 2020.

MORIN, E. Rumo ao Abismo: Ensaio sobre o destino da Humanidade. Bertrand Brasil, São Paulo, 2011.

OMS. Organização Mundial da Saúde. Global recommendations on physical activity for health. 2010. 58p.

OMS. Organização Mundial da Saúde. Global action plan on physical activity 2018-2030: more active people for a healthier world. 2018. 104p.

OLIVEIRA, L. F. L. \& COSTA, C. R. B. Educação Física escolar e a Obesidade Infantil. Revista Científica Multidisciplinar Núcleo Do Conhecimento. Vol 1. № 10, São Paulo, 2016. 
OLIVEIRA, L. C., FERRARI, G. L. M., ARAUJO, T. L. \& MATSUDO, V. Overweight, obesity, steps, and moderate to vigorous physical activity in children. Rev. Saúde Pública, Vol. 51, № 38. São Paulo, 2017.

PADRÃO DOS SANTOS, A. L. Sociologia do Esporte: o Esporte Estudado Pelas Ciências Sociais. Revista Eletrônica do Cedoc/seme. Vol.3 - n.1, 2012.

PAIVA, C. R.; GAYA, A. C.; BOTTARO, M.; NETOR, J. T. Bioimpedância vs absortometria radiológica de dupla energia na avaliação da composição corporal em crianças. Revista Unimontes Científica, v.3, n.1, 2002.

PASQUALI, L. Psicometria teoria e aplicações: a teoria clássica dos testes psicológicos. Brasília: Ed. da UnB, 1997.

POETA, L. S., DUARTE, M. de F. \& GIULIANO, I. de C. Qualidade de vida relacionada à saúde de crianças obesas. Revista da Associação Médica Brasileira, vol. 56, p.168-172, 2010.

POETA, S. L.; DUARTE, M. F. S.; GIULIANO, I. C. B.; MOTA, J. Interdisciplinary intervention in obese children and impact on health and quality of life. J Pediatr, Rio de Janeiro, v.89, n.5, p.499-504, 2013.

POLANYI, K. \& STIGLITZ, J. A Grande Transformação. Edições 70, 2016.

POLETTO, M. Bem-Estar subjetivo: um estudo longitudinal com crianças e adolescentes em situação de vulnerabilidade social. Tese de Doutorado. Universidade Federal do Rio Grande do Sul, 2011.

Programa das Nações Unidas para o Desenvolvimento - PNUD. Instituto de Pesquisa Econômica Aplicada - IPEA \& Fundação João Pinheiro - FJP., 2012.

PRATT, J. K.; LAZORICK, S.; LAMSON, A.; IVANESCU, A.; COLLIER, D. N. Quality of life and $\mathrm{BMI}$ changes in youth participanting in na integrated pediatric obesity treatmente program. Health and Quality of Live Outcomes, v.11, n.116, p.2-9, 2013.

RAVENS-SIEBERER, U., REDEGELD, M. \& BULLINGER, M. Quality of life after inpatient rehabilitation in children with obesity. International Journal of Obesity, 25:635, 2001. 
REVERDITO, R. S., GALATTI, L. R. LIMA, L. A. NICOLAU, P. S., SCAGLIA, A. J., PAES, R. R. O programa segundo tempo em municípios brasileiros: indicadores de resultado no macrossistema. J. Phys. Educ. Vol. 27, № 2754, 2016.

ROGERS, C. Um Jeito de Ser. 1 Edição. E.P.U., São Paulo, 1986.

SAMPIERI, R. H., COLLADO, C. F., LUCIO, P. B. Metodologia de Pesquisa. 3. Ed. McGraw-Hill. São Paulo, 2006.

SEABRA, A. F., MENDONÇA, D. M., THOMIS, M. A., ANJOS, L. A. \& MAIA, J. A. Determinantes biológicos e sócio-culturais associados à prática de atividade física de adolescentes. Cad. Saúde Pública, Vol.24, No.4. Rio de Janeiro, Apr. 2008.

SCHEER, C., HELAL, L., FERRARI, F., BELÉM, L. J., FABIANO, L. C.C., PINHEIRO, L. T. \& STEIN, R. The Olympic Experimental Gymnasium Program and its Association with the Prevalence of Cardiovascular Risk Factors in Adolescents: A Cross-Sectional Study. Arq. Bras. Cardiol, Vol. 112, №. 6, p. 775-781, São Paulo, June, 2019.

SECCHI, L. Políticas públicas: conceitos, esquemas de análise, casos práticos. Cengage Learning, 2. Ed. São Paulo, 2013.

SELIGMAN, M. E. P. \& CSIKSZENTMIHALYI, M. Positive Psychology: Na Introduction. American Psychology, 55, 5-14, 2000.

SHAW, K., GENNAT, H., O'ROURKE, P. \& DEL MAR, C. Exercise for overweight or obesity. The Cochrane database of systematic reviews. Vol. 18, № 4. Oct, 2006.

SILVA, J. B., SILVA, F. G. S., MEDEIROS, H. J., ROCANLLI, A. G. \& KNACKFUSS, M. I. Estado Nutricional de Escolares do Semi-Árido do Nordeste Brasileiro. Revista de Salud Pública, Bogotá, v.11, n.1, p.62-71, 2009.

SILVA, J. G., TEIXEIRA, M. L. O. \& FERREIRA, M. A. Alimentação na adolescência e as relações com a saúde do adolescente. Texto contexto - enferm., Vol. 23, №. 4, p. 1095-1103. Florianópolis, Dec. 2014.

SIQUEIRA, P. P.; ALVES, J. G.; FIGUEIRO, A. J. N. Fatores associados ao excesso de peso em crianças de uma favela do Nordeste brasileiro. Revista Paulista de Pediatria, v.27, n.3, p.251-257, 2009. 
SIQUEIRA, M. M. M. \& PADOVAM, V. A. R. Bases teóricas de bem-estar subjetivo, bem-estar psicológico e bem-estar no trabalho Psic.: Teor. e Pesq. Vol.24, No.2. Brasília, Apr./June 2008.

SOARES, C.L. Educação Física: raízes europeias e Brasil. 3ํeição. Campinas: Autores Associados, 2004.

SOUZA, C. M.C. \& KUCZYNSKI, E. Qualidade de Vida na Infância e Adolescência. IN: ASSUMPÇÃO JR., F. B. KUCZYNSKI, E. Tratado de Psiquiatria da infância e adolescência. 3ํㅡㄹ Edição, Editora Atheneu. Rio de Janeiro, 2018.

STEIL, B. The Marshall Plan: Dawn of the Cold War. Simon \& Schuster. Nova Iorque, 2019.

TRIGO, L. G. G. Introdução. IN: BETTINE, M., GUTIERREZ, G. \& MARQUES, R. Qualidade de Vida: definição, conceitos e interfaces com outras áreas de pesquisa. Edições EACH/USP, São Paulo, 2019.

TURCO, G.; BOBBIO, T.; REIMÃO, R.; ROSSINI, S.; PEREIRA, H.; FILHO, A. B. Quality of life and sleep in obese adolescents. Arq Neuropsiquiatr, v.71, n.2, p.7882, 2013.

VAITSMANI, J., ANDRADE, J. R. B. Satisfação e responsividade: formas de medir a qualidade e a humanização da assistência à saúde. Ciênc. saúde Coletiva, vol.10, no.3. Rio de Janeiro July/Sept, 2005.

VERONEZ, L. F. C. Quando o Estado joga a favor do privado: As políticas de esporte a partir da Constituição de 88. Tese de Doutorado: Universidade Estadual de Campinas, Campinas, 2005.

WANDERLEY, E. N. \& FERREIRA, V. A. Obesidade: uma perspectiva plural. Ciênc. saúde coletiva. Vol.15, No.1. Rio de Janeiro, Jan., 2010.

WEINBERG, R. S. \& GOULD, D. Fundamentos da psicologia do esporte e do exercício. Porto Alegre. Artmed, 2001.

WERNECK, F. Z. \& NAVARRO, C. A. Nível de atividade física e estado de humor em adolescentes. Psic.: Teor. e Pesq. Vol.27 No.2. Brasília, Apr./June 2011. 
WHOQOL GROUP. The World Health Organization Quality of Life Assessment: Potion paper from the World Health Organization. Special Issue "Quality of Life". In: Social Science and Medicine, 1995.

WINNICOTT, D. W. A Família e o desenvolvimento individual. 4 Edição, Martins Fontes. São Paulo, 2011.

WOOLDRIDGE, J. M. Introdução à Econometria: uma Abordagem Moderna. São. Paulo: Cengage Learning, 2011.

World Health Organization - WHO. Global strategy on diet, physical activity and health: childhood overweight and obesity. Geneva, 2014.

WOYCIEKOSKI, C., NATIVIDADE, J. C. \& HUTZ, C. S. As contribuições da personalidade e dos eventos de vida para o bem-estar subjetivo. Psic.: Teor. e Pesq. Vol.30 no.4. Brasília, 2014.

ZHAO, G., FORD, E. L. C. \& MOKDAD, A. Compliance with physical activity recommendations in US adults with diabetes. Diabetic medicine: a journal of the British Diabetic Association. Vol 25, № 2, p. 221-7. 2008. 
ANEXOS

ANEXO 1 - TEMAS TRANSVERSAIS DAS AULAS DO PROJETO ESPORTE CIDADÃO - INDAIATUBA/SP - ANO 2019 
TEMAS TRANSVERSAIS - 2019

\begin{tabular}{|c|c|c|c|c|c|c|c|c|c|c|}
\hline $\begin{array}{c}\text { SEMAN } \\
\text { A }\end{array}$ & FEVEREIRO & MARÇO & ABRIL & MAIO & JUNHO & JULHO & AGOSTO & $\begin{array}{c}\text { SETEMBR } \\
0\end{array}$ & OUTUBRO & $\begin{array}{c}\text { NOVEMBR } \\
0\end{array}$ \\
\hline & $\begin{array}{l}\text { PLURALIDAD } \\
\text { E CULTURAL }\end{array}$ & $\begin{array}{c}\text { MEIO } \\
\text { AMBIENTE }\end{array}$ & $\begin{array}{l}\text { TRABALH } \\
\text { OE } \\
\text { CONSUMO }\end{array}$ & ÉTICA & SAÚDE & SAÚDE & ESPORTE & ÉTICA & $\begin{array}{l}\text { TRABALHO E } \\
\text { CONSUMO }\end{array}$ & ESPORTE \\
\hline $\begin{array}{c}1^{\mathrm{a}} \\
\text { semana }\end{array}$ & & $\begin{array}{c}\text { 1-Despertar } \\
\text { a } \\
\text { consciência } \\
\text { ecológica }\end{array}$ & $\begin{array}{c}\text { 1-Consumo } \\
\text { Meios de } \\
\text { comunicaçã } \\
0\end{array}$ & $\begin{array}{c}\text { 1-Ganhar e } \\
\text { perder: } \\
\text { Bens de } \\
\text { consumo }\end{array}$ & $\begin{array}{l}\text { 1-Saúde } \\
\text { Higiene }\end{array}$ & $\begin{array}{c}5 \text { - } \\
\text { Alimentaçã } \\
\text { o saudável }\end{array}$ & & $\begin{array}{l}\text { 5-Civismo } \\
\text { Hino } \\
\text { nacional } \\
\text { Bandeira }\end{array}$ & $\begin{array}{l}\text { 5-Essencial } \\
\text { Supérfluo } \\
\text { Exagero }\end{array}$ & $\begin{array}{l}\text { 4-Valores no } \\
\text { Esporte: } \\
\text { Respeitar as } \\
\text { diferenças. }\end{array}$ \\
\hline $\begin{array}{c}2^{\mathrm{a}} \\
\text { semana }\end{array}$ & $\begin{array}{l}\text { 1-Origem } \\
\text { cultural de } \\
\text { brincadeiras e } \\
\text { brinquedos. } \\
\text { Musicalidade } \\
\text { e atividade } \\
\text { física }\end{array}$ & $\begin{array}{l}\text { 2-Material } \\
\text { reciclável }\end{array}$ & $\begin{array}{c}\text { 2-Relações } \\
\text { de Trabalho } \\
\text { Profissão }\end{array}$ & $\begin{array}{l}\text { 2-Ganhar e } \\
\text { perder: } \\
\text { Entes } \\
\text { queridos }\end{array}$ & $\begin{array}{l}2 \text { - Doenças de } \\
\text { inverno }\end{array}$ & & $\begin{array}{l}\text { 1-Valores no } \\
\text { Esporte: } \\
\text { Boas vindas } \\
\text { ao novos } \\
\text { alunos. } \\
\text { Regras e } \\
\text { Combinados }\end{array}$ & $\begin{array}{l}\text { 6-Respeito } \\
\text { Harmonia } \\
\text { Convivênci } \\
\text { a pacífica }\end{array}$ & $\begin{array}{l}\text { 6-Esporte e } \\
\text { Trabalho } \\
\text { infantil }\end{array}$ & $\begin{array}{l}\text { 5-Esporte } \\
\text { como } \\
\text { profissão }\end{array}$ \\
\hline $\begin{array}{c}3^{\mathrm{a}} \\
\text { semana }\end{array}$ & $\begin{array}{l}\text { 2-Boas vindas } \\
\text { aos novos } \\
\text { alunos. } \\
\text { Regras e } \\
\text { combinados. }\end{array}$ & $\begin{array}{l}\text { 3- } \\
\text { Correspons } \\
\text { a-bilidade } \\
\text { Perspectiva } \\
\text { s futuras }\end{array}$ & $\begin{array}{l}\text { 3-Poder } \\
\text { aquisitivo }\end{array}$ & $\begin{array}{l}\text { 3-Ganhar e } \\
\text { perder: } \\
\text { Tolerância } \\
\text { aos } \\
\text { resultados }\end{array}$ & $\begin{array}{c}3 \text {-Transmissão } \\
\text { e Prevenção } \\
\text { Vacinação }\end{array}$ & & $\begin{array}{c}\text { 2-Trabalho e } \\
\text { Esporte/Laz } \\
\text { er } \\
\text { O que fazer } \\
\text { no meu } \\
\text { tempo livre }\end{array}$ & $\begin{array}{l}\text { 7-Certo e } \\
\text { Errado }\end{array}$ & $\begin{array}{l}\text { 7-Consumo } \\
\text { Conciente }\end{array}$ & $\begin{array}{c}\text { 6-Valores do } \\
\text { Esporte: } \\
\text { Determinaçã } \\
\text { o }\end{array}$ \\
\hline $\begin{array}{c}4^{\mathrm{a}} \\
\text { semana }\end{array}$ & $\begin{array}{l}\text { 3-Habilidades } \\
\text { e diferenças } \\
\text { físicas }\end{array}$ & $\begin{array}{l}\text { 4-Praças e } \\
\text { parques } \\
\text { como } \\
\text { espaços } \\
\text { para } \\
\text { atividade } \\
\text { física }\end{array}$ & $\begin{array}{c}\text { 4- } \\
\text { Autonomia } \\
\text { Auxilio nas } \\
\text { tarefas } \\
\text { domésticas }\end{array}$ & $\begin{array}{c}\text { 4-Fair Play } \\
\text { Pontualidad } \\
e \\
\text { Participação } \\
\text { Compromiss } \\
0\end{array}$ & $\begin{array}{c}\text { 4- Higiene: } \\
\text { Doenças } \\
\text { infectocontagios } \\
\text { as }\end{array}$ & & $\begin{array}{l}\text { 3- } \\
\text { Diversidade } \\
\text { Esportiva e } \\
\text { Esporte } \\
\text { regionais }\end{array}$ & $\begin{array}{l}\text { 8-Vitória e } \\
\text { Derrota no } \\
\text { Esporte }\end{array}$ & $\begin{array}{c}\text { 8-Educação } \\
\text { financeiraxgas } \\
\text { to calóricox } \\
\text { sustentabilida } \\
\text { de }\end{array}$ & $\begin{array}{l}\text { 7-Atitude } \\
\text { Antidesporti } \\
\text { va }\end{array}$ \\
\hline
\end{tabular}

\section{PLURALIDADE CULTURAL}

Conhecimento sobre a origem cultural de brincadeiras e brinquedos que utilizamos até os dias de hoje.

1- Conscientizar sobre a importância de manifestações culturais e identidade regional. Reconhecer os tipos de músicas e as regiões de onde vêm, dissiminar a cultura popular brasileira por meio da aquisição de conhecimento específico. Investigar sobre os esportes criados no Brasil e ampliar a visão de mundo, estimulando a descoberta e valorização da cultura brasileira

Apresentar o conteúdo cultural do lazer como forma de diversificar as possibilidades de ocupação do tempo livre.

2- $\quad$ Organizar atividades lúdicas de forma individual e coletiva, como busca de prazer, participação, cooperação e contemplação de momenos felizes. Atividades para o grupo se conhecer.

3- $\quad$ Mostragem de diferenças e semelhanças nas características físicas e habilidades motoras

\begin{tabular}{|c|l|}
\hline \multicolumn{2}{|c|}{ MEIO AMBIENTE } \\
\hline $1-$ & $\begin{array}{l}\text { Reaproveitamento de materiais esportivos, uso consciente de recursos. Sensibilizar para a preservação e consumo } \\
\text { consciente dos recursos. }\end{array}$ \\
\hline $2-$ & $\begin{array}{l}\text { Entender quais materiais podem ser reciclados; conhecer o sistema de cores da reciclagem para poder jogar o lixo } \\
\text { corretamente }\end{array}$ \\
\hline $3-$ & $\begin{array}{l}\text { Promover a discussão sobre a corresponsabilidade da preservação do meio ambiente para hoje e para o futuro, } \\
\text { respeitando o ambiente que vivo e a qualidade de vida que quero para mim no ambiente que vivo. Restaurar ou } \\
\text { transformar. Na natureza nada se cria, nada se perde, tudo se transforma (Lavoisier). Levar os alunos à reflexão do } \\
\text { uso não conciente dos recursos naturais. }\end{array}$ \\
\hline $4-$ & $\begin{array}{l}\text { Conhecimento sobre esportes praticados nos espaços e prevenção desses ambientes, estimulando os alunos a } \\
\text { praticarem esportes ao ar livre. }\end{array}$ \\
\hline
\end{tabular}

\section{TRABALHO E CONSUMO}

1- $\quad$ Como os meios de comunicação nos estímulam a querer mais e ter mais. Isso é saudável?

2- $\quad$ Linha de produção, em que se trabalhará o indivíduo como unidade fundamental do grupo para a execução de um objetivo. Aprender a receber uma ordem e perceber a importância de executá-la em prol do grupo.

3- $\quad$ Conhecimento sobre o que é essencial e o que é supérfluo ou exagero. Sensibilizar os alunos de que não precisamos possuir muitos bens para satisfazer nossas necessidades e que podemos dividir o que temos

4- $\quad$ O que podemos aprender no esporte para nossa vida pessoal e profissional. Perceber a importância do esportes para nossa vida e o quão é importante auxiliar nas tarefas de casa.

5- $\quad$ Conceito de valores. Diferença entre essencial e supérfluo, conceito de valores. Valores essenciais para a nossa vida, nem sempre são os que pagamos 
Conhecimento sobre os direitos e deveres da criança em relação a infância. Conscientizar as crianças sobre a

6- $\quad$ importância de se ter uma infância sadia e do seu papel na sociedade, bem como da importância do brincar e de como isso reflete no seu desenvolvimento.

7- $\quad$ Concientizar sobre a diferença entre necessidade e desejo. Compreender que os excessos são desnecessários e compartilhar quando há falta

8- Compreender e discutir a relação com o dinheiro com base na educação financeira, buscando refletir o quanto possui, do que realmente precisa e o que podemos adquirir. Estabelecer um paralelo de economia entre o que se consome, o que se gasta de energia e o lixo que produzimos.

\begin{tabular}{|c|c|}
\hline \multicolumn{2}{|r|}{ ÉTICA } \\
\hline 1 & Ganhar presentes, doar roupas e brinquedos. Perder emprego, mudar de casa, cidade. Ter algo furtado \\
\hline 2 & Perder alguém muito próximo (pais, irmão, avós, amigos). Término de namoro, separação de pais. \\
\hline 3 & $\begin{array}{l}\text { Exercitar a tolerância aos resultados de jovos esportivos e situações que refletem experiência de vida. Estabelecer } \\
\text { relações positivas consigo e com os outros mediante resultados negativos, causados pelas derrotas. }\end{array}$ \\
\hline 4 & $\begin{array}{l}\text { Jogo limpo; aprender a ganhar e respeitar o adversário, afinal precisa-se de alguém para poder ter uma disputa. } \\
\text { Respeitar horário, comprometimento na participação das aulas/encontros e festivais. }\end{array}$ \\
\hline 5 & $\begin{array}{l}\text { Civismo. Compreensão de repeito a cidadania . Conhecimento sobre bandeira, hino nacional, postura e respeito } \\
\text { durante a execução do hino }\end{array}$ \\
\hline 6 & $\begin{array}{l}\text { Vivenciar formas de relacionamentos baseadas na ética, respeito, harmonia, transparência e na convivência } \\
\text { pacífica. Proporcionar um espaço de reflexão sobre a real possibilidade de (re)conhecer e analisar a onda de } \\
\text { violência. }\end{array}$ \\
\hline 7 & $\begin{array}{l}\text { Incutir nos alunos a diferença entre atitudes certas e erradas. Reconhecer uma ação boa ou ruim de uma cadeia de } \\
\text { acontecimentos. }\end{array}$ \\
\hline 8 & $\begin{array}{l}\text { Conhecimento sobre as consequências da vitória e derrota no mundo esportivo. Conscientizar os alunos sobre a } \\
\text { importância de se respeitar os limites de cada um, sobre o conceito do jogo e sobre como nos comportar diante da } \\
\text { vitória e da derrota }\end{array}$ \\
\hline \multicolumn{2}{|r|}{ SAÚDE } \\
\hline $1-$ & Conhecimento sobre condutas básicas: banho, escovar dentes, cuidar do cabelo, unhas, usar desodorante, etc. \\
\hline 2- & Doenças relacionados ao frio: resfriados, dores de garganta, ouvido, etc. \\
\hline 3- & $\begin{array}{l}\text { Manter as vacinas em dias, salas bem ventiladas, evitar ambientes fechados com muitas pessoas, tomar água, usar } \\
\text { alcool em gel, lavar as mãos diversas vezes ao dia, espirrar colando o "braço na frente" }\end{array}$ \\
\hline 4- & $\begin{array}{l}\text { Compreender os mecanismos de transmissão de doenças contagiosas e prevenir contaminação de si e de outro. } \\
\text { Incorporar hábitos diários de higiene para evitar a transmissão de doenças em ambientes educaconais. }\end{array}$ \\
\hline $5-$ & $\begin{array}{l}\text { A vida moderna e a obesidade; pesquisas científicas e estudos sobre o crescimento de jovens vítimas da obesidade } \\
\text { e suas complicações. Sensibilizar os alunos para a adoção de um estilo de vida mais saudável. Alimentos } \\
\text { orgânicos, industrializados, processados, embutidos. Saúdáveis ou Perigosos para a saúde }\end{array}$ \\
\hline
\end{tabular}

\section{ESPORTE}

1- $\quad$ Atividades para o grupo se conhecer. Conhecimento sobre as possibilidades de práticas de lazer. Estimular os alunos a vivenciar atividades físicas, jogos e brincadeiras no tempo de lazer.

2- $\quad$ Compreender o lazer como um momento de livre escolha para a realização de atividades de diversão que proporcionem prazer, com ênfase às atividades físicas. Optar pela realização de atividades físicas como lazer.

- Conhecimento sobre as diversas modalidades esportivas, coletivas individuais; espaços e acessórios para a prática.

3- $\quad$ Estimular os alunos a vivenciar diferentes práticas lúdicas com referências esportivas. Esportes praticados em diferentes regiões do pais, ou esportes característico de outro pais.

4- $\quad$ Conhecimento sobre pessoas portadores de deficiências e a prática da atividades física. Desenvolver nos alunos o sentimento de respeito a pessoa com deficiência.

5- $\quad$ Possibilitar a percepção nas diferentes estruturas do esporte, com componentes de uma aula de trein. normal voltada para o esporte escolhido.

6- $\quad$ Incutir nos alunos a ideia de que a persistencia deve ser considerada como estímulo para a realização de tarefas.

7- $\quad$ Falsificação de documentos de atletas em evento esportivos. Agressões físicas. Dopping. Sensibilizar os alunos para tenham um olhar mais crício em relação a atitudes ilegais em troca de títulos e vitórias 
ANEXO 2 - ESCALA MULTIDIMENSIONAL DE SATISFAÇÃO COM A VIDA INFANTIL / EMSVI 
Marque um $\mathbf{X}$ nas colunas ao lado o quanto você concorda com o que a frase diz. Se você concordar nem um pouco, marque (1); se concordar um pouco, marque (2); se concordar mais ou menos, marque (3); se concordar bastante, marque (4) e se concordar muitíssimo, marque (5).

\begin{tabular}{|c|c|c|c|c|c|c|}
\hline & \multirow{2}{*}{$\begin{array}{c}\begin{array}{c}\mathrm{Nem} \\
\text { um } \\
\text { pouco }\end{array} \\
1\end{array}$} & \multirow{2}{*}{\begin{tabular}{|c|}
$\begin{array}{c}\text { Um } \\
\text { pouco }\end{array}$ \\
2 \\
\end{tabular}} & \multirow{2}{*}{$\begin{array}{c}\text { Mais ou } \\
\text { menos }\end{array}$} & \multirow{2}{*}{\begin{tabular}{|c|} 
Bastante \\
4 \\
\end{tabular}} & \multirow{2}{*}{\begin{tabular}{|c|} 
Muitíssimo \\
5 \\
\end{tabular}} \\
\hline & & & & & & \\
\hline 1 & 1 Eu sou uma pessoa bem humorada. & & & & & \\
\hline 2 & 2 Minha família gosta de mim. & & & & & \\
\hline 3 & $\begin{array}{l}\text { As outras crianças são mais alegres do } \\
\text { que eu. }\end{array}$ & & & & & \\
\hline 4 & Eu sorrio bastante. & & & & & \\
\hline 5 & $\begin{array}{l}\text { Meus amigos são mais alegres do que } \\
\text { eu. }\end{array}$ & & & & & \\
\hline 6 & o Eu me sinto calmo(a), tranquilo(a). & & & & & \\
\hline 7 & Minha família me faz feliz. & & & & & \\
\hline 8 & B Eu sou divertido(a). & & & & & \\
\hline 9 & $\begin{array}{l}\text { Meus amigos ganham mais presentes } \\
\text { do que eu. }\end{array}$ & & & & & \\
\hline 10 & $\begin{array}{l}\text { Procuro fazer coisas que me deixam } \\
\text { feliz. }\end{array}$ & & & & & \\
\hline 11 & 1 Brigo muito com meus amigos. & & & & & \\
\hline 12 & $\begin{array}{l}\text { Eu me divirto com as coisas que eu } \\
2 \text { tenho. }\end{array}$ & & & & & \\
\hline 13 & $\begin{array}{l}\text { Os membros da minha família se dão } \\
\text { bem. }\end{array}$ & & & & & \\
\hline 14 & $\begin{array}{l}\text { Meus amigos me ajudam quando eu } \\
\text { preciso. }\end{array}$ & & & & & \\
\hline
\end{tabular}




\begin{tabular}{|c|c|c|c|c|c|c|}
\hline & \multirow{2}{*}{$\begin{array}{c}\begin{array}{c}\text { Nem um } \\
\text { pouco }\end{array} \\
1 \\
\end{array}$} & \multirow{2}{*}{\begin{tabular}{|c|} 
Um \\
pouco
\end{tabular}} & \multirow{2}{*}{$\begin{array}{c}\begin{array}{c}\text { Mais ou } \\
\text { menos }\end{array} \\
3 \\
\end{array}$} & \multirow{2}{*}{$\begin{array}{c}\text { Bastante } \\
4\end{array}$} & \multirow{2}{*}{$\begin{array}{c}\text { Muitíssimo } \\
5\end{array}$} \\
\hline & & & & & & \\
\hline 15 & Meus amigos podem fazer mais coisas do que eu. & & & & & \\
\hline 16 & Meus pais são carinhosos comigo. & & & & & \\
\hline 17 & Eu sou alegre. & & & & & \\
\hline 18 & Minha família me ajuda quando preciso. & & & & & \\
\hline 19 & $\begin{array}{l}\text { Eu gostaria que meus amigos fossem } \\
\text { diferentes. }\end{array}$ & & & & & \\
\hline 20 & Sempre encontro ajuda quando preciso. & & & & & \\
\hline 21 & Gosto de brigas. & & & & & \\
\hline 22 & Tenho pessoas que me ajudam. & & & & & \\
\hline 23 & $\begin{array}{l}\text { Eu me relaciono bem com meus } \\
\text { colegas. }\end{array}$ & & & & & \\
\hline 24 & Eu gosto de ir à escola. & & & & & \\
\hline 25 & $\begin{array}{l}\text { Meus amigos se divertem mais do que } \\
\text { eu. }\end{array}$ & & & & & \\
\hline 26 & Eu me divirto com muitas coisas. & & & & & \\
\hline 27 & É bom brincar com meus amigos. & & & & & \\
\hline 28 & Eu sou esperto(a). & & & & & \\
\hline 29 & Eu me divirto com a minha família. & & & & & \\
\hline 30 & Eu gosto de ajudar as pessoas. & & & & & \\
\hline 31 & Eu sou uma pessoa carinhosa. & & & & & \\
\hline 32 & Preciso receber mais atenção. & & & & & \\
\hline 33 & $\begin{array}{l}\text { Eu fico feliz quando a minha família se } \\
\text { reúne. }\end{array}$ & & & & & \\
\hline 34 & Meus amigos brigam muito comigo. & & & & & \\
\hline
\end{tabular}




\begin{tabular}{|c|c|c|c|c|c|c|}
\hline & & $\begin{array}{l}\text { Nem um } \\
\text { pouco }\end{array}$ & $\begin{array}{c}\text { Um } \\
\text { pouco }\end{array}$ & $\begin{array}{l}\text { Mais ou } \\
\text { menos }\end{array}$ & Bastante & Muitíssimo \\
\hline & & 1 & 2 & 3 & 4 & 5 \\
\hline 35 & $\begin{array}{l}\text { Estou satisfeito(a) com os amigos que } \\
\text { tenho. }\end{array}$ & & & & & \\
\hline 36 & Mantenho a calma. & & & & & \\
\hline 37 & Eu me divirto na escola. & & & & & \\
\hline 38 & Meus professores gostam de mim. & & & & & \\
\hline 39 & Eu me divirto com meus amigos. & & & & & \\
\hline 40 & Tenho facilidade para fazer amigos. & & & & & \\
\hline 41 & Eu me sinto bem na minha escola. & & & & & \\
\hline 42 & Meus amigos gostam de mim. & & & & & \\
\hline 43 & Brigar resolve os problemas. & & & & & \\
\hline 44 & $\begin{array}{l}\text { Gostaria que minha família fosse } \\
\text { diferente. }\end{array}$ & & & & & \\
\hline 45 & Eu gosto das atividades da escola. & & & & & \\
\hline 46 & Meus amigos brincam mais do que eu. & & & & & \\
\hline 47 & Sou irritado(a). & & & & & \\
\hline 48 & Eu aprendo muitas coisas na escola. & & & & & \\
\hline 49 & $\begin{array}{l}\text { As outras crianças têm mais amigos do } \\
\text { que eu. }\end{array}$ & & & & & \\
\hline 50 & Gosto de conversar com meus amigos. & & & & & \\
\hline
\end{tabular}


ANEXO 3 - QUESTIONÁRIO SÓCIOECONÔMICO E DEMOGRÁFICO 


\section{1) Informações do Responsável Legal}

Nome do responsável:

Seu grau de parentesco com o aluno (ex.: pai, mãe, avós, tios etc.)

Sexo: ( ) M ( ) F

Data de Nascimento do Responsável:

Bairro: E-mail ou Celular:

\section{2) Seu Estado Civil é:}
( ) Solteiro(a)
( ) Separado(a)/Divorciado(a)
( ) Casado(a) ou vivendo com
( ) Viúvo(a) companheiro(a)

\section{3) No trabalho principal, o(a) chefe da família é:}

( ) Empregado assalariado / Regime CLT;

( ) Empregado assalariado sem carteira assinada;

( ) Funcionário público concursado;

( ) Empregado que ganha por produção (comissão);

( ) Autônomo, trabalha por conta própria;

( ) Empregador, dono de negócio;
( ) Trabalha em casa ou em negócio familiar, sem remuneração;

( ) Presta Serviço Militar obrigatório, assistencial ou religioso, com remuneração;

( ) Estou desempregado;

( ) Sou aposentado (a) ou pensionista;

( ) Não trabalho;

( ) Do lar.

\section{4) Qual é a Renda Mensal da FAMILIA do ALUNO:}

( ) até $R \$ 937,00$;

( ) entre $R \$ 937,00$ e $R \$ 1.874,00$;

( ) entre $R \$ 1.874,00$ e $R \$ 3.748,00$;

( ) entre $R \$ 3.748,00$ e $R \$ 5.622,00$;

( ) entre $R \$ 5.622,00$ e $R \$ 7.496,00$;

( ) acima de $\mathrm{R} \$ 7.496,00$. 
5) Quantas pessoas (contando com você) VIVEM da renda familiar do ALUNO ?

6) Quantos destes itens abaixo existem do domicílio do ALUNO:

\begin{tabular}{|l|l|l|l|}
\hline \multicolumn{1}{|c|}{ Item } & Quantidade & \multicolumn{1}{|c|}{ Item } & Quantidade \\
\hline Banheiro & & Máquina de lava LOUÇA & \\
\hline Computador & & Secadora de roupa & \\
\hline Micro-ondas & & Empregada doméstica mensalista & \\
\hline Geladeira & & Automóvel & \\
\hline Freezer & Moto & \\
\hline Máquina de lavar ROUPA & & Aparelho de DVD & \\
\hline
\end{tabular}

7) Na moradia do ALUNO tem:
a) - Água encanada ( ) SIM ( ) NÃO
b) - Rua pavimentada ( ) SIM （）NÃO

8) Qual o grau máximo de escolaridade do(a) chefe da família do ALUNO?

\begin{tabular}{|c|c|c|c|}
\hline ( ) Analfabeto & ( ) $1^{\text {a }}$ série & ( ) $2^{\mathrm{a}}$ série & ( ) 3 $3^{\mathrm{a}}$ série \\
\hline ( ) $4^{a}$ série & ( ) $5^{\mathrm{a}}$ série & ( ) 6 $6^{\mathrm{a}}$ série & ( ) $7^{\text {a }}$ série \\
\hline ( ) 8 $8^{a}$ série & ( ) 1으o (Ensino Médio) & ( ) 2ํAno (Ensino Médio) & \\
\hline ( ) 3o Ano (Ensino Médio) & ( ) Ensino técnico & ( ) Superior Incompleto & \\
\hline ( ) Superior Completo & \multicolumn{3}{|c|}{ ( ) Pós-Graduação (completa ou não) } \\
\hline
\end{tabular}

9) Em relação à cor da pele, você se considera:

( ) Branco ( ) Pardo ( ) Negro ( ) Amarelo (oriental) ( ) Vermelho (indígena) 
ANEXO 4 - TERMO DE CONSENTIMENTO LIVRE E ESCLARECIDO - TCLE 


\title{
CONVITE E TERMO DE CONSENTIMENTO LIVRE E ESCLARECIDO - TCLE
}

\author{
Avaliação de Impacto do PROJETO ESPORTE CIDADÃO - Indaiatuba e \\ Americana/SP
}

\begin{abstract}
Esta pesquisa tem por objetivo avaliar o impacto que o Projeto Esporte Cidadão do município de Indaiatuba tem na vida das crianças e adolescentes que participam dele. Para tanto, serão feitas comparações entre crianças e adolescentes que participam do projeto (munícipes de Indaiatuba/SP) e crianças e adolescentes que não participam (munícipes de Americana/SP). Serão coletadas informações sobre: Aspectos Socioeconômicos e Demográficos; Satisfação com a Vida e Estado Nutricional (peso e altura do aluno). Este projeto apresenta risco mínimo e será acompanhado pelos professores e conduzido por profissionais treinados, que fornecerão todos os esclarecimentos necessários.

Cabe ressaltar que a participação é voluntária, não havendo qualquer penalidade ou custo no caso de recusa a esse convite, ou interrupção da participação a qualquer momento. A participação não terá nenhuma compensação financeira, nem previsão de indenização por danos. Todas as informações serão tratadas de modo confidencial, e os resultados coletados serão utilizados apenas para fins acadêmicos, sempre sem a identificação dos participantes.
\end{abstract}

Professores Responsáveis

Profa. Dra. Denise Cavallini Cyrillo (PRONUT-FEA/USP)
Pesquisadora Responsável

Msc. Jemima Giron (Psicóloga - PRONUT-USP)

\section{DECLARAÇÃO DO RESPONSÁVEL LEGAL DO PARTICIPANTE}

$\mathrm{Eu}$, responsável pelo menor

fui informado(a) dos objetivos da pesquisa de maneira clara e detalhada, e esclareci minhas dúvidas. Sei que em qualquer momento poderei solicitar novas informações e modificar minha decisão, se assim o desejar. Estou ciente de que todos os dados desta pesquisa serão confidenciais.

Em caso de dúvidas poderei entrar em contato com qualquer um dos pesquisadores ou com a Coordenadora do Projeto, Profa. Dra. Denise C. Cyrillo (11) 3091-5898, ou ainda com Comitê de Ética em Pesquisa da Faculdade de Ciência Farmacêuticas da Universidade de São Paulo.

Declaro que, após convenientemente esclarecido(a) e ter entendido o que me foi explicado, aceito o convite e consinto a participação do menor acima citado, se for de seu desejo, na referida pesquisa.

São Paulo, de 20 
ANEXO 5 - TERMO DE ASSENTIMENTO LIVRE E ESCLARECIDO - TALE 


\section{CONVITE E TERMO DE ASSENTIMENTO LIVRE E ESCLARECIDO - TCLE}

\section{Avaliação de Impacto do PROJETO ESPORTE CIDADÃO - Indaiatuba e Americana/SP}

Esta pesquisa tem por objetivo avaliar o impacto que o Projeto Esporte Cidadão do município de Indaiatuba tem na vida das crianças e adolescentes que participam dele. Para tanto, serão feitas comparações entre crianças e adolescentes que participam do projeto (moradores de Indaiatuba/SP) e crianças e adolescentes que não participam (moradores de Americana/SP). Você será convidado a preencher um questionário sobre Satisfação com a Vida e terá seu peso e altura medidos por seu professor.

Sua participação é VOLUNTÁRIA, você pode aceitar ou não participar desta pesquisa e não haverá nenhuma punição caso você não queira participar ou queira interromper sua participação a qualquer momento. Sua participação não terá nenhuma compensação financeira, nem previsão de indenização por danos. Todas as informações serão sigilosas. Este projeto apresenta risco mínimo e será acompanhado pelos professores e conduzido por profissionais treinados, que fornecerão todos os esclarecimentos necessários.

\section{Professores Responsáveis}

Profa. Dra. Denise Cavallini Cyrillo (PRONUT-FEA/USP)

\section{Pesquisadora Responsável}

Msc. Jemima Giron (Psicóloga - PRONUTUSP)

\section{DECLARAÇÃO DE ASSENTIMENTO DO PARTICIPANTE}

\section{$\mathrm{Eu}$,}

declaro que fui informado (a) dos objetivos da pesquisa de maneira clara e detalhada, e esclareci minhas dúvidas. Sei que em qualquer momento poderei solicitar novas informações e modificar minha decisão, se assim o desejar. Estou ciente de que todos os dados desta pesquisa serão confidenciais.

Sendo assim, eu aceito o convite e assinto minha participação na referida pesquisa.São Paulo, de 20 
ANEXO 6 - PARECER CONSUBSTANCIADO DO COMITÊ DE ÉTICA 


\section{USP - FACULDADE DE CIËNCIAS FARMACÉUTICAS DA UNIVERSIDADE DE SÂO}

\section{PARECER CONSUBSTANCIADO DO CEP}

\section{DADOS DO PROJETO DE PESQUISA}

Thtulo da Pocquica: Frojeto Esporte Cldadb: Avalaçbo de impacto de ums poiltes púbilca voltads ao esporte

Pecquicsdor: Denlae C Cyrlitio

Ares Tematios:

Vertso: 3

CAAE: T0473217.0.0000.0057

Inctitulgso Proponente: Faculdade de Ciencias Farmactisicas da Univerzidade de Sto Pasilo

Patrooinador Prinolpal: Fnanclamento Froprio

\section{DADOS DO PARECER}

Nümero do Parecer: 2.468 .512

Aprocentapso do Projoto:

Propbe-se aqul realzar um estudo quantsattivo nbo-erperimental, longltudnal, do tpo psinel e prospectivo com o objesvo de avalar o mpacto de uma poirtica pubilea voltada so esporte sobre o eetado nutricions e os aspectos emocionais de seus participantes. Para tal, a amoetra deste setudo serd composta por dois grupes: Orupo Participante (Grupo Caso) e Grupo NSo Participante (Or.po Controlel, tendo seu tamanho deteminado a patir de part metros de varabiliade extraidoe de estudo realizado en $201 / 22015$ na mezma

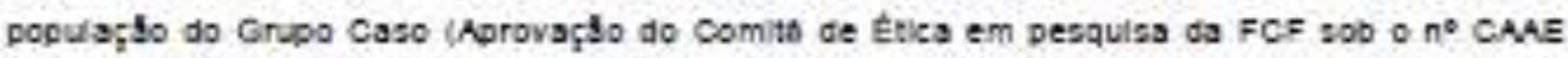
34222914.3.0000.0067), totalzando .787 crianças e adolescentes com ladses entre 8 e 11 ance (lasde de referincia no ano de 2017) em cads grupo. A coleta de dadot sers reslzads ao longo de 3 anos, de 2017 a 2019. Artes do nicio da pesolsa oa pais e os pantelpantes receberdo eaclarecimentos sobre a pesquas, suss etapas, seus rigco e bereficios. Obtendo o concentimento dos pas e o assentimento das cranças, os pals deverbo preencher um Questionario Bocioeconomico e Demogrdfico desenvolvido peio Grupo de Pesquisa PRINUTHA, a partir dos questionstios do IBGE. En seguida serbo coletadoa dados reterentes aos parsmetros antroporetricos, peso e aitura, sendo o disgncetco nutricional obtido a parti do indicacor Indice de Massa Corporal (pesolatura2) para a ldade (IMCI1, tomando-se como base aa curvas de crestimento propostas pela Organzaçbo Mundiai da saude e classificado em: magreza acentuada, magreza, eutrolla, sobrepeso obesidade e ocesidade grave. A Batigtap̧o com a Vida sers mencurada a partir de dols insthumertos que apresentam a mesma base teorica,

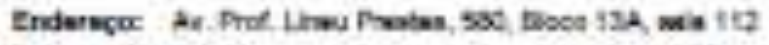

CE: $05.508-000$

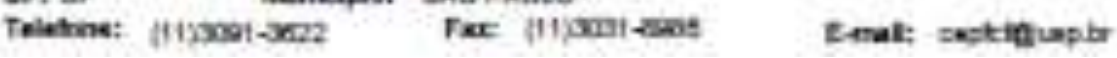




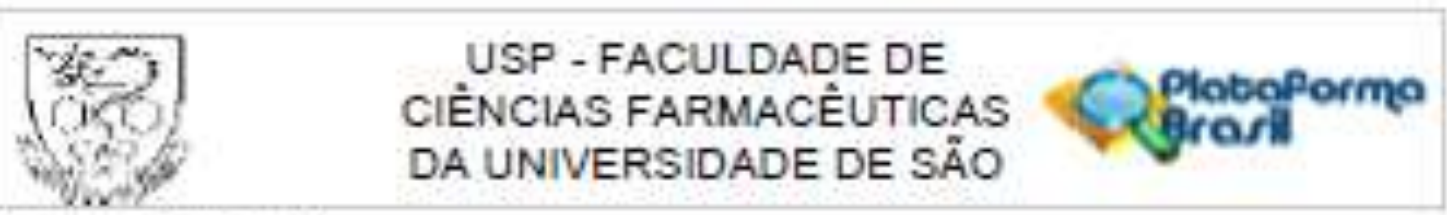

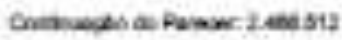

um voltado para crianças e outro para adoiescentes, aendo respectivamente: Egcsia Muitidimenalona de

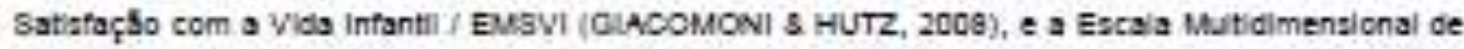

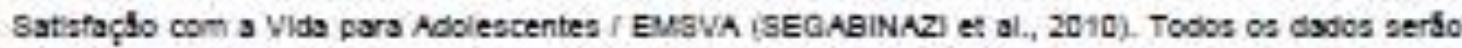
arquividos vila plataforma on ine REDCape (Research Electronic Data Capture). Fara as anslses doa dados serdo ut zadas estatistcas descritvas e a estimapjo de modelo de Diferenças em Drerenjas peio o programa SPSBs for Wholowse vers to 15.0 .

Objetivo de Pocquica:

Oejetivo Primario:

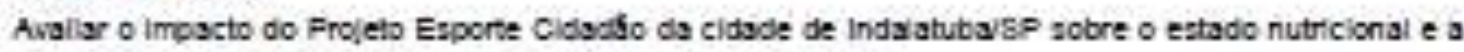
sasctap̧lo com a vida de cranças e adolescentes participantea.

Oejetwo Secunderio:

- Canacterizar aspecios sociosconomicos e demograficos das chanças = adoiescentes partidpantes e ndo particlipartes do projeto;

- Acomganhar o estado nutriciona utilizando medidas antroporetricas de peso e atura de cranças e adoiezcentes partcipantes e nfo participanter do projebo;

- Acompantar a evoluçfo da satlstoçto com a vida de criançaz e adolescentes participantes e nso particlpantes do grajeto;

- Comparar a evoluçto do estado nutricional e a satisfaço com a vida dos Orupos Participante e NŚ Participante do Projelo Esporte Cidadbo.

Avallspiso doc Fleooc o Beneficloc:

Riscoe:

A pesqusa spresenta reco minimo para os participantes.

Beneficios:

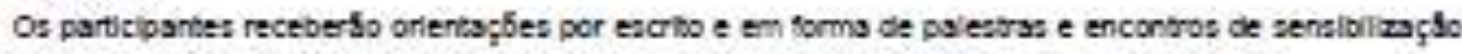
sobre almentaçso saudbvei e da importancla de manter a prastea regular de abvidade fiaica.

Comontarloc o Conciderspdec cobre a Pocquilca:

O presente estudo visa avalar o imoscto do Projeto Esporte CidadSo da cidade de Indsiatutarsp no que tange so estado nutricional e aspectos emocionss de seus participantes. De faso, a pratica

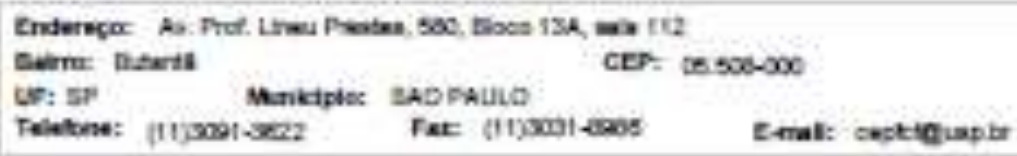




\section{USP - FACULDADE DE CIÉNCIAS FARMACÉUTICAS DA UNIVERSIDADE DE SĀO

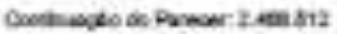

de atwidade flaics deve ser conthuanente estimulada, principaimente peloa efetos positivos que sia apresenta sobre o bem-eatar flalco e palcologico. Neate sentido, prople-se resizar um estudo longtudina do tipo painel com dols grupoe Orupo Participante - Crianças de 8 a 11 anos de indaishba (Grupo Caso) = Grupo NSo Participante - Crasças de \& a 11 anos da clasde de Americana/sP (Orupo Controle).

Concideragbec cobre oc Ternnoc de aprecentagso obrigatorla:

Oe termoa de consentamento e asventmento foram inciuldos contorme solicitaçlo deste CEF, estando de acordo com a ieglaçlo.

\section{Rooomendapoec:}

Sem recomendaģbes ou pendinclas.

Conolucdoc au Penddnolac o Licta do inadequapoec:

Erte CEF considera o projeto adsquado as expinclas legasa.

Concidorsplece Finsic a ortterio do CEP:

Eate Cef considera o projevo aprovado

Ecto psreoer fol elaborado bscosdo noc dooumentoc abalxo reisolonadoc:

\begin{tabular}{|c|c|c|c|c|}
\hline Thpo Documento & Arquivo & Postapen & Aunor & Etusgso \\
\hline $\begin{array}{l}\text { informaçbes Esalcas } \\
\text { do Projato }\end{array}$ & $\begin{array}{l}\text { PB_JNFOFUACOEE_BRSICAS_DO_P } \\
\text { ROUETO_B91051.pd }\end{array}$ & $\begin{array}{l}30 / 1 / 2017 \\
15: 33.00\end{array}$ & & Aceit \\
\hline $\begin{array}{l}\text { TCLE / Ternos de } \\
\text { Assentimento } \\
\text { dustuficasva de } \\
\text { Auesncla }\end{array}$ & Termo_de_Aseentimento.pdt & $\begin{array}{l}30 / 1 / 2017 \\
15: 32: 10\end{array}$ & JEMIMA GIRON & Acelb \\
\hline $\begin{array}{l}\text { TCLE / Tenmos de } \\
\text { Aasentimento of } \\
\text { dustuficasva de } \\
\text { Auesocis. }\end{array}$ & TCLE_novembro_2017.pdf & $\begin{array}{l}30 / 11 / 2017 \\
15: 31: 55\end{array}$ & JEMAIMA GIRON & Acelb \\
\hline Dutro: & Carta.put & $\begin{array}{l}09 / 102017 \\
17: 55: 52\end{array}$ & $\begin{array}{l}\text { Marinaha Siveira } \\
\text { Lma }\end{array}$ & Aceto \\
\hline $\begin{array}{l}\text { Decisagso de } \\
\text { inatrulgdo e } \\
\text { intraestuthra }\end{array}$ & deciaracao_chefe_departamento pod & $\begin{array}{l}29 / 06 / 2017 \\
16: 20: 09\end{array}$ & JEMIMA GIRON & Aceto \\
\hline $\begin{array}{l}\text { Decisrapso de } \\
\text { Peosulpadore }\end{array}$ & deciaracao_emimapdr & $\begin{array}{c}29 / 06 / 2017 \\
16 ; 19: 51\end{array}$ & JEMIIMA GIRON & Aceto \\
\hline $\begin{array}{l}\text { Decisraçso de } \\
\text { Peogulasodores }\end{array}$ & declaracao_denlae.pdt' & $\begin{array}{l}29 / 06 / 2017 \\
16: 19: 12\end{array}$ & JEMIMA GIRON & Acelto \\
\hline
\end{tabular}

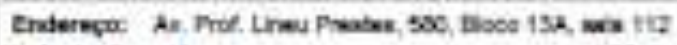
Derre Bubrti
CEP: IS:50000
Ur: sr Menkiples sabphito

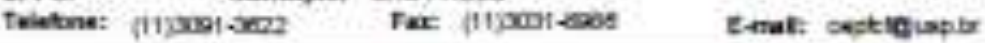




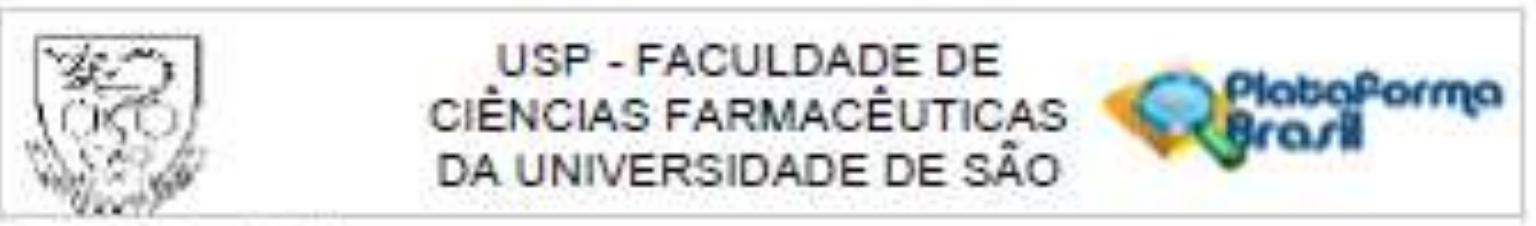

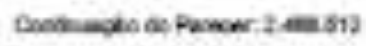

\begin{tabular}{|c|c|c|c|c|}
\hline $\begin{array}{l}\text { Deciaraç5o de } \\
\text { Pegeupadores }\end{array}$ & descrican_equipe dat & $\begin{array}{l}29 / 06 / 2017 \\
16: 18: 54\end{array}$ & JEMIMA OIRON & Acetb \\
\hline $\begin{array}{l}\text { Projeto Detacado I } \\
\text { Erochura } \\
\text { invegtigasor }\end{array}$ & Frojeto_Completo_corrigldo.pdif & $\begin{array}{l}22 / 0612017 \\
00: 37: 42\end{array}$ & JEMIMA GIRON & Aceto \\
\hline 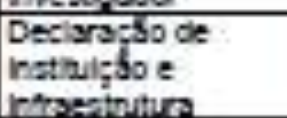 & 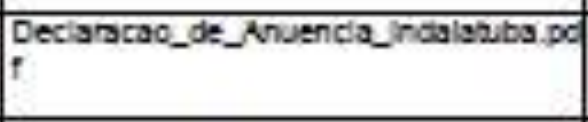 & $\begin{array}{l}22 \sqrt{06 / 2017} \\
00: 24: 39\end{array}$ & JEMIMA GIRON & Aceto \\
\hline 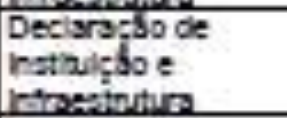 & $\begin{array}{l}\text { Decioracao_de_Anuencia_Americana pd } \\
f\end{array}$ & $\begin{array}{l}2206 / 2017 \\
00: 24: 23\end{array}$ & JEMIMA GIRON & Aceto \\
\hline Fo ha de Rocto & $\begin{array}{l}\text { Folhe_oe_Rosit__Assrada_Versos_fin } \\
\text { al potf }\end{array}$ & $\begin{array}{l}18 / 04: 2017 \\
08: 59: 20\end{array}$ & JEMIMA GIRON & Aceto \\
\hline
\end{tabular}

Stuspgso do Pareoer:

Norovado

Nooeccita Aproolagso da CONEP:

$\mathrm{NSO}$

SAO PAULO, 17 de Janeiro de 2018

Accinado por:

Cristina Northnlost do Abuquerquo

(Coordenador)

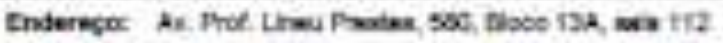

Deirro: Duserta

Ur: an Mankiples SADRAuLD

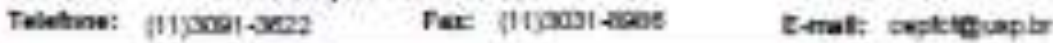

